\title{
Differential expression of nuclear lamins in normal and diseased human cells
}

Citation for published version (APA):

Machiels, B. M. (1998). Differential expression of nuclear lamins in normal and diseased human cells.

[Doctoral Thesis, Maastricht University]. Universiteit Maastricht. https://doi.org/10.26481/dis.19980116bm

Document status and date:

Published: 01/01/1998

DOI:

10.26481/dis.19980116bm

Document Version:

Publisher's PDF, also known as Version of record

\section{Please check the document version of this publication:}

- A submitted manuscript is the version of the article upon submission and before peer-review. There can be important differences between the submitted version and the official published version of record.

People interested in the research are advised to contact the author for the final version of the publication, or visit the DOI to the publisher's website.

- The final author version and the galley proof are versions of the publication after peer review.

- The final published version features the final layout of the paper including the volume, issue and page numbers.

Link to publication

\footnotetext{
General rights rights.

- You may freely distribute the URL identifying the publication in the public portal. please follow below link for the End User Agreement:

www.umlib.nl/taverne-license

Take down policy

If you believe that this document breaches copyright please contact us at:

repository@maastrichtuniversity.nl

providing details and we will investigate your claim.
}

Copyright and moral rights for the publications made accessible in the public portal are retained by the authors and/or other copyright owners and it is a condition of accessing publications that users recognise and abide by the legal requirements associated with these

- Users may download and print one copy of any publication from the public portal for the purpose of private study or research.

- You may not further distribute the material or use it for any profit-making activity or commercial gain

If the publication is distributed under the terms of Article $25 \mathrm{fa}$ of the Dutch Copyright Act, indicated by the "Taverne" license above, 


\title{
Differential expression of nuclear lamins in normal and diseased human cells
}

\author{
Proefschrift
}

ter verkrijging van de graad wan doctor

aan de Universiteit Maastricht,

op gezag van de Rector Magnificus, Prof. Dr. A.C. Nieuwenhuijzen Kruseman, volgens het besluit van het College van Decanen,

in het openbaar te verdedigen

op vrijdag 16 januari 1998 om 16.00 uur

door

Barbara Maria Machiels 
Promotor: Prof. dr. F.C.S. Ramaekers

Co-promotor: Dr. J.L.V. Broers

Beoordelingscommissie:

Prof dr. H.F.P. Hillen (voorzitter)

Prof. dr. R. van Driel (E.C. Slater Instituut, Amsterdam)

Ptof. dr. JP.M. Geraedts

Prof, dr. G. Krohne (Biocenter of the University of Würtzburg, Germany)

Dr. H.W.M. van Straaten 
8 



\section{Contents}

Chapter $1 \quad$ Gieneral Introduction

Chapter 2 A- and B-type lamins are differentially expressed in normal human tissues

Chapter 3 Nuclear lamin expression in normal testis and testicular germ cell tumours of adolescents and adults

Chapter 4 Comparison of A- and B-type lamin expression in nodular sclerosing Hodgkin's disease and reactive lymph nodes

Chapter 5 Abnormal A-type lamin organization in a human lung carcinoma cell line

Chapter 6 An alternative splicing product of the lamin $\mathrm{A} / \mathrm{C}$ gene lacks exon 10

Chapter 7 Lamin A is not required for incorporation of lamin $C$ in the nuclear lamina as demonstrated by GFP-tagged lamins

Chapter 8 Summary and General Discussion

Samenvatting

Curriculum Vitae

List of publications

Colour illustrations

Dankwoord 



\section{Chapter 1}

General Introduction 


\section{General Introduction}

Nuclear laming form a network of intermediate-sized filaments at the nucleoplasmic site of the nuclear membrane. Two main subtypes of nuclear lamins can be distinghuished, i.e. A-type lamins and B-type lamins. The A-type lamins comprise a set of three proteins arising from the same gene by alternative splicing, i.e. lamin A, lamin C [37] and lamin A $\Delta 10$ [44], while the Btype lamins include two proteins arising from two distinct genes [28], i.e. lamin B1 and B2. Furthermore, several germ cell specific lamins have been detected in various species, but not in humans.

\section{Lamin structure}

The nuclear lamins comprise a unique subclass of the intermediate filament protein family. Lamins share their molecular domain organization with the other intermediate filament proteins in that they are fibrous molecules that have an aminoterminal globular head, a central rod of $\alpha$ helices, and a carboxyterminal globular domain. The amino- and carboxyterminal domains are rather divergent among all intermediate fillament subclasses, but the rod domains are highly conserved in length and sequence. The $\alpha$-helical rod domain can be divided into three coiled regions termed $1 \mathrm{a}, \mathrm{lb}$ and 2 that are separated form each other by short linker sequences. In contrast to cytoplasmic intermediate filaments, the lamin rod domain contains an additinal 42 amino acids in coil $1 \mathrm{~b}$, due to six additional heptad repeats. Identically increased rod lengths were seen in intermediate filament proteins of invertebrate cells [76], suggesting that lamins may be the evolutionary ancesters of the intermediate filament proteins. It is suggested that during evolution the invertebrate cytoplasmic intermediate filament genes arose by lamin gene duplication, followed by loss of the nuclear localization signal and the isoprenylation site [14]. During the transition from invertebrates to vertebrates the cytoplasmic intermediate filament genes lost six heptad repeats from the rod domain.

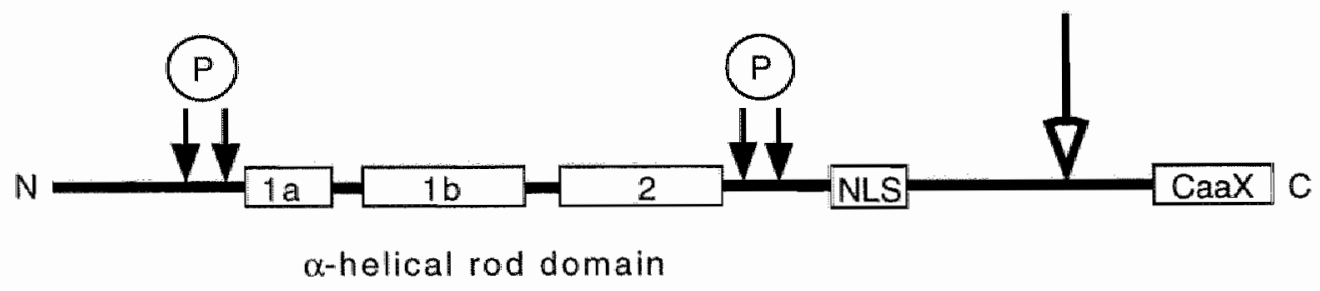

Figure 1. Schematic drawing of the primary structure of lamins, indicating the amino-(N) and carboxy-(C) termini, the phosphorylation sites $(\mathbb{P})$ that play a role in lamina disassembly during mitosis, the a-helical rod domain, the nuclear localization signal (NLS) and the isoprenylation site (Cax). Furthermore the open anrow indicates the site of lanin $\mathrm{A}$ where proteolytical cleavage takes place after farnesylation and catboxymethylation. 
Although lamins share many characteristics with the other intermediate fllament subclasses, they display several unique features [49]. For instance, lamins are localized in the nucleus linstead of the cytoplasm. For transport into the nucleus the carboxyterminal tail contains a nuclear localization signal (Figure I). Furthermore, cytoplasmic intermediate filaments form fibrous structures often extending from the nucleus to the plasma membrane, whereas nuclea: lamins form two-dimensional sheets underlying the nuclear membrane. Moreover, lamin expression is found to be widespread, accurring in virtually all nucleated cells, while other intermediate filament proteins show a more differentiation related expression pattern. Differentiation dependent expression of A-type lamins has been proven, but B-type lamins are still assumed to be constitutively expressed in all cells $[8,61]$.

\section{Lamin polymerization and lamina assembly}

Various approaches have been used to study lamin polymerization and lamina assembly. Expression of wild type and mutant lamin proteins in bacteria, followed by electron microscopic analysis of purified proteins, offers a powerful approach to investigate the structural determinants controlling lamin polymerization under defined in vitro conditions $[20,25,26,69]$. The initial lateral interaction between single lamin molecules results in formation of parallel unstaggered homodimers, formed by a coiled-coil formation of the $\alpha$-helical rod domains. $I n$ viwo studies using the yeast two hybrid system showed that A-and B-type lamins can form homodimers as well as heterodimers [77]. The next step is the formation of head-to-tail polymers. In vitro binding studies of mutant Drosophila lamins showed that the first $6-15$ amino acids of coil 1 a and the last 6-15 amino acids of coil 2 are essential for head-to-tail polymerization of lamin dimers [69]. These regions contain highly conserved sequences among all intermediate filament type proteins, and are also important for polymerization of cytoplasmic intermediate filaments. Lamin head-to-tail polymers may than form fillaments by lateral association, but lamin filaments of a stable $10 \mathrm{~nm}$ width are difficult to obtain in virro. Instead, head-to-tail polymers showed a pronounced tendency to form large paracrystals $[25,26]$.

In addition to the presence of the conserved rod sequences, phosphorylation of lamins is an important factor that determines whether lamins will assemble into dimers and further into headto-tail polymers or whether they will remain unassembled. In assays employing purified nuclei $[13,57]$ or in vitro reconstituted head-to-tail polymers $[56,69]$, lamin phosphorylation by p34cdc2 kinase caused disassembly of the filaments. "The phosphorylation sites have been mapped to residues flanking the conserved ends of the central rod domain [24]. Mutation of these sites, resulting in lamins that can not be phosphorylated, leads to formation of disassembly-resistant polymers [56].

The nuclear localization signal is responsible for the trafficking of lamins from the cytoplasm to the nucleus. Mutant lamins missing the nuclear localization signal assemble as cytoplasmic filamentous structures [38]. Furthermore, the lamins need to be targeted to the inner nuclear membrane. For this purpose B-type lamins and lamin A contain a carboxyterminal CaaX motif, 
a site for isoprenylation $[34,42]$. The cysteine residue of this motif will become farnesylated, and after proteolytic temoval of the a-a-X notif this cysteine will be carboxy-methylated as well. These modifications of the carboxyterminus of the lamins provides them with a hydrophobic anchorage site for the nuclear membrane: B-type lamins will remain farnesylated throughout their lifetime, whereas lamin $\mathrm{A}$ is further processed. Another 15 carboxyterminal amino acids are proteolytically cleaved off the protein together with the farnesyl tail, resulting in lamin A without hydrophobic anchorage site [75]. It is not clear whether this cleavage takes place before or after incorporation of lamin $A$ into the lamina.

Lamin $C$ does not contain a CaaX motif [37], and is consequently not isoprenylated. Furthermore, blocking of isoprenylation of lamins did not affect lamina assembly [12], and the mechanism for targeting of non-isoprenylated lamins to the membrane remains to be established. Lamina-associated polypeptides (LAPs), a class of intergral membrane proteins of the inner nuclear membrane that bind both $A$ - and B-type lamins $[18,45,65]$, may play an important role in membrane attachment and assembly of the nuclear lamina of non-isoprenylated lamins.

The fact that B-type lamins remain isoprenylated in contrast to A-type lamins, has an impact on lamin distribution during mitosis, when the nuclear membrane disintegrates into vesicles. At the same time the lamina disassembles as a result of hyperphosphorylation of the lamins by the p34di2 2 cyclin B kinase complex that is active during this phase of the cell cycle [41]. During mitosis the B-type lamins remain attached to the membrane vesicles with their isoprenylated carboxyterminus and by attachment to the transmembrane lamin B receptor [46], while the Atype lamins are released as soluble dimers or tetramers [19]. After completion of mitosis the nuclear lamina reassembles in the daughter cells. Three alternative pathways have been proposed for this reassembly (for review [31]). In one model soluble A-type lamins first assemble on the surface of decondensing chromosomes, which allows vesicle bound B-type lamins to associate "here whth und sdosequentiy 'the nudiear envelope is formed by fusion of B-type 'Lamin associated vesicles. In another model the vesicle bound B-type lamins will first associate with the chromatin, and only after fusion of the vesicles the soluble A-type lamins are transported into the new nucleus and incorporated into the lamina. In the third type of model both A- and B-type lamins bind to the condensed chromatin cooperatively and allow optimal envelope assembly. Evidence for all three models has been reported in literature $[7,22,31,52]$.

Despite the relative stability of lamins in witro, the lamina is not a rigid structure (for review [53, 541). Phosphorylation of lamins in interphase nuclei has been reported [15, 33, 68]. Phosphorylation sites and kinases distinct from those that play a role in mitosis are responsible for these modifications. Phosphorylation of lamins in interphase cells may modulate lamin dynamics. It may, for instance, facilitate incorporation of new lamins when DNA is replicated during $S$-phase and consequently the nucleus increases in size. Since the lamina organization is maintained, it is likely that newly synthesized lamins are transported into the nucleus and incorporated into the lamina at this stage. 
In apoptotic cells the lamin network is broken down. This is not due to phosphorylation and subsequent polymer dissociation, but the result of proteolytic lamin degradation [55]. Lamm cleavage during apoptosis requires the activation of ICE-like proteases, and lamin fragments of $46-48 \mathrm{kDa}$ are generated $[35,74]$. Lamin degradation has been reported to preceed DNA fragmentation [51]. Expression of degradation resistant lamins delays the process of apoptosis by 12 hours, but does not block the process completely [60]. Therefore it was concluded that lamin breakdown during apoptosis facilitates the process but is not a prerequisite.

\section{Differential lamin expression in cells and tissues}

In general it is assumed that A-type lamins are expressed in well differentiated cells and tissues, whereas undifferentiated cells express B-type lamins $[8,9,61]$. Furthermore, inverse staining patterns of A-type lamins and the proliferation marker $\mathrm{Ki}-67$ have been reported in lung tumour sections $[9,62]$, suggesting that A-type lamins represent a non-proliferation marker. Only recently it became clear that not only A-type lamin expression is differentially regulated, but that differential expression of distinct B-type lamins occurs as well in normall human tissues [5].

Contrasting results on A-type lamin expression in early mouse embryos have been reported. For instance, Schatten et al. [64] and Stewart and Burke [66] reported that A-type lamins were absent from several developmental stadia of mouse embryos, whereas others $[10,29]$ reported low, but detectable levels of A-type lamins throughout the whole preimplantation embryonal development.

In a study upon lamin expression during further embryonic development of mice [61] it bas been reported that expression of A-type lamins was not seen until tissue differentiation takes place. Thereafter A-type lamin expression starts in some tissues and continues until well after birth. Expression of B-type lamins is seen throughout all developmental stages. Similar results have been described for chicken embryos [36], while development dependent expression has also been reported for Xenopus lamins [3, 67].

Many adult tissues express A-type lamins $[5,8]$, but in diseased cells the expression patterns may change. Downregulation of A-type lamin expression in chronic hybernating myocardium has been reported [1], and can be explained by the dedifferentiated state of these cells. Furthermore, differential expression of A-type lamins in human lung cancer subtypes [6, 62], and human testicular germ cell tumours [43] have been reported.

However, transfection of A-type lamins into undifferentiated cells that do not express. endogenous levels of lamin $\mathrm{A}$ and $\mathrm{C}$ does not lead to differentiation of these cells, despite the fact that the lamins will be properly incorporated into the lamina [58]. Apparently, additional. factors are required in the differentiation process.

Furthermore, cell type specific alternative splicing products of both A- and B-type lamins are found in specific cells. In mice, spermatocyte specific lamins B3 and C2 have been detected. Lamin B3 is an alternative splicing product of the lamin B2 gene [16]. Spermatocyte specific lamin $\mathrm{C} 2$ and somatic lamins A/C [17] arise from the same locus, but are under control of two 
separate promotors, i.e. a somatic promotor for lamin $A$ and $C$ and a testis-specific promotor for lamin $\mathrm{C} 2$ [50]. The testis-specific promotor is located within the first intron of the lamin $\mathrm{A} / \mathrm{C}$ gene. Also in rat lamins specific for male germ cells have been found $[70,71,73]$. In general, these germ cell specific lamins are shorter than the somatic lamins. Their expression is found during the process of spermatogenesis, in either pre-and postmeiotic germ cells. In pre-meiotic spermatogonia both germ cell specific and somatic lamins were detected, but the somatic lamins were down regulated upon further maturation of the germ cells.

Previously, in Xenopus lamin IV has been reported to be restricted to malle germ cells [2], while lamin LIII (B3) was pedominantly detected in Xenopus oocytes, but also in a few other highly differentiated cells such as muscle cells and neurons [3].

\section{Possible functions of the nuclear lamina}

Many biochemical and molecular features of lamins have been studied, but their functions remain still largely undetermined. The functions that have been proposed are based on ultrastructural observations (for review [48]).

Lamins form a stable polymer network adjacent to and interacting with the nuclear membrane. Therefore, one of the functions ascribed to the lamina is the maintenance of the structural integrity of the nucleus. Further indications for functions in maintaining structural integrity of the nucleus were obtained from experiments where mouse spermatocyte specific lamins were expressed in somatic cells [16]. This resulted in obvious changes in nuclear morphology of these cells. Additionally, interactions of nuclear lamins with cytoplasmic intermediate filaments may also be functional in the maintenance of cellular and nuclear morphology $[59,63]$. Connections with cytoplasmic intermediate filaments may furthermore provide a mechanism for signal transduction and communication within the cell [11].

Besides interactions with the nuclear membrane and other intermediate filaments, lamins interact with the nuclear cluromatin. Eukaryotic chromatin is organized into loops, which are attached to the nuclear matrix. This organization is thought to contribute to compaction of the chromatin and regulation of gene expression. Lamins, as a part of the nuclear matrix, may be involved in these processes since chromatin binding sites have been detected in both $A$ - and B-type lamins [21, 27]. Several putative binding sites have been recognized in the $\alpha$-helical rod domain, as well as on the carboxyterminal tail [21,72]. Recently, it was shown that histones constitute a link between chromatin and the lamin $C$ carboxyterminus. However, direct lamin-DNA interactions have been described to occur as well. Both $A$ - and B-type lamins have been shown to interact with martix attachment regions (MARs), defined DNA sequences that bind to the nuclear matrix $[39,40]$. In concordance with these observations several reports describe intranuclear foci of Aand B-type lamins $[4,30,47]$, suggesting a role for lamins in intranuclear chromatin organization. Recently, Moir et al. [47] provided evidence that intranuclear foci of B-type lamins coincided with intranuclear loclization of sites of DNA replication in S-phase cells, suggesting a role for B-type lamins in reorganization of chromatin during DNA duplication. In contrast, A- 
type lamins were not colocalized with sites of DNA replicattion. The function of intranuclear Atype lamins may be correlated with chromatin rearrangenents in interphase nuclei durng $\mathrm{Gl}$ phase, since the intranuclear structures were most obvious at this stage of the cell cycle [4]. Further evidence for the interactions of lamins with replicating DNA has been obtained from studies with Xenopus oocytes, in which the lamina was not assembled and DNA replication was not initiated $[23,32]$.

\section{Scope of the thesis}

Earlier studies in our research group have shown that lamin expression in lung tumours is dependent on the subtype of cancer [6], its aggresiveness, proliferative capacity and degree of differentiation. Furthermore, an aberrant cytoplasmic localization of nuclear lamins was noted, in particular in adenocarcinomas of the lang. The studies described in this thesis aim at establishing (1) the differential expression patterns of lamins in normal human tissues and cellis as well as in several other human tumour types, and (2) the molecular background of aberrant lamin expression in cancer cells by means of in vitro studies.

\section{References}

[1] Ausma, J., G.J.J.M. van Eys, J.L.V. Broers, F. Thone, W. Flameng, F.C.S. Ramaekers, M. Borgers: Nuclear lamin expression in chronic hybernating myocardium in man. J. Mol.Cell Cardiol. 28, 1297-1305 (1996).

12] Benavente, R. G. Krohne: Change of karyoskeleton during spermatogenesis of Xenopws: Expression of lamin IV, a lamina protein spedific for the male gern line. Proc. Natl. Acad. Sci. USA 82, 6176×6180 (1985).

[3] Benavente, $R_{n}, G$. Krohne, W.W. Franke: Cell type-specific expression of nuclear laminat proteins during development of Xenopus laevis. Cell 41, 177-190 (1985).

[4] Bridger, J.M., I.R. Kill, M. O'Farrel, C.J. Hutchison: Internal lamin structures within G1 nuclei of dermal fibroblasts. J. Cell Sci. 104, 297-306 (1993).

[5] Broers, J.L.V., B.M. Machiels, H.J.H. Kuijpers, F. Smedts, R. van den Kieboom, Y. Raymond, F.C.S. Ramaekers: A- and B-type lamins are differentidly expressed in nomal human tissues. Histocherm. Ceil Biol. 107, 505-517 (1997).

[6] Broers, I.I.V., Y. Raymond, M. Klein Rot, H.u.H. Kuijpers, S.S. Wagenaar, F.C.S. Ramackers: Nucloan A type lamins are differentially expressed in human lung cancer subtypes. Am. J. Pathol. 143, 21 1-220 (1993).

[7] Burke, B. L. Gerace: A cell-free system to study reassembly of the nuclear envelope at the end of nitosis. Cell 44, 639-652 (1986).

[8] Cance, W.G., N. Chaudhary, H.J. Woman, G. Blobel, C. Condon Cando: Expression of the muclear lamins in normal and neoplastic human tissues. J. Exp. Clin. Cancer Res. 11, 233-246 (1992).

[9] Coates, PJ., C. Hobbs, J. Crocker, D.C. Rowlands, P. Murray, R. Quinlan, P.A. Hall: Idenification of the antigen recognized by the monoclonal amtibody BU3J as lamins A and C. J. Pathol. 178, 21-29 (1996).

[1.0] Coonen, E., J.C.M. Dumoulin, F.C.S. Ramaekers: Intermediate filament proten expression in early developmental stages of the mouse. Histochemistry 99, 141-149 (1993).

[11] Cowbin, P., B. Burke: Cytoskeleton-1membrane interactions. Curr. Opin. Cell Biol. 8, 56\%65 (1996).

[1.2] Dalton, M.B., K.S. Fantle, H.A. Bechold, L. DeMaio, R.M. Evalns, A. Krystosek, M. Sinensky: The farnesyl protein transferase inhibitor BZA-5B blocks farnasylation of nuctear lamins and p2l ras but does not alfect their function or localization. Cancer Res. 55, 3295-3304 (1995).

[13] Dessew, G., C. Iowchewa-Dessew, J.R. Bischoff, D. Beach, R. Goldman. A complex containing p34cde2 and cycin B phosphorylates the nuelear lamim and disassembles nuclei of clan oocytes in vitro. J. Cell Biol. 112 , $523-533(1991)$

[14] Dodemont, H., D. Riemer, N. Ledger, K. Weber: Eight genes and alternatiwe RNA processing pathways generate an whexpectedly large diversity of cytoplasmic intermediate filament protems in the mematode Caenorhabdit elegans. EMBO J. 13, 2625-2638 (1994). 
(15) Eggert, M, N. Radomski, D. Linder, D. Tripier, P. Traub, E. Jost: Identification of novel phosphorylation silkes in murine A-type lamins. Eur. J. Biochem. 213,659-671 (1993).

[16] Furukawa, K., Y. Hotta: CDNA cloning of a germ cell specific lamin B3 from mouse spermatocyles and analysis of its function by ectopic expression in somatic cells. EMBO J. 12, 97-106 (1993).

[17] Furukawa, $K, \mathrm{H}$. Inagaki, Y. Hotta: Inidentification and clonung of an mRNA coding for a germ cell-specific A-type lamin in mice. Exp. Cell Res. 212, 426-430 (1994).

[18] Furukawa, K. N. Pante, U. Aebi, L. Gerace Cloning of a cDNA for lamina-associated polypeptide 2 (LAP2) and identification of regions that specify targetting to the nuelear envelope. EMBO J. 14, 1626-1636 (1995).

[19] Gerace, L. G. Blobel: The nuclear envelope lamina is reversibly depolymerized during mitosis. Cell 19, $277.287(1980)$.

[20] Gielfers, C., G. Krohne: In vitro reconstitution of recombinant lamin A and a lamin A mutant lacking the carboxyterminal tail. Eur. J. Cell Biol. 55, $191-199$ (1991).

[21] Glass, C.A., J.R. Glass, H. Taniura, K.W. Hasel, J.M. Blevitt, L. Gerace: The alpha-helical rod domain of human Jamins $A$ and $C$ contains a chromatin binding site. EMBO J. 12, 4413-4424 (1993).

[22] Glass, J.R., L. Gerace: Lamins $A$ and $C$ bind and assemble at the surface of mitotic chromosomes. J. Cell Biol. 111, 1047-1057 (1990).

[23] Goldberg, M., H. Jenkins, T. Allen, W.G. Whitfield, C.J. Hutchison: Xenopus lamin B3 has a direct role in assembly of a replication competent nucleus: evidence from cell-free egg extracts. J. Cell Sci. 108, 3451 3461 (1995).

[24] Heald, R., F. McKeon: Mutations of phosphorylation sites in lamin A that prevent nuclear lamina disassembly in mitosis. Cell 61, 579-589 (1990).

[25] Heillinger, E., M. Peter, M. Häner, A. Lustig, U. Aebi, E.A. Nigg: Expression of chicken lamin B2 in Escherichia coli : Characterization of its structure, assembly and molecular interactions. J. Cell Biol. 113. 485-495 (1991).

[26] Heitlinger, E. M. Peter, A. Lustig, W. Villiger, E.A. Nigg, U. Aebi: "The role of the head and tail domain in lamin structure and assembly: Analysis of bacterially expressed chicken lamin A and truncated B2 lamins. J.Struct. Biol. 108, 74-89 (1992).

[27] Höger, T.H., G. Krohne, J.A. K.leinschmidt: Interaction of Xenopus Jamins A and LII with chromatin in witro inediated by a sequence element in the carboxyterminal domain. Exp. Cell Res. 197, 280-289 (1991).

[28] Höger, T.H., K. Zatloukal, th. Waizenegger, G. Krohne: Characterization of a second highly conserved Bi-type lamin present in cells previously thought to contain only a single B-type lamin. Chronosoma 99, 379-390 (1990).

[29] Houlliston, E., M. Guilly, J. Courvallin, B. Maro: Expression of nuclear lamins during mouse preimplantation development. Development 102, 271-278 (1988).

[30] Horak, P., A.M..-J. Sasseville, Y. Raymond, P. Cook: Lamin proteins form an internal nucleoskeleton as well as a peripherall lamina in human cells. J. Cell Sci, 108, 635-644 (1995).

[31] Hutchison, C.J., I.M. Bridger, L.S. Cox, I.R. Kill: Weaving a pattern from disparave threads: Iamin function in nuclear assembly and DNA replication. J. Cell Sci. 107, 3259-3269 (1994).

[32] Jenkins, H., W.G. Whitfield, M.W. Goldberg, T.D. Allen, C.J. Hutchison: Evidence for the direct inwolvement of lamins in the assembly of a replication competent nucleus. Acta Biochin. Pol. 42, 133-143 (1995).

[33] Kill, I.R., C.J. Hutchison: S-phase phosphorylation of lamin B2. FEBS Lett, 377, 26-30 (1995).

[34] Kitten, G.T... E. A. Nigg: The CaaX motif is required for isoprenylation, carboxyl methylation, and nuclear membrane association of lamin B2. J. Biol. Chem. 113, 13-23 (1991).

[35] Lazebnik, Y.A. A. Takahashi, R.D. Moir, R.D. Goldman, G.G. Poirier, S.H. Kaufman, W.C. Earnshaw: Studies of the lanin proteinase reveal multiple parallel biochemical pahways during apoptotic execution. Proc.Natl. Acad. Sci. USA 92, 9042,9046 (1995).

[36] Lueliner, C.F. R. Stick, H.M. Eppenberger, E.A. Nigg: Differentiall expression of nuclear lamin proteins during chicken developenent. J. Cell Biol. 105, 577-587 (1987).

137) Lim, $F_{*}$, H.J. Worman: Structural organization of the human gene encoding nuclear lamin $A$ and nuclear lamin C. J. Biol Chem. 268, 1632 l-16326(1986).

[38] Loewinger, L., F. McKeon: Mutations in the nuclear lamin proteins resulting in their abrercant assembly in the cytoplasm. EMBO J. 7, 2301-2309 (1988).

[39] Luderus, M.E.E., A. de Graal, E. Mattia, J.L. den Blaawwen, M.A. Grande, L. de Jong, R. van Driel: Binding of matrix attachment regions to lamin B 1 . Cell 70, 949-959 (1990).

[40] Luderus, M.E.E. J.L. den Blaauwen, O.J.B. de Smit, D.A Compton, R. wan Driel: Binding of matrix attuchment regions to lamin polymers involves single-stranded regions and the minor groove. Mol. Cell. Biol. 14, 6297-6305 (1994).

[41] Luscher, B., L. Brizuela, D. Beach, R.N. Eisenman: A role for $34 c d c 2$ kinase and phosphatases in the regulation of phosphorylation and disassembly of lamin $\mathrm{B} 2$ during the cell cycle. EMBO J. 10, 865-875 (1991). 
[42] Lutz, R.J., M.A. Trujillo, K.S. Denham, L. Wenger. M. Sinensky. Nucteoplasmic localization of prelamin A: implications for prenylation-dependent lamin A assembly into the nuclear lamina. Proc. Natl Acnd Sei. USA $89,3000-3004$ (1992).

[43] Machiels "B.M., F.C.S. Ramaekers, H.J.H. Küjpers, J,S. Groenewoud, J. W Oosterhuis, LH H. Loojenga: Nuclear lamin expression in normal testis and testicular germ cell tumours of adolescents and adults. J. Pathol. 182, 197-204 (1997).

[44] Machiels, B.M., A.H.G. Zorenc, J.M. Endert, H.J.H. Kuijpers, G.J.J.M van Eys, F.C.S. Ramaekers, J.L.V. Broers: An alternative splicing product of the lamin $A / C$ gene lacks exon 10. J. Biiol. Chem. 271, 9249-9253 (1996).

[45] Martin, L., C. Crimaudo, L. Gerace: CDNA cloning and characterization of lamina-associated polypeptide IC (LAPIC), an integral protein of the inner nuclear membrane. J. Biol. Chem. 270, 8822-8828 (1995).

[46] Meier, J., S.D. Georgatos: Type B lamins remain associated with the integrad muclear envelope protein p58 during mitosis: implications for nuclear reassembly. EMBO J. 13, 1888-1898 (1994).

[47] Moir, R.D., M. Montaglowy, R.D. Goldman: Dynamic properties of nuclear lamins: Lamin B is associated with sites of DNA replication. I Cell Biol 125, 1201-1212 (1994).

[48] Moir, R.D., T.P. Spann, R.D. Goldman: The dynamic properties and possible functions of nuclear lamins. Int. Rev. Cytol. 162B, 141-182. (1995).

[49] Monteiro, M.J., C. Hicks, L. Gu, S. Janicki: Determinants for intracellular sorting of cytoplasmic and nuclear intermediate filaments. J. Cell Biol. 127, 1327-1343 (1994).

[50] Nakajima, N., K. Abe: Genomic structure of the mouse A-type lanin gene locus encoding somatic and germ cell-specific lamins. FEBS Lett. 365, 108-114 (1995).

[51] Neamati, N., A. Fernandez, S. Wright, J. Kiefer, D.J. McKonkey: Degradation of lamin Bl precedes oligonucleosomal DNA fragmentation in apoptotic thymocyles and isolated thymocyte nuclei. J. Immunol. 154, 3788-3795 (1995).

[52] Newport, J.W., K.L. Wilson, W.G. Dunphy: A lamin-independent pathway for nuclear envelope assembly, J. Cell Biol. 111, 2247-2259(1990).

[53] Nigg, E.A.: Assembly and cell cycle dynamics of the nuclear lamina. Sem. Cell Biol. 3, 245-253 (1992).

[54] Nigg. E.A.: Assembly-disassembly of the nuclear lamina. Curr. Opin. Cell Biol. 4, 105-109 (1992).

[55] Oberhammer, F.A., K. Hochegger, G. Fröschl, R. Tiefenbacher, M. Pavelka: Chromatin condlensation during apoptosis is accompanied by degradation of lamin $A+B$, without enhanced activation of cdc2 kinase. J. Cell Biol. 126, 827-837 (1994).

[56] Peter, M., E. Heitlinger, M. Häner, U. Aebi, E.A. Nigg: Disassembly of in vitro formed Jamin head-to-tail polymers by cdc2 kinase. EMBO J. 10, 1535-1544 (1991).

[57] Peter, M., J. Nakagawa, M. Dorée, J.-C. Labbé, E.A. Nigg: In witro disassembly of the nuclear lamina and M-phase specific phosphorylation of lamins by cdc2 kinase. Cell 61, 591-602 (1990).

[58] Peter, M., E.A. Nigg: Ectopic expression of an A-type lamin does not interfere with differentiation of lamin A-negative embryonal carcinoma cells. J. Cell Sci. 100, $589-598$ (1991).

[59] Pienta, K.J., D.S. Coffey: Nuclear-cytoskeletal interactions: evidence for physical connections between the nucleus and cell periphery and their alteration by transformation. J. Cell. Biochem. 49, 357-365 (1992).

[60] Rao, L., D. Perez, E. White: Lamin proteolysis facilitates nuclear events during apoptosis. J. Cell Biol. 135. $1441-1455(1996)$.

[61] Röber, R.A., K. Weber, M. Osborn: Differential timing of nuclear lamin A/C expression in the various organs of the mouse embryo and the young animal: a developmental study. Development 105, 365-378 (11989).

[62] Rowlands, D.C., C.M. Bunce, J. Crocker J.G. Ayres, G.D. Johnson, N. Ling, G. Brown: Expression of a nuclear envelope protein recognized by the monoclonal antibody BU3. in lung turnours: relationslip to Ki67 antigen expression. J. Pathol. 173, 89-96 (1994).

[63] Sarria, A.J., J.G. Lieber, S.K. Nordeen, R.M. Evans: The presence or absence of a vimentin-type internediate filament network affects the shape of the nucleus in human $\mathrm{SW}-13$ cells. J. Cell Sci. 107, 1593. 1607 (1994).

[64] Schatten, G., G.G. Maul, H. Schatten, N. Chaly, C. Simerly, R. Balczon, D.L. Brown: Nuclear lamins and peripheral nuclear antigens during fertilization and embryogenesis in mice and sea urchins. Cell Biol. 82, 4727-4731 (1985)

[65] Smith. S., G. Blobel: Colocalization of vertebrate lamin B and lamin B receoptor (LBR) in nuclear envelopes and in LBR-induced membrane stacks of the yeast Saccharomyces cerevisiae. Proc. Natl. Acad. Sci. USA 91, 10124-10128 (1994).

[66] Stewart, C., B. Burke: Teratocarcinoma stem cells and early mouse embryos contain only a single major lamin polypeptide closely resembling lamin B. Cell 51, 383-392 (1987).

[67] Stick, R., P. Hausen: Changes in nuclear lamina composition during early development of Xenopus leavis. Cell 41. 191-200(1985).

[68] Stuurman, N., N. Maus, P.A. Fisher: Interphase phosphorylation of the Drosophila nuclear lamin: sitemapping using a monoclonal antibody. J. Cell Sci. 108, 3137-3144 (1995). 
[69] Stuurmän, N., B. Sasse, P.A. Fisher: Intermediate filament polymerization: Molecular analys sis of Drosophila nuclear lamin head-to-tail binding. J. Struct. Biol. 117, 1-15 (1996).

(70) Sudhakar, L., M.R.S. Rao: Stage-dependemt changes in localization of a gem cell-specific lamuin during maminalian spermatogenesis. J. Biol Chem: 265, 22526-22532 (1990).

[71] Sudhakar, L., N. Sivakumar, A. Behal, M.RS. Rao. Evolutionary conservation of germ cell-specific lamin persisting through mammalian spermiogenesis. Exp. Cell Res. 198, 78-84 (1992).

[72) Tarnura, H, C. Glass; L, Gerace. A chromatin binding site in the tail domain of nuclear lamins that interacts with core histones. J. Cell Biol, 131, 33-44 (1996).

[73] Vester, B3., A. Smith, O. Krohne, R, Benawente: Presence of a nucllear lamina in pachytene spermatocytes of the rat. J. Cell Sci 104, 557-563(1993).

$174]$ Wealer, V.M. CE Carson, P.R. Walker, N. Chaly, B. Lach, Y. Raymond, D.L. Brown, M. Sikorska: Degradation of muclear matrix and DNA cleavage in apoptotic thymocytes. J. Cell Sci. 109, 45-56 (1996).

[75] Weber, $K_{i}, U$. Plessmanin, $\mathrm{P}$. Traub: Maturation of nuclear lamin $\mathrm{A}$ involves a specific carboxy-terminal trimming, which removes the polyisoprenylation site from the precursor: implications for the structure of the nuclear lamina. FEBS Leti. 257, $411-41.4$ (1989).

[76] Weber, K. U. Plessmann, W. Unich: Cytoplamic intermediate filament proteins of invertebrates are closer to nuclear lamins than are vertebrate intermediate filament proteins; sequence characterization of two muscle proteins of a nematode. EMBO J. 8, 3221-3227(1989).

[77) Ye, Q. H.J. Worman: Protein-protein inferactions between human nuclear lamins expressed in yeast. Exp. Cetl Res. 219, 292-298 (1995). 


\section{Chapter 2}

A- and B-type lamins are differentially expressed in normal human tissues

Jos L.V. Broers, Barbie M. Machiels, Helma J.H. Kuijpers, Frank Smedts, Ronald van den Kieboom, Yves Raymond, Frans C.S. Ramaekers.

Histochemistry and Cell Biology (1997), 107: 505-517. 


\section{Summary}

A selection of normal human tissues was investigated for the presence of lamins B1, B2 and Atype lamins, using a panel of antibodies specific for the individual lamin subtypes. By use of immunoprecipitation and two-dimensional immunoblotting techniques we demonstrated that these antibodies do not cross-react with other lamin subtypes and that a range of different phosphorylation isoforms is recognized by each antibody. The lamin B2 antibodies appeared to decorate the nuclear lamina in all tissues examined, except hepatocytes, in which very little lamin B2 expression was observed. In contrast to previous studies, which suggested the ubiquitous expression of lamin B1 in mammalian tissues, we show that lamin B1 is not as universally distributed throughout normall human tissues as was to be expected from previous studies. Muscle and connective tissues are negative, while in epithelial cells lamin $\mathrm{B} \|$ seemed to be preferentially detected in proliferating cells. These results correspond well with those obtained for lamin B1 in chicken tissues. The expression of A-type lamins is most prominent in well-differentiated epithelial cells. Relatively undifferentiated and proliferating cells in epithelia showed a clearly reduced expression of A-type lamins. Furthermore, most cells of neuroendocrine origin as well as most hematopoietic cells were negative for A-type lamin antibodies.

\section{Introduction}

The nuclear lamina is a polymeric meshwork of proteins lining the inner nuclear membrane. The most prominent proteins within this structure are the nuclear lamins, which in mammals are subdivided into $\mathrm{A}$ - and B-type lamins. A-type lamins consist of lamin $\mathrm{A}$, Jamin $\mathrm{A} \Delta 10$, lamin $\mathrm{C}$ and lamin $C 2$, arising by alternative splicing from the lamin $A / C$ gene [17]. Lamins $A$ and $C$ share the first 566 amino acids and differ in their carboxy-terminal tail regions, which consist of 98 and 6 unique amino acids, respectively [9]. Lamin $\mathrm{C} 2$ is identical to lamin $\mathrm{C}$ except for the $\mathrm{N}$-terminal segment, containing the head and the $\alpha$-helical coil $1 \mathrm{~A}$ domain, which is replaced by a short non- $\alpha$-helical stretch of amino acids [11]. Lamin $A \Delta 10$ is identical to lamin $A$, except for a stretch of 30 amino acids, encoded by exon 10 of the lamin $\mathrm{A} / \mathrm{C}$ gene, which is absent [19]. In general it is assumed that lamins $\mathrm{A}$ and $\mathrm{C}$ are expressed in well-differentiated cells and tissues and can be absent in highly proliferating and/or poorly differentiated cells such as embryonic cells $[8,12,23,25,26]$. The presence of lamin $\mathrm{C} 2$ mRNA has only been demonstrated in (mouse) spermatocytes [11]. Lamin A 10 mRNA is present in minor amounts in a variety of human tissues [19]. B-type lamins Bi1 and B2 are encoded by two different genes [2, 16, 24]. Lamin B3 occurs only in (mouse) spermatocytes and is an alternative splicing product of lamin $B 2$ [10]. While it is generally accepted that lamin $B 1$ is present in all somatic cells $[13,24]$, there is only little evidence to support this assumption, since most studies were performed with antibodies which do not differentiate between lamins B1 and B2 (see also [7]). 
In this study we have investigated the tissue distribution of lamins using a panel of antibodies which can differentiate between lamin B1, lamin B2, lamin $A$ and lamin A/C protein expression. We show that in particular the expression level of lamin B 1 is highly variable and even absent in many tissues examined. Furthermore, lamin B1 expression seems to be inversely related to the expression of A-type lamins in epithelia, while lamin B2 shows a universal distribution pattern.

\section{Materials and Methods}

\section{Tissues}

The tissue samples used in this study were obtained at autopsies with post mortum delay of less than four hours. Specimens were snap-frozen in liquid nitrogen and stored until use.

Frozen 5-10 $\mu \mathrm{m}$ thick sections were cut, air-dried and fixed in methanol $\left(-20^{\circ} \mathrm{C}\right.$ for 1 mimute) followed by acetone ( $4^{\circ} \mathrm{C}, 3$ dips 5 seconds each).

\section{Immunoperoxidase technique}

The immunoperoxidase staining procedure has been described before $[4,5]$. The following primary antibodies were used in this study:

1) monoclonal antibody LN43 (IgG1), directed against lamin B2 [3], kindly provided by Dr. E.B. Lane (Dundee, U.K.); 2) monoclonal antibody X223 (IgG1) directed against lamin B2 [13], kindly provided by Dr. G. Krohne (Würzburg, Germany); 3) monoclonal antibody 119D5F1 (IgG1) directed against lamin B1 [18]; 4) monoclonal antibody 41CC4 (IgM) kindly provided by Dr. G. Warren (Heidelberg, Germany) and recognizing human lamins $A$ and $C$ by immunoblotting [6]; 5) monoclonal antibody R27 (IgM), a gift from Dr. G. Krohne (Würzburg, Germany), recognizing only lamins $A$ and $C$ and not reacting with lamin $B$ [31]; 6) mouse monoclonal antibody $133 \mathrm{~A} 2$ recognizing lamin $\mathrm{A}$ and not lamin C [14]. In immonoperoxidase staining procedures LN43, X223,41CC4 and R27 were used as undiluted culturing supernatant, while 119D5F1 (mouse ascites) was used $1: 250$ and 133A2 (mouse ascites) 1:1000. As secondary antibody rabbit anti mouse immunoglobulins conjugated to peroxidase (DAKO $\mathrm{A} / \mathrm{S}$, Glostrup, Denmark), diluted 1:100 was used. Peroxidase activity was detected with 3-amino-9ethylcarbazole (Sigma, St. Louis, MO, USA) as a substrate. Nuclei were counterstained with hematoxylin and preparations were mounted in Kaiser's glycerol gelatin (Merck, Darmstadt, Germany).

\section{Immunoprecipitation technique}

Cells from the aclenocarcinoma cell line GLC-A2, previously shown to abundantly express both A- and B-type lamins [18], were grown in $162 \mathrm{~cm}^{2}$ flasks, washed twice with PBS, followed by the addition of $2 \mathrm{ml}$ of lysis buffer, containing $140 \mathrm{mM} \mathrm{NaCl}, 20 \mathrm{mM}$ Tris- $\mathrm{HCl} \mathrm{pH} 8.0,0,75 \%$ (w/w) sodium dodecyl sulphate (SDS, Merck, Darmstadt, Germany), 0.5\% (w/v) sodium deoxycholate (Merck), $1 \%$ (w/v) Triton X-100 (BDH, Poole, England), I mM 
phenylmethylsulfonyl fluoride (Aldrich, Steinheim, Germany), $10 \mu \mathrm{g} / \mathrm{ml}$ aprotinin (Sigma) and $12.5 \mu \mathrm{g} / \mathrm{ml}$ leupeptin (Sigma). In this solution cells were scraped from the bottom of the cultare flask using a rubber policeman. The cell suspension was collected and put on ice for 30 minutes, while vortexing at regular intervals. The lysate was centrifuged for 10 minutes at $13000 \mathrm{~g}$ at $4^{\circ} \mathrm{C}$ and the supermatant was divided into $200 \mu \mathrm{l}$ samples. To each of the samples one of the lamin antibodies was added ( $200 \mu \mathrm{l}$ of culture supernatant or $5 \mu \mathrm{l}$ ascites fluid) and the volume was actjusted to $1 \mathrm{ml}$ with lysis buffer not containing Triton X-100. Antibodies were allowed to bind to lamins overnight at $4^{\circ} \mathrm{C}$. Next, $5 \mu 1$ rabbit anti-mouse immunoglobulins (DAKO A/S, Glostrup, Denmark) was added and the mixture was incubated for 3 hours at $4^{\circ} \mathrm{C}$. Thereafter, $100 \mu \mathrm{l}$ of protein A Sepharose $(30 \mu \mathrm{g} / \mathrm{ml}$, Pharmacia, Uppsala, Sweden) was added and the suspension was incubated while rotating for 3 hours at $4^{\circ} \mathrm{C}$. The complexes were pelleted at $13000 \mathrm{~g}$ for 10 minutes, washed with a buffer containing $140 \mathrm{mM} \mathrm{NaCl}, 20 \mathrm{mM}$ Tris- $\mathrm{HCl} \mathrm{pH}$ $8.0,0.75 \%$ SDS and $1 \%$ Triton X-100, and solubilized in $30 \mu$ of SDS-sample buffer by boiling for 5 minutes. Samples were analysed by gel electrophoresis followed by immunoblotting.

\section{Gel electrophoresis and immunoblotting}

One-dimensional SDS polyacrylamide-gel electrophoresis and two-dimensional gel electrophoresis were essentially performed as described [21]. Samples from cell lines were Triton X-100 extracted and treated with RNaselDNase as described for two-dimensional gel electrophoresis [18]. For the analysis of tissue samples twenty to thirty frozen sections (20 $\mu \mathrm{m}$ thick) were collected and extracted using the same procedure as used for the cell lines. Gels containing $10 \%$ acrylamide and $0.1 \%$ SDS were used for one-dimensional gel electrophoresis, while isoelectric focusing for two-dimensional gels was performed in $4 \%$ polyacrylamide gels containing $8 \mathrm{M}$ ureum, 2\% Bio-Lyte 3/10 carrier ampholytes (Bio-Rad) and $25 \mathrm{mM} 3-[(3-$ Cholamido-propyl)-dimethylammoniol-1-propanesulfonate (CHAPS, Bio-Rad). Immunoblotting was performed essentially according to Towbin [28], using the Mini Trans-Blot Cell (Bio-Rad) at $100 \mathrm{~V}$ for 1 hour. Proteins were blotted onto nitrocellulose sheets (BA85, Schleicher and Schüll, Dassel, Germany). Immunochemical detection was performed as described [18] using an enhanced chemiluminescence western blotting detection kit (ECL, Amersham, Buckinghamshire, England).

\section{Results}

\section{Lamin subtype specificity of the antibodies}

To confirm the immunospecificity and to exclude mutual cross-reactivity of the antibodies used in this study, immunoprecipitation assays were performed with extracts of cell line GLC-A2, which was previously shown to contain lamins B1, B2, and lamins A and C [18]. Figure 1, Panel A shows that when lamin BI was immunoprecipitated with antibody 119D5FI, this protein was only recognized by this antibody in immunoblots of these preparations, and not by the 
antibodies to lamin B2, lamin $\mathrm{A}$ or antibodies to lamins $\mathrm{A} / \mathrm{C}$ (panel A). Similurly, when lamin B2 was immunoprecipitated from this cell line with LN43 (panel B) or $X 223$ (not shown), only the antibodies to lamin $B 2$ and not the antibodies to lamin $B 1, A$, or $A / C$ were able to recognize the precipitated lamin B2. After immunoprecipitation with the lamin A antibody $133 \mathrm{~A} 2$ (panel $C)$, the captured lamins showed no cross-reactivity with the lamin B I or lamin B2 antibodies. When the lamin $A$ antibody or the lamin $A / C$ antibodies were applied to the immunoblot, a single band was observed at the lamin A level. These results confirm that the lamin antibodies used in this study do exhibit the expected lamin subtype specificity.

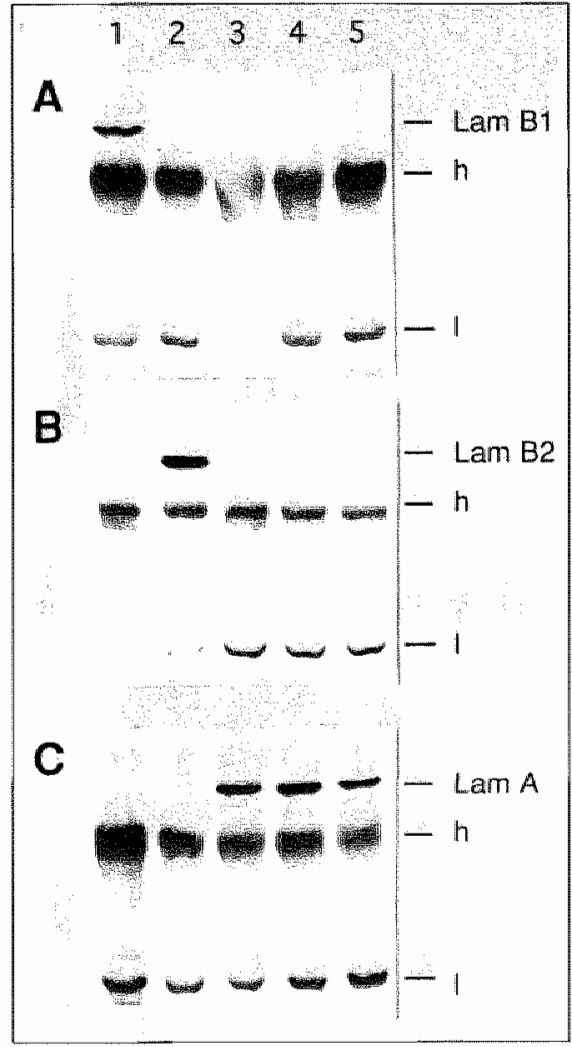

Figure 1. Lysates of cell tine GLC-A2 were immunoprecipitated with the lamin BI antibody 119D5F1 (panel A), the lamin B2 antibody LN43 (panel B) and the lamin A antibody 133A2 (panel C). The blots were incubated with antibodies. 119D5H1 (lanes 1), the Jamin B2 antibody LN43 (lanes 2), the antibody $133 \mathrm{A2}$ directed against. lamin A (lanes 3), the lamin A/C antibody $41 \mathrm{CC}$. (lanes 4 ), or the lamin $A / C$ antibody R27 (lanes 5 ). The immunoprecipitated heavy and light chatios of immunoglobulins recognized by the secondary antibody are indicated by b and $d_{*}$ respectively.

Since only one lamin B1 antibody was available for our immunohistochemical studies it was of importance to show that this reagent recognizes the non-phosphorylated as well as different phosphorylated states of lamin B1. Two-dimensional immunoblotting shows that at least four different phosphorylation isoforms of lamin $\mathrm{B} 1$ are recognized by this antibody (Fig. 2). In addition, different phosphorylation states of the $45 \mathrm{kDa}$ fragment, a well-recognized degradation fragment of lamin B1 [22], are obserwed (asterisk). Moreover, we observed a prominent staining of the lamin B1 antibody with lamina aggregates in mitotic figures of cultured cells (not shown) 
indicating that byperphosphorylated lamins are recognized by this antibody. Conversely, bacterially expressed recombinant lamins $B \perp$, which are unphosphorylated, are also positive with the antibody used (data not shown).

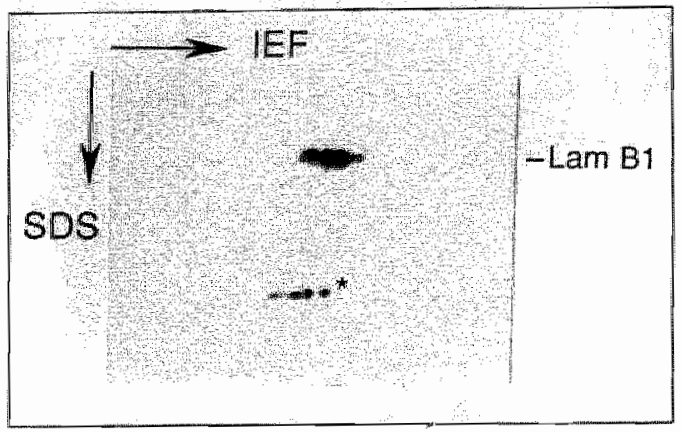

Figure 2. Two-dimensional immunoblots of an extract from cell line GLC-A2 using the lamin B1 antibody 119D5F1. Note that at least four different phosphorylation isoforms of both lamin $B 1$ and its $45 \mathrm{kDa}$ breakdown product (asterisk) are recognized.

\section{Distribution of lamin subtypes in tissue and cel] types}

The results of the immunostaining reactions in normal human tissues are outlined in Table 1 and illustrated in figures 3 to 5 . The subcellular lacalization of the staining reactions observed with all lamin antibodies was in general restricted to the nuclear periphery.

\section{Skin}

The basal cells of skin epidermis show a strong expression of lamin B2, while the expression of A-type lamins and lamin B1 is reduced or absent. In the parabasal cells A-type lamins are rather weakly expressed, while lamin B1 shows a strong staining. In the prickle cell layer the expression of lamin B1 decreases, while the expression level of the A-type lamins increases considerably. Finally, in the granular layer expression of all lamins appears to be lost in many cells. In the underlying connective tissue lamin B2 is recognized in all cells, while stromal fibroblasts, but not lymphoid infiltrates in the stroma are positive with the A-type lamin antibodies. In contrast, the lamin B1 antibody reacts only with some lymphoid cells but not with stromal fibroblasts. Endothelial cells present in the stromal layer are strongly positive for lamin $B 2$, lamins $A$ and $C$, but negative with the lamin $B 1$ antibody. Since this staining pattern was observed in all endothelial cells, we will not further mention the staining of these cells in other tissues.

\section{Digestive tract}

In tongue (Fig. 3a-c) and epiglottis (not shown) similar staining patterns were observed. In tongue all epithelial and stromal cells are positive with the lamin B2 antibody (Fig. 3a), while the lamin B1 antibody predominantly decorates parabasal cells and the lower layers of prickle cells (Fig. 3b). In the underlying connective tissue only occasional lymphoid cells are positive. 
A-type lamins are only very weakly expressed in the basal and parabasal epithelial layers, while the prickle cell layer is strongly positive (Fig. 3c). In epithelium of the submandibular gland all acinar and ductal cells are positive for all lamin antibodies. In stomach the epithelial lining is positive with all lamin antibodies, except for gastric gland cells, which appear to be negative for lamin B1.

In small intestine all cells are recognized by the lamin B2 antibody, while the antibody to lamin B1 is positive in most epithelial cells and negative in most stromal cells. A-type lamins are present in all epithelial as well as most of the stromal cells. In colon and appendix all crypt cells are strongly positive with the lamin $B 1$ and $B 2$ antibodies, while the lamin $B 1$ antibody is negative in fibroblasts. Lymphocytes in connective tissue are clearly positive. A-type lamins are present in all epithelial cells as well as most stromal cells. However, lymphoid cells of the B-cell lineage such as plasma cells appear to be negative for A-type lamin antibodies.

In liver the reduced expression of lamin B2 (Fig. 4a) and lamin B1 (not shown) in hepatocytes is very striking. Both B-type lamins are only weakly expressed in some of the cells. In contrast, Kupffer cells and bile duct epithelium are positive with B-type lamin antibodies. The lamin A/C antibodies react weaker with hepatocytes than the lamin $A$ antibody, while the reactivity with bile duct epithelial cells is similar.

In pancreas acini both lamin B2 and A-type lamins are present, while the expression of lamin B. has a rather heterogeneous appearance (Fig. 4b).

\section{Respiratory tract}

In non-neoplastic bronchi lamin $\mathrm{B} 2$ appeared to be present in all cases in virtually all epithelial and non-epithelial cells in a rather homogeneous fashion (Fig. 3d). The localization and expression level of lamin B 1 , however, varied considerably. The most commonly observed pattern was staining of the bronchial basal cells and not of the columnar cells (Fig. 3e). A similar heterogeneity was observed with the A-type lamin antibodies. In general, the antibodies to lamins $\mathrm{A} / \mathrm{C}$ showed a predominant staining in columnar cells and not in basal cells of the bronchus (Fig. 3f). However, in several sections lamins $\mathrm{A} / \mathrm{C}$ were observed throughout the whole bronchial epithelium. Alveolar pneumocyltes were positive for the lamin B2 and the Atype lamin antibodies, while lamin Bl seems to be very heterogeneously expressed. The epithelium of sero-mucous glands is positive for the lamin B2 and the A-type lamin antibodies. and only partly positive for the Jamin B1 antibody.

\section{Urinary tract}

In human kidney the lamin B2 antibodies stain all epithelial and connective tissue cells, with the epithelium of proximal and distal tubules showing weaker reactivity, as compared to the surrounding tissues (Fig. 3g). Lamin B1 is detected as a faint staining reaction in most cells of the proximal and distal tubules (Fig. 3h), and more prominently expressed in Henle's loops. Strikingly, lamin B1 is completely absent in both the epithelial and endothelial cells of the 


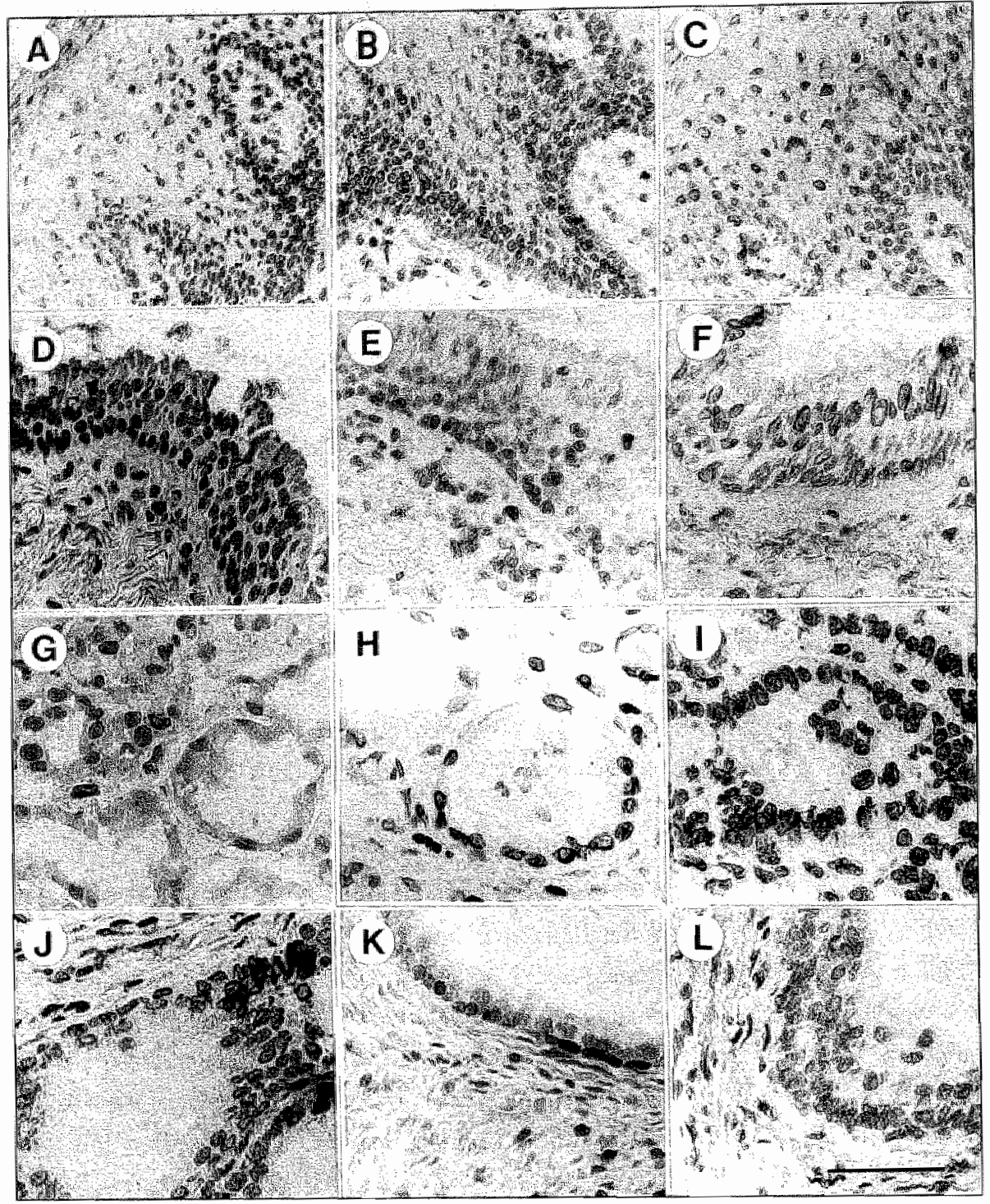

Figure 3. Immunoperoxidase staining of tongue (A-C), bronchus epilheliam (D-F), kidney (G-D), and prostate (J-L) using antitodies to lamin $B 2(A, D, G, J)$, lamin $B /(B, E, H, K)$, lamins $A / C$, $C, F$, I) and lamin $A$ (L). Nate immunoreactivily in all nuclei wih the lamin $B 2$ antibody $L N 43(A, G)$ and $X 223(D, 3)$. In tongue epithehum staning of lamin $B \|$ is most pronounced in the parabasal cell layer (B), while lamins $A / C$, stained with antibody $41 \mathrm{CC}$, are most clearly present ir the prickle cell layer and nuch weaker in the (parabasal cells (C). In bronchial epithelium the lamin $B I$ antiboly reacts with most basal cells and only few columnar cells (E), while the Jamin A.C antibody $\mathrm{R} 27$ reacts predominanty with columnar cells and nuch weaker with basal cells (F). In kidney, both the lamin $B 2$ antibody $L N 4,3$ (G) and the lamin $B \perp(H)$ antibody teact rather weakly with sone nuclei in the proximal ubules, while nuclei of distil tubules are clearly positive. The lamin A antibody $133 \mathrm{~A} 2$ strongly stains all tubular epithelium cells of kidney (1). In prostate the lamins B I anibody stains only part of the basal epithelial cells and not any lurninal cells nor sucrounding muscle cells (K). In contrast the lamin $A$ antibody stains all epithelial cells as well as surrounding muscle cell muclei(L). Bar represents $80 \mu$ in in $A, B$ and $C ; 50 \mu m$ in $D, F-L ;$ and $70 \mu m$ in $E$. 


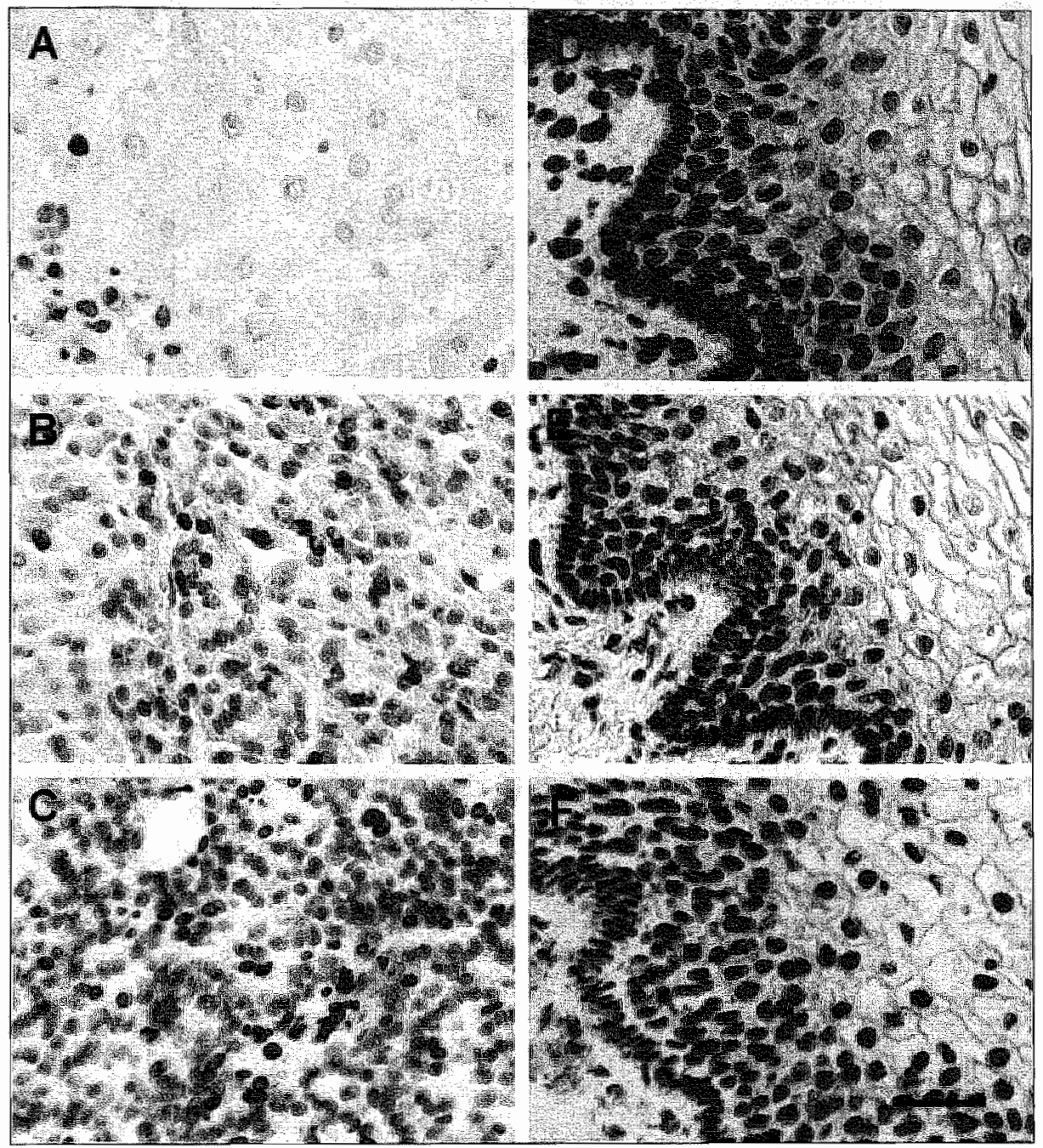

Figure 4. Immunoperoxidase staining of liver $(A)$, pancreas $(B)$, parathyroid $(C)$ and vagina epithelium (D-F), using the lamin $B 2$ antibody $L N 43(A, D)$, the lamin $B 1$ antibody $(B, E)$ the larnin $A$ antibody $(C)$ and the lamin $A / C$ antibody $41 \mathrm{CC} 4(\mathrm{~F})$. Note the very weak staining of hepatocyles as compared to bile duct cells using the lamin $\mathrm{B} 2$ antibody (A). In pancreas lamin B1 staining shows targe variation in intensities between different acinar cells (B). Parathyroid cells are only very weakly stained with the lamin A antibody, while surrounding stromall and vascular: cells are strongly positive (C). In vagina (D-F), all epithelial and stromal nuclei are stained with the lamin B2 antibody (D). In contrast, the lamin BI antibody stains few basal cells and all parabasal cells. Staining intensity is clearly decreased in the upper intermediate layer and superficial layer of epithelium (E). Lamins $A / C$ are (very). weakly expressed in basal cells and staining intensity increases with level of differentiation ( $F$ ). Bar represents 50 $\mu \mathrm{m}$. For colour illustrations see page 130. 
glomeruli. Lamins $\mathrm{A} / \mathrm{C}$ are present in all cells of the kidney, with a pronounced staining in distal and collecting tubules (Fig. 3i), and a somewhat reduced expression in the proximal tubules.

In the urinary bladder the transitional epithelium is negative with the lamin B1 antibody. All other antibodies show a clear staining reaction in all epithelial cell layers.

\section{Male reproductive tract}

In the prostate antibodies to lamin B2 react positively in all epithelial as well as non-epithelial cells (Fig. 3j). Using the lamin BI antrbody the absence of staining in the luminal cells of the prostate gland is remarkable (Fig. $3 \mathrm{k}$ ). In addition, not all of the basal cells seem to be positive. The antibodies to lamins $\mathrm{A} / \mathrm{C}$ show a heterogeneous reactivity. While both basal and luminal cells are positive, the intensity of staining seems to be weaker than in surrounding smooth muscle cells (Fig. 31).

\section{Female reproductive tract tissues.}

Vagina epithelium show staining patterns identical to the other non-keratinizing squamous cell epithelia, i.e. the presence of lamin B2 in all epithelial layers (Fig. 4d) and the most prominent staining of lamin B 1 in the proliferative parabasal cell layer (Fig $4 \mathrm{e}$ ). Lamin $\mathrm{A} / \mathrm{C}$ antibodies are most prominently expressed in layers of highly differentiated cells of the prickle cell layer (Fig. 4f). Interestingly, in the superficial layer, containing many apoptotic cells, the detectabillity of all lamins decreases considerably. In the vaginal connective tissue cells expression of lamin $B 2$ is constantly high, while lamin $B 1$ is absent in fibroblasts. The expression of lamins $A / C$ in connective tissue cells is variable.

In normal ectocervical stratified epithelium lamin B2 is expressed in all cell layers (Fig. 5a). In contrast to other non-keratinizing stratified squamous cell epithelia, lamin BI is most prominently expressed both in the basal and in the parabasal epithelial cells (Fig. 5b), with a reduction of staining in the upper cell layers. Also in contrast to other stratified epithelia, lamins A/C antibodies show prominent staining of the entire epithelium (Fig. 5c).

More than 30 cases of cervical intra-epithelial neoplasia (CIN) were examined for their lamin expression patterns. In both low and high grade CIN lesions the normal differentiation of the squamous epithelium is largely lost. While lamin staining patterns are similar in either lesion type, a general decrease in lamin expression is noticeable in high grade CIN lesions. Lamin B2 is present in most epithelial cells (Fig. 5d). Lamin B 1 expression seems to remain confined to the lower layers of this epithelium (Fig. Se), while A-type lamins are expressed heterogeneously throughout all layers of the epithelium (Fig. 50).

In endocervical columnar epithelium most cells are positive with the antibodies examined, except for the reserve cells which are largely negative for lamin $\mathrm{B} 1$. In connective tissue cells of the endocervix all antibodies are positive except for the lamin B1 antibody, which is negative in the fibroblasts, but positive with most lymphoid cells. 


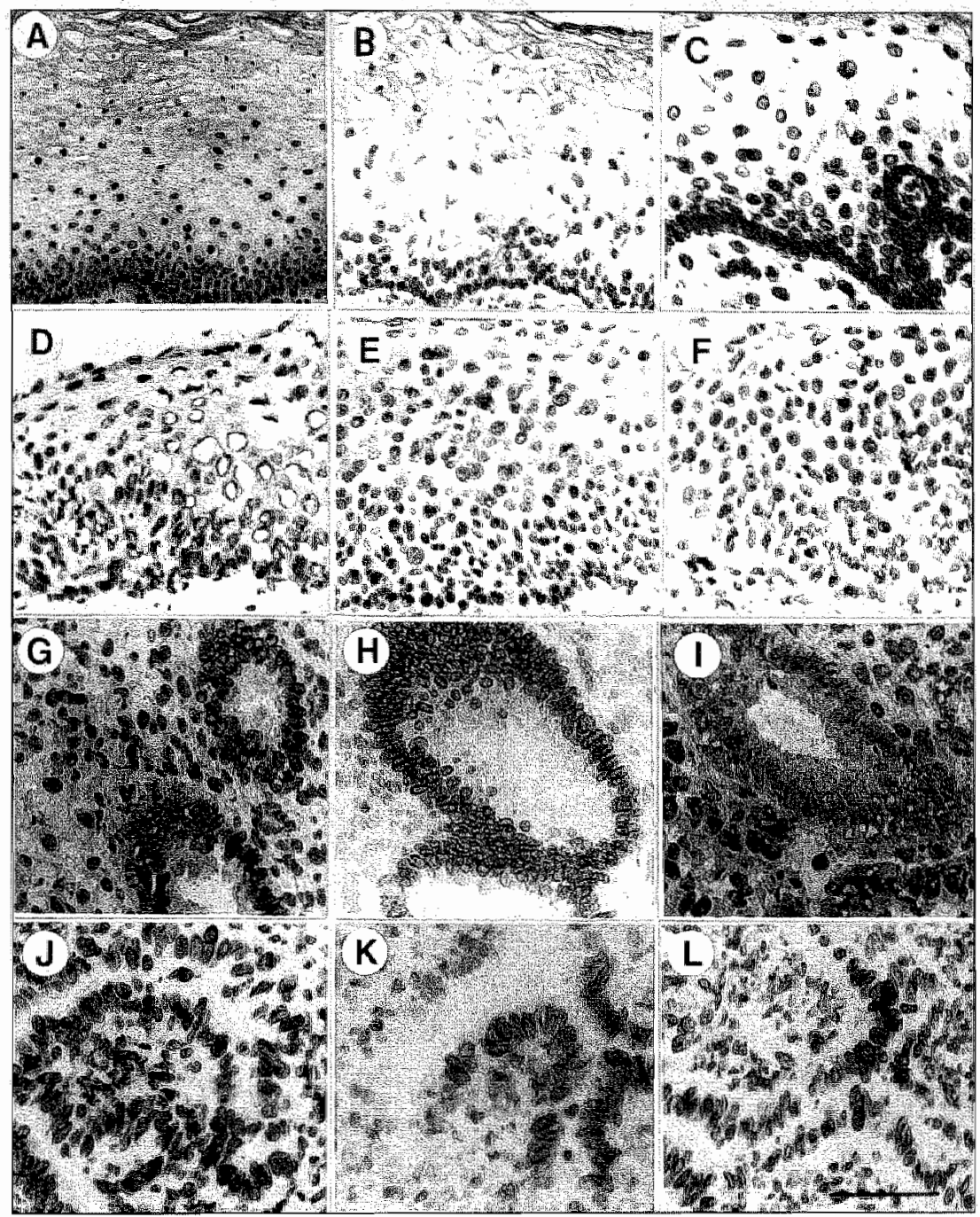

Figure 5. Immunoperoxidase staining of ectocervix (A-C), cervical intra-epiahelial neoplasia (CIN, D-Wi), endometrium (G-I), and fallopian tube ( $J-L)$, using antibody $L N 43$ to lamin $B 2(A, D, J)$, the antibody 10 lamin $B L$ $(B, E, G, H, K)$, lamins $A / C$ antibody $R 27(C, F)$ and the lamin $A$ antibody $(I, L)$. Normal eclocervix is positive in all cells with the lamin $B 2$ antibody (A), while lamin $B 11$ expression is confuned to the lower layers of the epithelial cells (B). Lamins $\mathrm{A} / \mathrm{C}$ are expressed throughout the ectocervical epithelium (C). In a laggh grade CIN lesion lamin B2 shows expression in all epithelia cells (D), whille lanin BI in mainly expressed in lower epithellat compartment (E). Lamins $A / C$ are only present in scattered cells throughout this epithelium $(F)$. In endometrium lamin $B I$ is expressed in cells of both proliferating (G) and secretory $(H)$ epithelial cells. Strikingly, stromal cells of proliferating endometrium are strongly positive, while these cells are barely stained in secretory endometrium (compare $\mathrm{G}$ and $\mathrm{H}$ ). Lamin $\mathrm{A}$ cam be stairted in all nuclei of stromal and epithelial endometrim cells (I). In Fallopian tube all nuclei are stained with the lamin $B 2$ antibody $(J)$, while lamin $B$ I is only present in part of the columnar epithelial cells $(\mathrm{K})$. The lamin A antibody stains most, but not all columnar cells next 10 all stromal cells $(\mathbb{L})$. Bar represents $110 \mu \mathrm{m}$ in $\mathrm{A} ; 100 \mu \mathrm{m}$ in $\mathrm{B}, \mathrm{D}$ and $\mathrm{E} ; 90 \mu \mathrm{m}$ in $\mathrm{C}$ and $\mathrm{F} ; 70 \mu \mathrm{m}$ in $\mathrm{C}, \mathrm{H}, \mathrm{J}, \mathrm{K}$ and $\mathrm{L}$; and $50 \mu \mathrm{m}$ in $\mathrm{I}$. 
We have examined endometrium tissue specimens from different stages of the menstrual cycle. In all cases examined the lamin $B 2$ antibodies recognize virtually all nuclei. In myometrium most cells are strongly positive for lamin B2. Lamin B1 appears to be present in all epithelial cells, but not in all stromal celis of endometrium. The stromal cells are mostly positive in the proliferation phase (Fig. $5 \mathrm{~g}$ ). In contrast, in late secretory phase and in inactive endometrium there is barely any stainng with the lamin Bl antibody in the stromal cells (Fig. 5h). In myometrium no staining of lamin B1 is observed. In the basal layer of endometrium the expression of A-type lamins is generally stronger than in the functional layer, especially in endometrium in the proliferative phase. However, expression of lamins $A / C$ and of lamin $A$ is visible in epithelial cells of both proliferative and secretory endometrium (Fig. 5i). In proliferating endometrium the expression of A-type lamins, especially using the lamin $A$ antibody, appears to be reduced in the epithelial cells as compared to the surrounding stromal tissues.

In the fallopian tube the lamin B2 antibodies react strongly with the epithelial lining (Fig. $5 \mathrm{j}$ ). The antibody to lamin B 1 appears to recognize the intercalated cells and only a part of the ciliated and secretory cells (Fig. 5k). In contrast, the lamins A/C antibodies do not recognize the intercalated cells while most ciliated and secretory cells are positive. The antibody to lamin $A$ seems also to recognize some intercalated cells next to the ciliated/secretory cells (Fig. 51). In ovary both lamin B2 and A-type lamins are expressed in all stromal cells. No staining is obserwed with the lamin $B 1$ antibody in stromal cells of the ovary.

\section{Endocrine tissues}

We investigated some endocrine tissues which were previously reported to be negative for $A$ type lamin antibodies. In thyroid lamin B2 and A-type lamins are present in all cells, while lamin $B 1$ is absent. The staining of lymphocytes in these samples is however very obvious asing the lanin B.1 antibody. In parathyroid lamin B2 is again clearly positive, while both lamin B1 and A-type lamins (Fig. 4c) are negative in the endocrine cells of this organ. Also in adrenal gland both lamin B 1 and A-type lamins are negative in most endocrine cells.

\section{Muscle tissues}

In striated skeletal muscle and in myocard lamin B2 and A-type lamins were expressed in most or all cells. In contrast, the expression of lamin $B I$ seems to be absent in both types of muscle cells (see also [17). Also in several smooth muscle cells studied in several organs lamin BI seems to absent.

\section{Lymphoid rissues}

In spleen lamins B2 and B1 are evident in all cells, while B-type lymphocytes in the white pulp are negative for A-type lamins. The expression of lamins in lymph nodes will be described in chapter 4 of this thesis. 
Absence of lamin B1 staining in several tissues is not caused by epitope masking

We have performed immunoblotting experiments of myometrium and endometrium in order to confrrm our immunoperoxidase staining data. These tissues were chosen beease of the observation that in the immunoperoxidase technique myometrial cells are not stained, while in endometrium all epithelial cells are positive with the lamin BI antibody. Figure 6 shows. immunoblots incubated with the lamin B1 antibody (lanes 1 and 2). In endometrium a discrete band at the lamin B1 level is present (arrow), while in myometrium no band is visible. Only after prolonged exposure of the immunoblot a very faint band became visible in myometrium (not shown). For comparison of the amounts of protein loaded onto the gel lanes, a parallel blot was incubated with a lamin B2 antibody, showing no obvious differences in staining intensities (lanes 3 and 4).

Figure 6. Immunoblothing of an extrnct of myometrium (lanes 1 and 3 ) and endometrium (lanes 2 and 4) using the lamin $B 1$ antibady 119D5F1 (lanes 1 and 2) and the lamin B2 antibody LN43 (lanes 3 and 4). Note the presence of lamin B1 (arrow) in endometrium and not in myometrium. Based on the similar reactivity of the lamin B2 antibody (compare lanes 3 and 4) and the accompanying Coomassie stained gel (not shown) we conclude that the protein amounts loaded onto the lanes were similar.

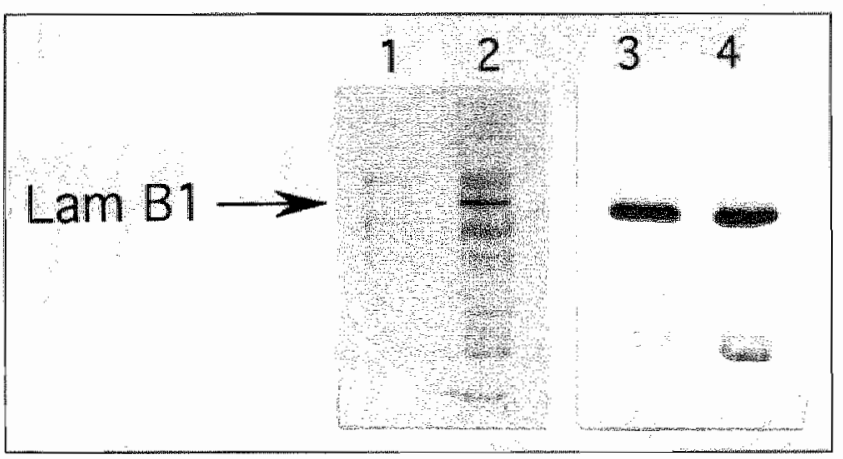


Table 1: Immunoperoxidase staining patterns of human tissues with lamin antibodies

\begin{tabular}{|c|c|c|c|c|}
\hline & Lamin B2 & Lamin B1 & $\operatorname{Lamin} A / C$ & $\operatorname{Lamin} A$ \\
\hline \multicolumn{5}{|l|}{ Skin } \\
\hline \multicolumn{5}{|l|}{ Epidermins } \\
\hline Basal cells & ++ & \pm & \pm & $+1-$ \\
\hline Parabasal cells & ++ & ++ & \pm & $+1-$ \\
\hline Prickle cell layer & ++ & + & $+t$ & ++ \\
\hline Granular layer & ++1 & $+1-$ & $++\%$ & ++1 \\
\hline Stromal fibroblasts & ++ & - & ++ & + \\
\hline Endothelial cells & ++ & - & + & + \\
\hline \multicolumn{5}{|l|}{ Digestipe tract } \\
\hline \multicolumn{5}{|l|}{ Tongue and epiglottis } \\
\hline Basal cells & ++ & - & \pm & $+1-$ \\
\hline Parabasal cells & ++ & ++ & \pm & $+1-$ \\
\hline Prickle cell layer & ++ & + & ++ & ++ \\
\hline Granular layer & ++ & $+1-$ & ++ & ++ \\
\hline \multicolumn{5}{|l|}{ Submandibular glands } \\
\hline Acini & + & + & + & + \\
\hline Ducts & ++ & + & + & + \\
\hline \multicolumn{5}{|l|}{ Stomach corpus } \\
\hline Surface epithelium & ++ & ++ & ++ & ++ \\
\hline Gastric gland cells & ++ & - & ++ & ++ \\
\hline \multicolumn{5}{|l|}{ Small intestine } \\
\hline Crypt cells & + & ++ & $++1-$ & $+1-$ \\
\hline \multicolumn{5}{|l|}{ Colon } \\
\hline Crypt cells & ++ & ++ & $+1-$ & $+1=$ \\
\hline Fibroblast & ++ & - & ++ & $+t$ \\
\hline Stromal lymphoid cells & ++ & ++ & $+/-$ & +1 \\
\hline \multicolumn{5}{|l|}{ Liver } \\
\hline Hepatocytes & \pm 1 & +1 & $+1-$ & + \\
\hline Kupffer cells & + & + & + & + \\
\hline Sinusoidal endoth. & + & + & + & + \\
\hline \multirow{2}{*}{\multicolumn{5}{|c|}{$\begin{array}{l}\text { Bile duct epithelium } \\
\text { Pancreas }\end{array}$}} \\
\hline & & & & \\
\hline Acinar cells & ++ & $++/ \pm$ & ++ & ++ \\
\hline
\end{tabular}


Table 1 (continued)

\begin{tabular}{|c|c|c|c|c|}
\hline & Lamin B2 & Lamin B1 & Lamin $\mathrm{A} / \mathrm{C}$ & Lamin A \\
\hline Respiratory tract & & & & \\
\hline Bronchus & & & & \\
\hline Basal cells & ++ & ++ & +1 & +1 \\
\hline Columnar cells & ++ & $+1-$ & ++ & ++ \\
\hline \multicolumn{5}{|l|}{ Lung alveoli } \\
\hline Pneumocytes & + & $+\infty$ & ++ & ++ \\
\hline Stromal cells & ++ & +1 & + & + \\
\hline \multicolumn{5}{|l|}{ Urinary tract } \\
\hline \multicolumn{5}{|l|}{ Kidney } \\
\hline Prox. tubules & + & $+1-$ & + & + \\
\hline Distal tubules & + & $+1-$ & ++ & + \\
\hline Loops of Henle & ++ & + & + & + \\
\hline \multicolumn{5}{|l|}{ Gllomeruli } \\
\hline Epithelium & +1 & - & ++ & ++ \\
\hline Endothelium & ++ & - & $4+$ & ++ \\
\hline Collecting tubules & $+t$ & $+1-$ & + & + \\
\hline Juxtaglom. apparatus & ++ & N.D. & + & + \\
\hline \multicolumn{5}{|l|}{ Urinary bladder } \\
\hline Urothelium & ++ & - & + & ++ \\
\hline Fibroblasts & + & - & ++ & ++ \\
\hline Smooth muscle & $++1-$ & - & $+\%$ & $+1-$ \\
\hline \multicolumn{5}{|l|}{ Male reproduct. tract } \\
\hline \multicolumn{5}{|l|}{ Prostate } \\
\hline Basal ep. cells & ++ & $++1-$ & ++1 & $4+1-$ \\
\hline Luminal cells & ++ & - & $+1-$ & $+1-$ \\
\hline
\end{tabular}


Table 1 (continued)

Female reproduct tissue

Vagina

Epithelium

Basal layer

Parabasal layer

Intermediate layer

Superficial layer

Fibroblasts

Endocervix

Columnar epithelium

Reserve cells

Fibroblasts

Endothelial cells

Ectocervix

Normal epithelium

Basal layer

Parabasal layer

Intermediate layer

Superficial layer

Low-grade CIN

Basal compartment

Intermediate comp.

Superficial comp.

High-grade CIN

Basal compartment

Intermediate comp.

Superficial comp.

Uterus

Endometrium

Basal part

Column. epithelium

Stroma

Functional layer

Column. epithelium

Stroma

Myometrium

$\begin{array}{llll}++ & \pm & - & \pm \\ ++ & ++ & +- & + \\ ++ & ++ & ++ & +1 \\ +/- & +/ & +/- & +1 \\ ++ & - & +/- & +1-\end{array}$

$\pm$

$+$

$+1 /$

$+1-$

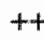

$+$
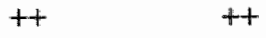

$+$

$4 \pi$

$+$

$+$

$+$

$+$

$++$

$+$

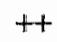

++
++
++
+

$+$

$+$

$+$

$+\quad+$

$++1-$

$++$

$+$

$+1$

$+t$

$++$

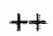

$+$

$+$

$+$

$+$

$+$

$+$

$+4$

$++$

$+$

$+$

$+$

$+$

$\pm$

$\pm$

$\pm$

$\pm$

$\pm$

++
++
++
++
$++1-$

$+$

$++$

$+$

\pm i-

$+$

$++$

$+1-$

++
$+1-$

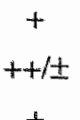

$+1 / t$ 
Table 1 (continued)

\begin{tabular}{|c|c|c|c|c|}
\hline & Lamin B2 & Lamin B 1 & Lamin A/C & Lamin $\mathrm{A}$ \\
\hline \multicolumn{5}{|l|}{ Fallopian tube } \\
\hline \multicolumn{5}{|l|}{ Epithelium } \\
\hline Ciliated/secr cells & ++ & +1 & $+t$ & + \\
\hline Intercalated cells & ++ & ++ & - & +1 \\
\hline Fibroblasts & $+t$ & - & ++ & ++ \\
\hline Smooth muscle & ++ & - & $+1++$ & $t+$ \\
\hline \multicolumn{5}{|l|}{ Ovary } \\
\hline Stromal cells & ++ & - & + & + \\
\hline Smooth muscle & H+ & - & \pm & + \\
\hline \multicolumn{5}{|l|}{ Muscle } \\
\hline Skeletal muscle & $+t$ & - & + & + \\
\hline \multicolumn{5}{|l|}{ Heart } \\
\hline Muscle cells & + & - & $+1-$ & \pm \\
\hline Interstitial fibroblasts & + & - & + & + \\
\hline Smooth muscle & ++ & - & + & + \\
\hline \multicolumn{5}{|l|}{ Immune system } \\
\hline \multicolumn{5}{|l|}{ Spleen } \\
\hline White pulp & ++ & ++ & - & - \\
\hline Red pulp & ++ & ++ & ++ & $+t$ \\
\hline \multicolumn{5}{|l|}{ Neuroendocrime tissues } \\
\hline Thyroid foll. epithelium. & ++ & - & ++ & ++ \\
\hline Parathyroid gland cells & ++ & - & +1 & $+1-$ \\
\hline Adrenal gland cells & ++ & - & \pm & + \\
\hline
\end{tabular}

$\begin{array}{ll}++ & \text { strong reactivity in all cell } \\ + & \text { positive staining in most cells } \\ ++/- & \text { positive staining in part of the cells } \\ 0+t- & \text { weak staining in part of the cells } \\ \pm & \text { no staining in any cells } \\ \text { N.D. } & \text { not determined }\end{array}$




\section{Discussion}

In this paper we describe the differential expression of the nuclear lamins in a variety of normal human tissues. The study was performed using a panel of well-defined monoclonal antibodies, which not only differentiate between lamins B1 and B2, but can also recognize specifically lamin $A$, in addition to antibodies which recognize both lamins $A$ and $C$. Most of the previous studies to categorize the expression levels of lamins in normal tissues have been performed in animal tissues of several species $[15,25,29]$ or used antibodies with unknown specificity for the B-lype lamins (see e.g. [7]). As a result, the exact tissue distribution of lamins in human tissues remained to be clarified.

Our immunoprecipitation studies combined with the two-dimensional gel electrophoresis experiments show that antibodies used in this study are indeed specific for the individual lamin subtypes.

\section{Differential distribution of nuclear lamins in human tissues}

To generalize the lamin subtype distribution patterns, we have summarized our findings according to cell type (Table 2 ).

The lamin B2 antibodies were positive in all cell types in all tissues examined, except for hepatocytes, which were partly negalive.

Lamin B1 expression was much less ubiquitous as compared to lamin B2. In non-keratinizing squamous epithelia lamin B 1 was mainly present in parabasal cells, while the staining intensity decreased in more differentiated epithelial layers. In pseudostratified epithelia basal cells were positive, while columnar cells were only partly positive. In simple columnar epithelia most cells were positive, while in columnar glands the absence of lamin BI in most cells was striking. Lamin B1 appeared to be absent in almost all non-epithelial cell types, except for part of the hematopoietic cells types and stromal cells of proliferating endometrium, which were strongly positive.

The expression of A-rype lamins in stratified squamous epithelia was most abundant in layers of highly differentiated cells, while basal as well as parabasal cells were in general negative to weakly positive. In pseudostratified columnar epithelia in particular antibodies recognizing both Vamin $\mathrm{A} / \mathrm{C}$ showed a reduced staining reaction in the basal cells. This reduction was less pronounced with the lamin A antibody. Most columnar cells were positive. In other columnar epithelia A-type lamins were positive in almost all epithelial cells, with the exception of reserve cells which were occasionally negative. In other tissues A-type lamins were positive in connective tissue fibroblasts and muscle cells, although the staining intensity in cardiac muscle cells was relatively weak. Several types of blood cells, including lymphocytes in inflammatory infiltrates and cells of white pulp in spleen, were negative. In addition, A-type lamins were absent in most neuroendocrine cells examined. 
Table 2: Lamin subtype distribution according to cell type

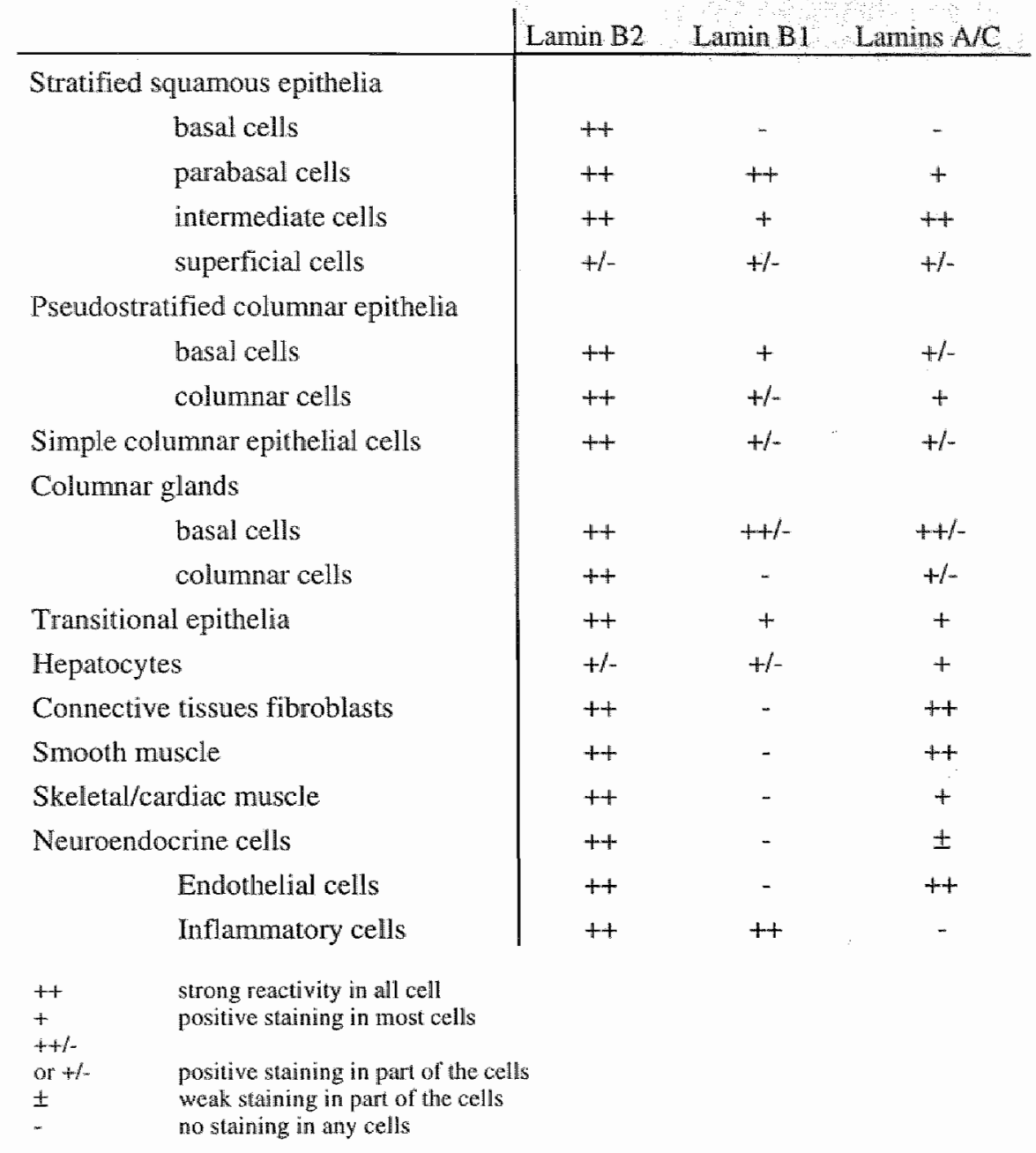

Expression of lamin $B 1$ is much more restricted than lamin $B 2$

Our study shows that of the B-type lamins, lamin B2 and not lamin B1 is extensively expressed in human tissues. The presence of two distinct B-types lamins was not generally recognized until 1990 [13,25]. Later studies have shown that both B-type lamins are products of different genes [2, 24] located on different chromosomes [30]. Previous studies in chicken tissues have shown that lamin B2 and not lamin B1 is the main lamin in this species [15]. Studies in other animals also indicate differences between B-type lamin isoform expression (see e.g. [25.), but 
from these studies it is not clear whether the antibodies used differentiate between lamins $\mathrm{B} 1$ and $\mathrm{B} 2$, or between different phosphorylation isoforms of either lamin. The underlying study revealed similar lamin distribution patterns in human tissues as compared to chicken, in that lamin BI is absent in human muscle cells (see also [1]), fibroblasts and endothelial cells. Moreower our study shows that lamin B1 expression is reduced or absent in epithelial cells with a high level of differentiation.

Our observation that basal cells of squamous epithelia, which in general serve as stem cells and do not proliferate, are negative for lamin BI and the obserwation that parabasal cells, which show proliferation as based on $\mathrm{Ki}-67$ expression [27], are strongly positive with the lamin B1 antibody, suggest that lamin B1 expression is correlated with proliferation in some cell types. This correlation has also been suggested in a study, which showed that reactive regions of lymph nodules express more lamin B1 than lamin B2. Furthermore, when normal peripheral blood mononuclear cells were stimulated to proliferate a dramatic increase in lamin BI mRNA expression was noticed [20]. However, such a correlation does not hold true for the CIN lesions examined. In high grade CIN proliferation is higher than in low grade CIN [27] and is not confined to the lower compartment of the epithelial cells. Surprisingly, lamin B1 expression does remain confined to this lower compartment. Possibly the high incidence of human papilloma virus (HPV) infection in especially high grade CIN lesions can cause alterations in lamin expression. This suggestion is currently under investigation. Another indication that lamin B1 expression is not a universal proliferation marker is found in cells which have ceased to proliferate, such as secretory phase endometrium cells, in which the expression of lamin Bl seems to be maintained. The negative reaction of the lamin B1 antibody in several tissues examined is not due to the lack of cross-reactivity of this antibody with different phosphorylation states of its antigen, since our studies have shown that the complete scale from unphosphorylated up to hyperphosphorylated lamin B1 is recognized by the antibody used. Therefore, we cannot sustain previous findings which suggest that observed differences in $B$ type lamin expression are due to differences in cross-reactivity of antibodies with different phosphorylation states of these proteins [29]. Also masking of the lamin B1 epitope in tissues sections has been excluded since denatured protein samples of myometrium, showing no staining in frozen tissue sections, also showed no immunoreactivity after immunoblotting. The general assumption that lamin Bl is present in all tissues (see also [16]) may be due to the use of antibodies that do not completely differentiate between lamin B1 and lamin B2. Our twodimensional immunoblots have revealed that the different phosphorylation forms of (human) lamin B1 do not completely separate from lamin B2 isoforms (not shown). Therefore, if conclusions are to be drawn about the specificity of lamin antibodies next to two-dimensional gel electrophoresis additional experiments, such as immunoprecipitation should always be performed to exclude cross-reactivity. Using two different antibodies to lamin B2 we have shown that lamin B2 is expressed in large amounts in nearly all cells examined. 
A-rype lamins are related with the commitment to a differentiation lineage

There is general consensus regarding the tissue distribution of A-type lamins. Several studies reported the absence or reduced expression of A-type lamins in developing embryonic tissues of mouse [26], and chicken [15] In adult mouse tissue A-type lamins are absent from spleen, bone marrow and thymus [26], while in adult human tissues a variety of neural and neuroendocrine cells showed no A-type lamins expression [7]. These findings were confirmed in our study. The reduced expression of A-type lamins in proliferating cells as previously suggested [7, 8] was confirmed using three different A-type Jamin antibodies. However, a general correlation between absence of cellular proliferation and increased A-type lamin expression can not be sustained, since cells from many tissues, known to be quiescent, do not stain with any A-type lamin antibody examined.

\section{Acknowledgements}

The authors wish to thank Dr. Birgitte Lane, Dr. Georg Krohne and Dr. Warren for providing antibodies used in this study. Dr. Lou de Leij is acknowledged for providing cell line GLC-A2.

\section{References}

I1』 Ausma, J., G.J.J.M. van Eys, J.L.V. Biroers, F Thoné, W. Flameng, F.C.S. Ramaekers, M. Borgers: Nuclear lamin expression in chronic hibernating myocardium in man. J. Mol. Cell Cardiol. 28, 1297-1305 (1996).

[2] Biamonti, G., M. Giacca, G. Perini, G. Contreas, L. Zentilin, F. Weighardt, M. Guerra, G. Della Valle, S. Saccone, S. Riva, A. Falaschi: The gene for a novel human lamin maps at a highly transcribed locus of chromosone 19 which replicates at the onset of S-phase. Mol. Cell. Biol. 12, 3499-3506 (1992).

[3] Bridger, J.M., I. Kill, M. O'Farrell, C.J. Hutchison: Internal lamin structure within Gl nuclei of human dermal fibroblasts. J Cell Sci. 104, 297-306 (1993).

[4] Broers, J.L.V. D.N. Carney, M. Klein Rot, G. Schaart, E.B. Lane, G.P. Vooijs, F.C.S. Ramaekers: Jmermediate filament proteins in classic and wariat types of small cell lung carcimoma cell lines: a biochemical and immunochemical analysis using a panel of momoclonal and polyclonal antibodies. I. Coll Sci. $83,37-60(1986)$

(5] Broers, J.L.V., Y. Raymond, M. Klein Rot, H. Kuipers, S. Wagenaar, F.C.S. Ramaekers: Nucloar A.4ype lamins are differentially expressed in human lung cancer subtypes. Am. J. Pathol. 143, 211-220 (1993).

[6] Burke, B., G. Tooze, G. Warten: A monoctonat antibody which recognises eacti of the nuclear lamin polypeptides in mammalian cells. EMBO J. 2, 361-367 (1983).

[7] Cance, W.G., N. Chatudhary, H.J. Worman, G. Blobel, C. Cordon Cardo: Expression of the nuclear lamins bn normal and neoplastic human lissues. J. Exp. Clin. Cancer Res. 11, 233-246 (1992).

18] Coates, P.J., C. Hobbs, I. Crocker, D.C. Rowlands, P. Murray, R, Quinlani, P.A. Hall: Identilication of the antiger recognized by the monoclonal antibody $B$ U3 1 as lamins $A$ and C. J. Pathol 178, $21-29$ (1996).

[9] Fisher, D.Z., N. Chaudhary, G. Blobel: CDNA sequencing of nuclear lamins A and C reveals primary and secondary structural homology to intermediate fiament proteins. Proc. Natl. Acad. Sci. USA 83, 6450-6454 (1986).

[10] Furukawa, K., Y. Hotta: cDNA cloning of getri cell spectic lamin B3 from mouse spcrmatocytes and analysis of its function by ectopic expression in somatic cells. EMBO J. 12, 97-106 (1993).

[11] Furukawa, K., H. Inagaki, Y. Hotta: Identificalion and cloning of an mRNA coding for a gern celli-specific A-type lamin in mice. Exp. Cell Res. 212, 426-430 (1994).

[12] Guilly, M.N. J.P. Kolb, F. Gost, F. Godean, J.C. Courvallin: Lamins A and C ane not expressed at early stages of human lymphocyte differentiation. Exp. Cell Res. 189, 145-147 (1990).

[13] Höger, T.H. K. Zatloukal, I. Waizenegger, G. Krohne: Characterization of a second highty conserwed $\mathbb{B}$ type lamin present in cells previously thought to contan only a single B-type lamin. Chromosoma 99,379 $390(1990)$. 
114] Hork, P.M.-I. Sassevile, Y. Kaymond, P.R. Cook Lamin proteins form an internal nucleos as a peripherallamina in tuman cells. J. Cell Sci. 1018, 635-64 (1995).

[15] Lehner, C.F. R. Stck, H.M. Eppenberger, E.A. Nigg: Differential expression of naclear lamin protems during chick development. I. Cell Biol 105, 577-587 (1987).

[16] Lin, F. H. Worrian: Structural organizaton of the human gene (LNNB1) encoding nuclear lamin B I. Gencomics 27, 230-236(1995).

[17] Lin, F. H.Y. Worman: Structural orgenzation of the human gene encoding nucilear lamun A and nuclear Lamin C. J. Biol. Chem. 268, 16321-16326(1993).

[18] Machiels, B.M., J.L.V. Broers, Y. Ramond, L. de Ley, H.J.H. Kurjpers, N.E.H. Caberg, F.C.S. Ramaekers. Abnormal A-type lamin organization in a human lung carcinoma cell hine. Eur. J. Cell Biol. 67, 328-335 $(1995)$

[19] Machie 1 ; B.M. A.H.G. Zorenc, J.M. Endert, H.J.H. Kujpers, G.J.M.M. van Eys. F.C.S. Ramaekers, J.L.V Broens: An allernative splicing product of the lamin $\mathrm{AC}$ gene lacks exom 10. J. Biol. Chem. 271, 9249-9253. (1996).

[20] Muller, P.R. R. Meler, A. Hir, I.J. Bodmer, D. Janic, K. Leibundgut, A.R. Luthy, H.P. Wagner: Nuclear lamin expression reweals a surprisingly high growth fraction in childhood acute lymphoblastic leukemia cells. Leukemia 8,940-945 (1994).

121] OFarrel1, P.H. High resolution two-dimensional alectrophoresis of proteins: J Biol Chem 230, 4007-4021 $(1975)$.

[22] Oberhammer, F.A., K. Hochegger, G. Fröschl, R. Tiefenbacher, M. Pavelka: Chromatin condensation during apoptosis is accompanied by degradation of lanin $A+B$, without enthanced activation of cde2 kinase. $J$. Cell Biol. $126,827-837(1994)$.

[23] Paulin-Lewasseur, M, A. Scherbarth, G. Giese, K. Röser, W. Bohn, P. Traub: Expression of nuclear lamins in mammalian somatic cells lacking cytoplasmic intermediate filament proteins. J. Cell Sci. 92, 361-370 $(1989)$.

[24] Pollard, K.M. E.K.L. Chan, J. Grant B, K.F. Sullivan, E.M. Tan, C.A. Glass: In witro posttranslational modification of lamin B eloned from a human T-cell line. Mol. Cell. Biol. 10, 2164-2175 (1990).

[25] Röber, R.-A., H. Sauter, K. Weber, M. Osbom: Cells of the cellular immune and hemopoietic system of the mouse lack lamins $\mathrm{A} / \mathrm{C}$ : distinction versus other somatic cells. J, Cell Sci, 95, 587-598 (1990).

[26] Röber, $\mathbb{R} . A$. K. Weber, M. Osborn: Differential timing of nuclear lamin A./C expression in the varions organs of the mouse enbryo and the young animal: a developmental study. Development 105, $365-378$ (1989).

[27] ter Harmsel, W.A., J. Kuijpers, F. Smedts, M. Jeunink, B. Trimbos, F. Ramaekers: Progressing imbalance between proliferation and apoptosis with increasing severity of CIN. Int. J. Gyn. Pathol. in press, (1997).

[28] Towbin H. T. Staehelin $_{\text {. J }}$ Gordon" Electrophoretic transfer of proteins from polyacrylamide gels to nitrocellulose sheets: procedure and some applications. Proc Natl Acad Sci USA 76, 4350-4354 (1979).

[29] Worman, H.J., I. Lazaridis, S.D. Georgatos: Nuclear lamina heterogeneify in mammallan cells. J. Biol. Chem. 263, 12135-12141 (1988).

[30] Wydner, K.L., J.A. MoNeil, F. Lin, H.J. Worman, J.B. Lawrence: Chromosomal assignment of human nuclear envelope protein genes LMNA, LMNB 1, and LBR by fuorescence in situ hybridization. Genomics $32,474-478(1996)$.

[31] Zatloukal, K, H. Denk, G. Spurej, H. Huter. Modulation of protein composition of nuclear lamina reduction of laming-B.I and lamins-B2 in liwers of griseofulvin-treated mice Lab. Invest. 66, 589-597 (1992). 


\section{Chapter 3}

Nuclear lamin expression in normal testis and testicular germ cell tumours of adolescents and adults

Barbie M. Machiels, Frans C.S. Ramaekers, Helma J.H. Kuijpers, Jacqueline S. Groenewoud, J. Wolter Oosterhuis, Leendert H.J. Looijenga

Journal of Pathology (1997), 182: 197-204. 


\section{Summary}

Nuclear A-and B-type lamins are differentially expressed in tissues, depending on the degree of cellular differentiation and proliferative status. By studying lamin expression in testis parenchyma and testicular germ cell tumours, further insight may be gained into the degree of cellular differentiation in normal testis and into the whole spectrum of differentiation lineages found in testicular germ cell tumours. Frozen tissue sections of normall testis and the different tyjes of testicular germ cell tumours were immunostained with monoclonal antibodies to distinct lamin subtypes. Lamin reactivity was evaluated in relation to the lineage and degree of cellular differentiation and the reactivity patterns were compared to each other and to those in normal testis. In normal testis, both A- and B-type lamins were expressed in Sertoli, Leydig and peritubular cells, while in spermatogonia only B-type lamins were found and spermatocytes showed weak reactivity with the A-type lamin antibodies. Carcinoma in situ was most often positive for both of the B-type lamins and negative for the A-type lamins (lamins $A$ and $C$ ). In testicular germ cell tumours, B-type lamins were always expressed, while A-type lamins were differentially expressed. Differentiated nonseminomas were positive for both of the A-type lamins, whereas embryonal carcinomas were positive for lamin $\mathrm{C}$ and negative for lamin $\mathrm{A}$. Seminomas were negative for both of the A-type lamins, with the exception of seminomas containing a Ras mulation. Spermatogonia and seminoma cells, which follow a differentiation pathway along the spermatogenic lineage and show characteristics of germ cells, do not express A-type lamins. Nonseminomas, showing embryonal or extra-embryonal differentiation, express A-type lamins to varying degrees, distinguishing embryonal carcinoma cells from other nonseminomatous components. This may aid in the evaluation of the percentage of embryonal carcinoma in nonseminomatous testicular germ cell tumours as a prognostic parameter.

\section{Introduction}

The incidence of human testicular germ cell tumours (TGCT) of adolescents and adults, the most common type of cancer in young men [38], has more than doubled in most western countries over the last forty years [5]. TGCT present a complex histopathology, in which two major, clinically relevant entities can be distinguished; seminomas (SE) and nonseminomas (NS) [23]. The SE are composed of malignant counterparts of early (primordial) germ cells. The NS are histologically subdivided into embryonal carcinoma (EC), teratoma (TE), yolk sac tumour (YS) and chotiocarcinoma (CH), occurring either in a pure form or intermixed. The EC cells are now considered to be the stem cells from which the other NS-components originate [1]. Histogenesis within TGCT thus represents a caricature of cell differentiation during early embryogenesis [31]. In spite of the histological heterogeneity of TGCT, they all develop via carcinoma in situ (CIS) [36], which is most probably initiated during early embryonic life [16]. 
No clear cut differences between CIS and SE have been reported, except for the invasive behaviour of the latter [31].

Studying differentiation antigens may provide further insight into normal germ cell development, as well as into different derivatives of malignant transformed early germ cells, as represented by the whole spectrum of differentiation lineages found in testicular germ cell tumours. For example, intermediate filament proteins are markers for distinct tissue types and the tumours originating therefrom [34]. Lamins are intermediate filament-type proteins that form a major component of the nuclear lamina, a filamentous meshwork associated with the inner nuclear membrane $[22,26]$. Two main types of lamins can be distinguished, A-type and B-type lamins. A-type lamins consist of lamins A and C, two products of the same gene, generated by alternative splicing [19]. A-type lamins are differentially expressed in mammalian tissues, depending on the degree of differentiation or proliferative activity of the cells. Undifferentiated and highly proliferative cells usually lack A-type lamin expression. B-type lamins consist of lamins B1 and B2, products of two distinct genes [3, 32]. B-type lamins are considered to be expressed constitutively and independently of cellular differentiation.

The lamin expression patterns in TGCT were compared to the expression patterns in normal testis. Furthermore, by studying nuclear lamin expression in preinvasive and invasive TGCT, we have gained further insight into the relationship between the different histological components of this tumour type.

\section{Materials and Methods}

\section{Antibodies}

The following mouse monoclonal antibodies were used in this study:

- LN43 (IgG1), directed against lamin B2 and not cross-reacting with لamin B1 [6], kindly provided by Dr. E.B. Lane (Dundee, U.K.).

- X223 (IgG1), directed against lamin B2 and not cross-reacting with lamin B1 [13], kindly provided by Dr. G. Krohne (Heidelberg, Germany).

- 11905 (IgG1), directed against lamin B1 and not cross-reacting with lamin B2 [20], kindly provided by Dr. Y. Raymond (Montréal, Canada).

- 41CC4 (IgM), recognizing human lamins $\mathrm{A}$ and $\mathrm{C}$ in immunoblotting [7], kindly provided by Dr. G. Warren (Heidelberg, Germany).

- R27 (IgM), recognizing both lamins $A$ and $C$ and not reacting with human B-type lamins [40], a gift from Dr. G. Krohne (Heidelberg, Germany).

- 133 A2 (IgG3), raised against the carboxy-terminus of 98 amino acids present in lamin $A$ and absent from lamin $\mathrm{C}$. As a result this antibody recognizes lamin $\mathrm{A}$ but not lamin $\mathrm{C}$. Epitope mapping using several deletion mutants of lamin A showed that the amino acids 598-611 form the epitope recognized by $133 \mathrm{~A} 2$ [15]. The antibody was kindly provided by Dr. Y. Raymond (Montréal, Canada). 
In immunostaining and immunoblotting studies LN43, X223,41CC4 and R27 were used as undiluted culturing supernatant, while $119 \mathrm{D} 5$ (mouse ascites) was used in a $1: 750$ dilution for immunosiaining of sections and 1:250 in immunoblotting. Antibody $133 \mathrm{A2}$ (mouse ascites) was dilluted 1:1000 for rimmunostaining of sections and for immunoblotting.

The antibodies $41 \mathrm{CC} 4$ and $\mathrm{R} 27$ both recognize lamin $\mathrm{A}$ and $\mathrm{C}$ and will be referred to as lamin $A / C$ antibodies unless otherwise specified. Since the antibodies $L N 43$ and $X 223$ both recognize Jarnin $B 2$ they will be referred to ass lamin B2 antibodies unless otherwise specified. $133 \mathrm{~A} 2$ will be referred to as lamin $\mathrm{A}$ antibody and 11905 will be referred to as lamin B1 antibody.

\section{Testicular germ cell tumours}

Thirty-two orchidectomy specimens for germ cell tumour were collected and representative parts of both the tumour and the adjacent parenchyma (when available) were snap frozen in liquid nitrogen. Tumours were classified according to the World Health Organization recommendations [23] as described [30]. Sixteen cases were diagnosed as SE and another 16 as NS (seven pure and nine mixed). Six of $16 \mathrm{SE}$ contained a mutated Ras gene [28]. Four samples of normal testicular parenchyma (two cases unrelated to TGCT and two orchidectomy specimens because of prostatic carcinoma) were included in this survey, as well as 10 samples of parenchyma adjacent to SE and 12 adjacent to $\mathrm{NS}$.

\section{Immunohistochemistry}

Frozen tissue sections $(5 \mu \mathrm{m})$ were air dried at room temperature (RT) for $\mathbb{1}$ hour. Subsequently they were fixed in cold $\left(-20^{\circ} \mathrm{C}\right)$ methanol for 15 seconds followed by three dips in acetone (RT) and air dried for 5 minutes. Endogenous peroxidase activity was inactivated by incubation for 10 minutes with $0.15 \mathrm{M}$ phosphate buffered saline (PBS; containing $8 \mathrm{~g} / 1 \mathrm{NaCl}, 0.2 \mathrm{~g} / \mathrm{KCl}, 1.15$ $\mathrm{g} / \mathrm{Na} \mathrm{NaPO}_{2}$ and $0.2 \mathrm{~g} / 1 \mathrm{KH}_{2} \mathrm{PO}_{4}$ at $\mathrm{pH} 7.4$ ) containing $0.2 \%$ (w/v) bovine serum albumin (BSA; Sigma, St Louis, MO/USA) and $0.3 \% \mathrm{H}_{2} \mathrm{O}_{2}$. Then the sections were washed wice with PBS for 5 minutes and subsequently pre-absorbed for 10 minutes with PBS containing $1 \%$ BSA. The sections were washed with PBS and incubated for 1 hour with the lamin antibodies, appropriately diluted in PBS containing $1 \%$ BSA. Thereafter, the sections were washed three times for 10 minutes with PBS and incubated for 1 hour with a rabbit anti-mouse Ig antibody conjugated to peroxidase (DAKO A/S, Glostrup, Denmark) diluted 1:100 in PBS containing $1 \%$ BSA. The sections were washed three times for 10 minutes with PBS and peroxidase reactivity was visualized by incubation with $1 \mathrm{mg} / \mathrm{ml} \mathrm{3,3}$ diaminobenzidine $\mathrm{HCl}$ (DAB, Sigma) and $0.01 \% \mathrm{H}_{2} \mathrm{O}_{2}$ in $5 \mathrm{mM}$ Tris- $\mathrm{HCl}$ pH 7.7. The sections were washed with water for 5 minutes, stained with haematoxylin (haematoxylin solution, Gill no. 3, Sigma) diluted 1:20 in water for 30 seconds, washed with water for 10 minutes, dehydrated and mounted in Entellan (Merck, Darmstadt, Germany). Immunostained preparations were evaluated for lamin reactivity by two individuals experienced in the histology of TGCT. In a number of cases, data from immunostaining of tissue sections were confirmed by immunoblotting. 
Tissue sample preparation for gell electrophoresis

Ten $20 \mu \mathrm{m}$ thick frozen sections were suspended in buffer containing $10 \mathrm{mM}$ Tris- $\mathrm{HCl} \mathrm{pH} 7.4$, $10 \mathrm{mM} \mathrm{NaCl}, 1.5 \mathrm{mM} \mathrm{MgCl}$, $0.5 \mathrm{mM}$ phenylmethylsulphonyl chloride (PMSC, Merck) and $0.5 \%$ Triton $\mathrm{X}-100$ (BDH, Poole England), and stirred vigorously for 10 minutes at $0^{\circ} \mathrm{C}$. The cissue remnants were collected by centrifugation at $1500 \mathrm{x}$ at $4^{\circ} \mathrm{C}$ and the pellet was washed with buffer containing $10 \mathrm{mM}$ Tris-HCl pH 7.4, $10 \mathrm{mM} \mathrm{NaCl}, 1.5 \mathrm{mM} \mathrm{MgCl}, 0.5 \mathrm{mM}$ PMSC (Merck). Thereafter the tissue remnants were collected by centrifugation at $1500 \times \mathrm{g}$ at $4{ }^{\circ} \mathrm{C}$, resuspended in buffer containing $10 \mathrm{mM}$ Tris- $\mathrm{HCl}$ pH $7.4,10 \mathrm{mM} \mathrm{NaCl}, 1.5 \mathrm{mM} \mathrm{MgCl} 2,0.5$ $\mathrm{mM}$ PMSC (Merck), $1 \mathrm{mg} / \mathrm{ml}$ DNase 1 (Sigma) and $50 \mu \mathrm{g} / \mathrm{ml}$ RNase A (Sigma), and incubated for 20 minutes at RT. Then the pellet was washed with $10 \mathrm{mM}$ Tris- $\mathrm{HCl} \mathrm{pH} 7.4,10 \mathrm{mM} \mathrm{NaCl}$, $1.5 \mathrm{mM} \mathrm{MgCl} 2,0.5 \mathrm{mM}$ PMSC (Merck). After centrifugation and discarding of the buffer the tissue pellet was resuspended in approximately 1 volume of SDS-sample buffer and boiled for 5 minutes.

For two-dimensional gel electrophoresis Triton X-100 extracted NCl-H125 cell pellets were used, prepared as described before [20].

\section{Gel electrophoresis and immunoblotting}

One-dimensional SDS-gel electrophoresis in 10\% polyacrylamide (Bio-Rad Laboratories, Hercules, California) slab gels containing $0.1 \%$ SDS (Merck), was performed according to Laemmli [18]. Gels were run on the Mini-Protean II system (Bio-Rad Laboratories) for approximately 45 minutes at $200 \mathrm{~V}$. Two-dimensional electrophoresis gels were run essentially as described by O'Farrel [27], with minor modifications as described by Machiels et al. [20].

Western blotting was performed essentially according to Towbin et al. [39] using the Mini Trans-Blot Cell (Bio-Rad Laboratories) at $100 \mathrm{~V}$ for 1 hour. Proteins were blotted onto nitrocellulose (BA85, Schleicher and Schüll, Dassel, Germany), the sheets were air-dried and blocked for 1 hour at RT in buffer containing $10 \mathrm{mM}$ Tris- $H \mathrm{HCl}$ pH 7.6, $0.35 \mathrm{M} \mathrm{NaCl}$ and $3 \%$ BSA (Sigma). Thereafter the blots were incubated with the primary antibodies for $30-60$ minutes at RT in appropriate dilutions in buffer containing $10 \mathrm{mM}$ TRIS-HCl pH 7,6, 0.15 M NaCl, $0.3 \%$ BSA, $1 \%$ Triton X-100 (BDH), 0.5\% DOC (Merck) and 0.1\% SDS (Merck). Then the blots were washed three times with PBS containing $0.5 \%$ Triton X-100 (BDH), and incubated for 30-60 minutes at RT with the secondary peroxidase conjugated rabbit anti-mouse $\mathrm{Ig}$ antibody (DAKO A/S), diluted 1:1000 in PBS containing 0.5\% Triton X-100 (BDH) and 0.5\% BSA (Sigma). Then the blots were extensively washed with PBS containing $0.5 \%$ Triton X-100 $(\mathrm{BDH})$ and peroxidase activity was detected by chemiluminescence (ECL-kit. Amersham, Buckinghamshire, UK). RX Fuji medical X ray films (Fuji, Tokyo, Japan) were used for the: visualisation of the luminescent signals. 


\section{Results}

\section{Antibody specificity}

Two-dimensional immunoblotting studies were performed to examine cross-reactivity of the lamin antibodies. The results of these assays on Triton X-100 extracted cell pellets of NCI-H125 cells are shown in figure 1 . The arrays of spots with identical molecular weights are the distinct phosphorylation isoforms of the individual lamins. From these experiments, it was obvious that the lamin antibodies used in this study exhibited the reported specificity for lamin subtypes (see Materials and Methods). Strikingly, antibody $4 J \mathrm{CC} 4$ shows a relatively stronger reactivity with lamin C than with lamin A.

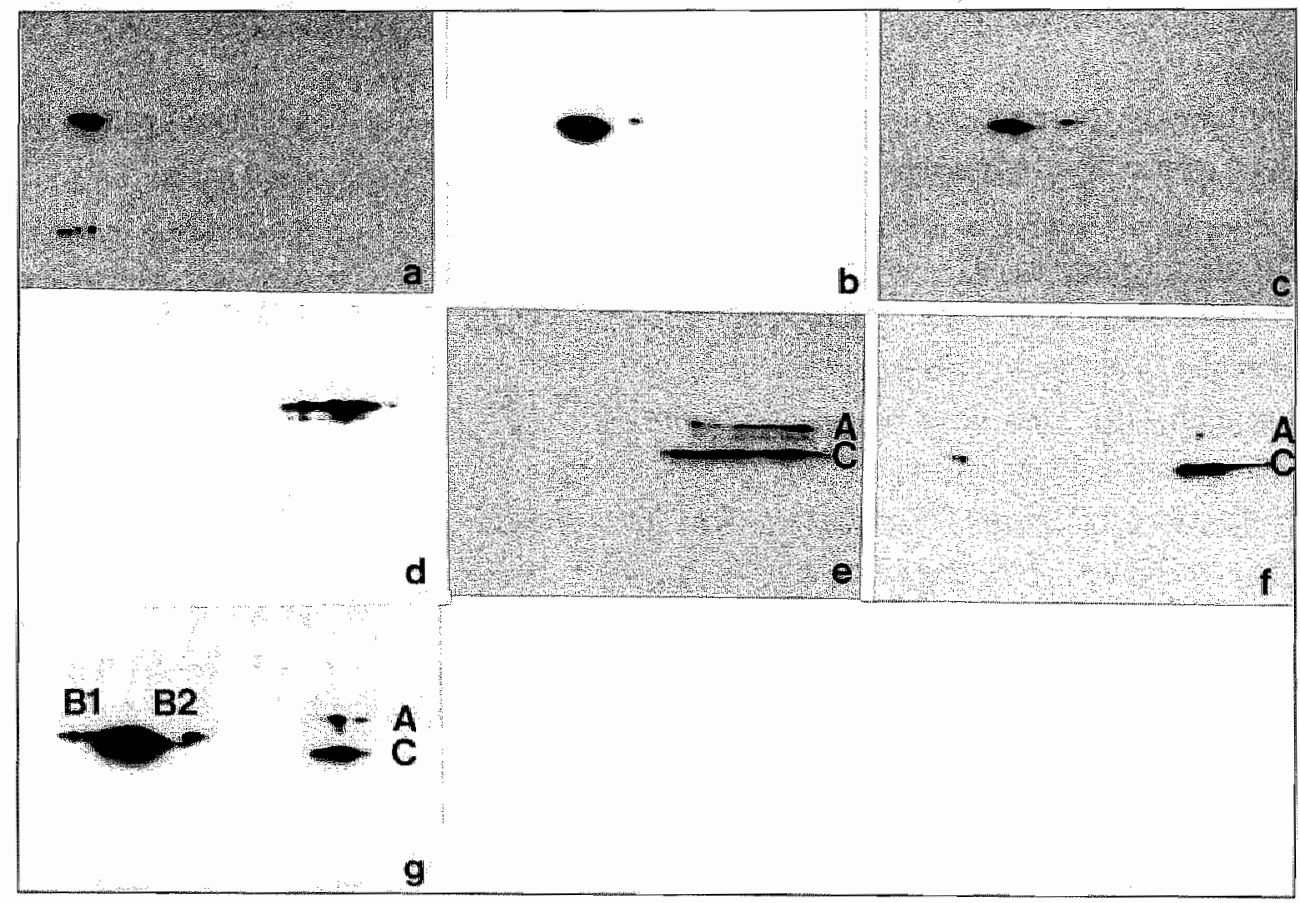

Figure 1. Two-dimensional immunoblot analysis confirmed the specificity of the lamin antibodies used in this study. "Triton X-100 extracted cell pellets of NCI-H125 cells were used for two-dimensional gel electrophoresis and bilotted. The blots were incubated with (a) lamin B1 antibody 11905 , (b) lamin B2 antibody $\mathbb{L}$ N43, (c) lamin B2 antibody $X 223$, (d) lamin $A$ antibody $133 \mathrm{~A} 2$, (e) lamin $A / C$ antibody $R 27$, (D) lamin $A / C$ antibady $41 C C 4$ and $(\mathrm{g})$ a mixture of the antibodies to latmin $B 1$ (119D5), Jamin B2 (LN43), lamin A (133A2) and lamin A and C (41CC4).

\section{Normal testis}

A summary of the results of lamin immunostaining reactions in tissue sections of normal testis and testicular parenchyma adjacent to TGCT is shown in table $I$ and depicted in figure $2 \mathrm{a}-\mathrm{c}$. Sertoli, Leydig and peritubular cells, all express both A- and B-type lamins. However, it should 
be noted that Sertoli and Leydig cells expressed lamin B2 (Fig. 2b), but showed in general no reaction with the lamin Bl antibody (Fig. 2a). Spermatogonia were mostly positive for lamins $\mathrm{B} 1$ and $\mathrm{B} 2$, but no A-type lamins were detected in these cells (Fig. 2c), despite their highly specialized commitment to differentiate into spermatocytes. In contrast; spermatocytes showed no reactivity at all with the B-type lamin antibodies. In some cases, a reactivity with the A-type lamin antibodies was seen, but this reaction was weak and only detectable in a part of the spermatocyte population.

Table I Results of immunostaining reactions with lamin antibodies in normal testis and parenchyma adjacent to TGCT

(positive cases / total number of cases tested)

\begin{tabular}{|c|c|c|c|c|c|c|}
\hline & $\operatorname{lamin}_{133 \mathrm{~A} 2} \mathrm{~A}$ & $\begin{array}{l}\operatorname{lamin} A / C \\
\text { R27 }\end{array}$ & $\begin{array}{l}\operatorname{lamin} A / C \\
41 C C 4\end{array}$ & $\begin{array}{l}\operatorname{lamin} B 1 \\
11905\end{array}$ & $\operatorname{lamin}_{\mathrm{L} N 43} \mathrm{~B} 2$ & $\underset{X 223}{\operatorname{lamin} B 2}$ \\
\hline Sertoli cells & $4 / 4$ & $4 / 4$ & $4 / 4$ & $0 / 4$ & $4 / 4$ & $4 / 4$ \\
\hline Leydig cells & $4 / 4$ & $4 / 4$ & $4 / 4$ & $0 / 4$ & $4 / 4$ & $4 / 4$ \\
\hline Peritubular cells & $4 / 4$ & $4 / 4$ & $4 / 4$ & $4 / 4$ & $4 / 4$ & $4 / 4$ \\
\hline Spermatogonia & $0 / 4$ & $0 / 4$ & $0 / 4$ & $4 / 4$ & $4 / 4 W$ & $4 / 4 W$ \\
\hline Spermatocytes & $4 / 4 W$ & $4 / 4 W$ & $0 / 4$ & $0 / 4$ & $0 / 4$ & $0 / 4$ \\
\hline \multicolumn{7}{|l|}{ Adjacent to SE } \\
\hline Sertoli cells & $4 / 4$ & $6 / 6$ & $5 / 5$ & $0 / 8$ & $9 / 10$ & $9 / 10$ \\
\hline Leydig cells & $4 / 4$ & $6 / 6$ & $6 / 6$ & $0 / 8$ & $10 / 10$ & $9 / 10$ \\
\hline Peritubular cells & $4 / 4$ & $6 / 6$ & $6 / 6$ & $6 / 8$ & $10 / 10$ & $10 / 10$ \\
\hline Spermatogonia & $0 / 4$ & $0 / 6$ & $0 / 6$ & $8 / 8$ & $8 / 10$ & $7 / 10$ \\
\hline Spermatocytes & $1 / 4 * *$ & $2 / 6 * *$ & $0 / 6$ & $0 / 8$ & $0 / 10$ & $0 / 10$ \\
\hline \multicolumn{7}{|l|}{ Adjacent to NS } \\
\hline Sertoli cells & $5 / 6$ & $8 / 8$ & $8 / 8$ & $4 / 10$ & $12 / 12$ & $1 \| / 11$ \\
\hline Leydig cellls & $6 / 6$ & $8 / 8$ & 818 & $2 / 10$ & $12 / 12$ & $11 / 11$ \\
\hline Peritubular cells & $6 / 6$ & $8 / 8$ & $8 / 8$ & $8 / 10$ & $12 / 12$ & $11 / 11$ \\
\hline Spermatogonia & $0 / 6$ & $1 / 8$ & $1 / 8$ & $6 / 10$ & $11 / 12$ & $6 / 11$ \\
\hline Spermatocytes & $1 / 6 *$ & 1.18 & $1 / 8 *$ & $0 / 10$ & $1 / 12$ & $0 / 11$ \\
\hline
\end{tabular}

s One case was partially posidive for all A-type llamin antibodies

* Two cases were partially positive with antibody $\mathrm{R} 27$, and one of those was also positive with arilibody $133 \mathrm{~A} 2$

W: Weak positive reaction in a fraction of the cells 


\section{Testicular germ cell tumours}

The resultu of the immunohistochemical staining reactions of the different subtypes of TGCT are summarized in table II and depicted in figure $2 \mathrm{~d}-\mathrm{h}$. It was obvious that all tested TGCT gave perinuclear staining with the B-type lamin antibodies for both the B1 and B2 subtypes (illustrated for SE in Fig. $2 \mathrm{~d}$ ).

A-type lamin expression patterns were heterogeneous. The SE used in this study could be divided into wo groups, a group of 6 selected SE that contained a mutation in $\mathrm{K}$ - or N-Ras (Rast, see reference [28]), and a group of 10 SE without any detectable mutation in the Ras genes (Ras-). The overall incidence of Ras matations in TGCT is low, therefore the presence of six SE with such a mutation in our series of 16 does not reflect the actual incidence (being approximately $15 \%$, see reference [28]). The difference in the staining pattern of antibody $41 \mathrm{CC} 4$ when comparing Rast and Ras-SE cases was striking: the Ras- SE were negative and the Ras+ SE were positive, although sometimes weakly. Interestingly, one case was known to contain a heterogeneous population of tumour cells with and without Ras mutation [28]. This tumour also showed a heterogeneous staining pattern with antibody 41CC4 (not shown). Most $\mathrm{SE}$ were negative with the lamin $\mathrm{A} / \mathrm{C}$ antibody $\mathrm{R} 27$, with only one Ras+ SE case being positive, while the lamin A antibody $133 \mathrm{~A} 2$ showed partial reactivity with only two Ras+ SE. None of the Ras- SE gave a staining reaction with the A-type lamin antibodies (Fig. 2e).

Most NS-components were positive with lamin A/C antibodies R27 and $41 \mathrm{CC} 4$. Strikingly, EC was found to be negative for lamin A using antibody $133 \mathrm{~A} 2$, but positive for lamin $\mathrm{A} / \mathrm{C}$ using antibody R27 and 41CC4 (Fig. 2f,g). A low expression of lamin A together with a normal or high expression of lamin $C$ may explain this reactivity pattern. Normally lamins $A$ and $C$ are expressed to comparable degrees, although an imbalance in the expression ratio of lamin $\mathrm{A}$ over $C$ may occur, and has already been reported for a lung adenocarcinoma cell line [20]. To examine this phenomenon further, samples of three EC were used for immunobloting. When these blots were stained with the lamin $\mathrm{A} / \mathrm{C}$ antibodies, two bands were detected for lamin $\mathrm{C}$ and a single band was found for lamin A (Fig. 3). It was obvious that the reactivity level of the lamin $C$ bands was much stronger than that of lamin $A$, which confirmed the immunohistachemical obsenvations. The presence of lamin $A$ in the blots was confirmed by reactivity with the lamin $A$ antibody $133 \mathrm{A2}$ (Fig. 3). Lamin A reactivity on blots of EC samples may be overrepresented as a result of non-EC components that are present in the tumour tissue, such as small blood vessels, and that do express A-type lamins. The very low expression level of lamin $A$ and the imbalanced expression of lamin $A$ and lamin $C$ may account for our interpretation that the sections of $E C$ are negative for Iamin $\mathrm{A}$.

YS, CH and TE could not be distinguished by A-type lamin expression. These three histologically distinct tumour types gave perinuclear staining with the lamin A antibody as well as the lamin $A / C$ antibodies (illustrated for TE in Fig $2 \mathrm{~h}$ ). 

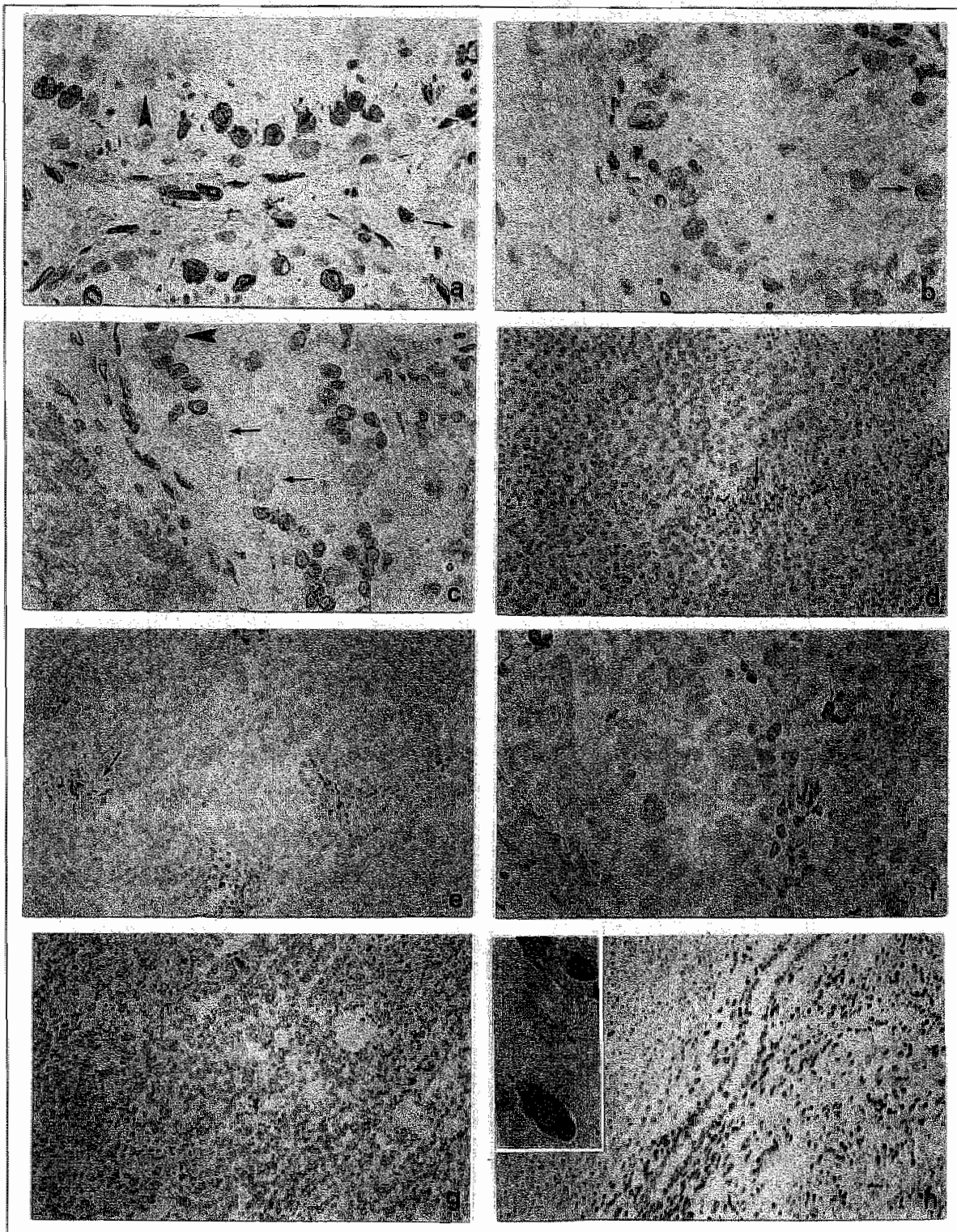

Figure 2. Representative illustrations of immunostainings of parenchyma adjacent to testicular germ cell tumours $(\mathrm{a}-\mathrm{c})$ and testicular germ cell tumours $(\mathrm{d}-\mathrm{h})$. (a) Testicular parenchyma adjacent to testicular germ cell tumours containing carcinoma in situ, stained with lamin BI antibody 119D5; Sertoli (arrow/head) and Leydig (arrow) cells are negative for lamin B.1. (b) Testicular parenchyma adjacent to embryonal carcinoma containing carcinoma in situ, staned with lamin B2 antibody X223; Sertoli cells (arrows) are positive for lamin B2. (c) Testicular parenchyma adjacent to a testicular germ cell tumour containing carcinoma in situ, stained with lamin $A / C$ antibody R27, spematogonia (arrowhead) and carcinoma in situ (arrows) are negative for A-lype lamins. (d) Ras- seminoma stained with lamin B2 antibody X223; both normal (lymphocytes, arrow) and tumour cells are positive for lamin B2. (e) Ras- seminoma stained with lamin $A C$ antibody $R 27$; tumbur cells are negative for lamin $A$ and $C$, whille focal spots of normal tissue (lymphocytes, arrow) are positive for lamin A and C. (f) Embryonal carcinoma stained with lamin A anibody $133 \mathrm{~A} 2$; tumour cells are negative for Hamin A. (g) Embryonal carcinoma stained with lamin A/C antibodly R27; both tumour cells and normal tissues are positive. (h) Teratoma stained with lamin A/C antibody $\mathbb{R} 27$; the inset shows a higher magnification of the teratoma illustrating the lamina staining. For colour illustration see page 131 . 
Table II Results of immunostaining reactions of TGCTs with lamin antibodies (positive cases / total number of cases lested)

\begin{tabular}{|c|c|c|c|c|c|c|}
\hline & $\begin{array}{l}133 \mathrm{Am} A \\
133\end{array}$ & $\begin{array}{l}\operatorname{lamin} A / C \\
R 27\end{array}$ & $\begin{array}{l}\operatorname{lamin} A / C \\
41 C C 4\end{array}$ & $\begin{array}{l}\operatorname{lamin} B I \\
1905\end{array}$ & $\operatorname{lamin}_{L N 4} B 2$ & $\operatorname{lamin}_{\times 223} B 2$ \\
\hline$\overline{S E}$ & $2 / 16 *$ & $1116 *$ & $6 \sqrt{16}$ & $16 / 16$ & $14 / 15$ & 1616 \\
\hline$E C$ & $0 / 7$ & $9 / 10$ & $8 / 10$ & 77 & $10 / 10$ & $10 / 10$ \\
\hline YS & $5 / 5$ & $5 / 5$ & $6 / 6$ & $5 / 5$ & $6 / 6$ & $6 / 6$ \\
\hline $\mathrm{CH}$ & $5 / 5$ & $5 / 5$ & $4 / 5$ & $5 / 5$ & 515 & $5 / 5$ \\
\hline $\mathrm{TE}$ & $4 / 4$ & $4 / 5$ & $4 / 4$ & $4 / 4$ & $5 / 5$ & $6 / 6$ \\
\hline $\mathrm{CIS}(\mathrm{SE})$ & $0 / 4$ & $0 / 6$ & $2 / 6 *$ & $8 / 8$ & $7 / 10$ & 619 \\
\hline CIs (NS) & $10 / 5$ & $0 / 8$ & $0 / 7$ & $6 / 9$ & $11 / 1 \mathbb{1}$ & $8 / 9$ \\
\hline
\end{tabular}

* Positive cells were detected only in SE containing a Ras mutation and its adjacent CIS

SE: seminoma; EC: embryonal carcinoma; YS: yolk sac turnour; CH: choriocarcinoma; TE: teratoma; CIS (SE): carcinoma in situ adjacent to seminoma: CIS (NS): carcinoma in situ adjacent to nonseminoma.

Table IIr Lamin B1 expression in Sertoli cells, spermatogonia and CIS adjacent to NS

\begin{tabular}{l|ccc} 
Adjacent to NS & Sertoli & Spermatogonia & CIS \\
\hline 4 cases & + & - & - \\
5 cases & - & + & + \\
nommal testis & - & + &
\end{tabular}

- all cells rogetive

$+\quad$ atl colls posinve

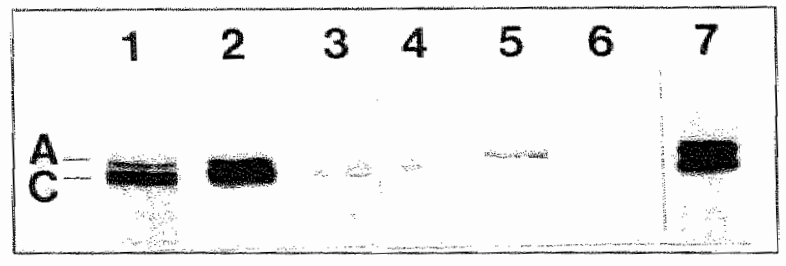

Figure 3. Inmmunobloting results of three EC samples. The blots were incubated with Jamin $A / C$ antibody R27 (latyes 1,2,3) and lamin $A$ anuibody 133A2 (lanes 4,5,6). Note the low expression level of lamin $A$ compared to lamin $C$ in $\mathrm{EC}$. For comparison, the lamin A over Jamin $C$ expression ratio in cell line NCI-H125 is shown (lane 7). 


\section{Carcinoma in situ}

Lamin expression in carcinoma in situ (CIS), the precursor of all TGCT [36], resembled in general that of SE (table II). Although in most of the cases both B-type lamins were seen, CIS adjacent to SE may lack lamin B2 and CIS adjacent 10 NS may lack lamin B1. Furthermore the A-type lamins were absent, except in two cases of CIS adjacent to Ras+ SE, which were partially positive with antibody $41 \mathrm{CC} 4$.

Comparison of B-type lamin expression patterns in CIS with those in spermatogonia at the llexel of individual cases resulted in some remarkable observations. The B-type lamin expression in CIS resembled that in spermatogonia. When CIS adjacent to SE was positive with a lamin B2 antibody, spermatogonia were also positive (with one exception); when CIS was found to be negative with a lamin B2 antibody, the spermatogonia were negative as well. Spermatogonia in normal testis were only partially and weakly positive for lamin $\mathrm{B} 2$, while in parenchyma adjacent to SE all spermatogonia were clearly positive. Lamin B2 expression in spermatogonia adjacent to SE seems therefore slightly increased. When CIS adjacent to NS (table III) was negative for lamin B 1, spermatogonia were also negative; when CIS was positive for lamin B1, spermatogonia were also positive. In addition, the reaction of the Sertoli cells in these sections was always opposite to that of spermatogonia and CIS. In normal testis Sertoli cells were negative and spematogonia were positive for lamin B1, being the physiological expression pattern. In four cases of parenchyma adjacent to $\mathrm{NS}$, completely inverse reaction patterns were found in Sertoli cells, spermatogonia and CIS. Furthermore, it was remarkable that such inverse lamin expression patterns were detected in parenchyma adjacent to NS with a large component of $\mathrm{EC}$ or pure $\mathrm{EC}$.

\section{Discussion}

\section{Normal testis}

B-type lamins have been found to be expressed almost ubiquitously in all somatic cell types, regardless of their degree of differentiation or proliferative activity. However, differential expression patterns of lamins B1 and B2 have been described occasionally, with lamin B1 not being expressed, in general, in differentiated cells which lack proliferative activity. For instance, heart muscle cells, which are fully differentiated and non-proliferative cells, were negative for lamin B 1 and positive for lamin B2 [2], while centroblasts, which are proliferating cells in the follicle centre of reactive lymph nodes, were positive for lamin $\mathrm{B} 1$ and negative for lamin $\mathrm{B} 2$ (unpublished results). Absence of lamin B1 in Sertoli and Leydig cells, which are fully differentiated cells, is in concordance with the previously reported differential expression of $B$ type lamins.

Although A-type lamin expression is restricted to differentiated cells, no A-type lamins were detected in spermatogonia, despite their highly specialized commitment to differentiate into spermatocytes. Furthermore, spermatocytes were found to be negative for B-type larnins and 
only weakly positive for A-type lamins. Apparently, the spermatogonia loose their B-type lamin expression in the process of differentiation towards spermatocytes. A simillar phenomenon has been found in rats, in which the somatic B-type lamins disappear during differentiation of spermatogonia into spermatocytes [21]. At the same time, a germ cell specific B-type lamin becomes expressed in these cells. Also in mice two distinct germ cell specific lamins have been identified, lamin B3 [12] and lamin C2 [11]. So far such a germ cell specific lamin protein has not been identified in humans, but its existence is likely. The weak reactivity of the A-type lamin antibodies in spermatocytes may on the one hand be due to a low A-type lamin expression in these cells, but might on the othel hand be due to cross-reactivity of the antibodies with an as yet unidentified human counterpart of the germ cell specific lamins identified in other species.

\section{Testicular germ cell minours}

Ras-induced changes in A-type lamin expression have been described before in a human lung cancer cell line by Kaufmann et al. [17]. Elevated levels of Ras expression resulted in elevated levels of A-type lamins. The possibility of a Ras-responsive element in the promotor region of the lamin $\mathrm{A} / \mathrm{C}$ gene was proposed. The results with $\mathrm{Ras}+\mathrm{SE}$, in which the Ras gene is constinutively activated [28] and A-type lamins were detected with antibody $41 \mathrm{CC} 4$, are in concordance herewith.

Based on the lamin expression patterns in TGCT, it became apparent that NS, in particular YS, $\mathrm{CH}$ and TE, should be considered as the most differentiated of the spectrum, and SE as the least differentiated TGCT type. These results are in favour of the "linear progression model" as originally proposed by Ewing [8]), and further developed by others [9, 25, 29, 30, 33]. In this model, EC is an intermediate between SE and NS. When this model is translated to lamin expression in TGCT, this would imply that expression of only lamin $\mathrm{C}$, as seen in $\mathrm{EC}$, is an intermediate state between absence of A-type lamins in undifferentiated SE and expression of lamins $A$ and $C$ in differentiated TGCT. This would mean that during the process of differentiation, expression of lamins $A$ and $C$ is not started simulaneously, but that expression of only lamin $C$ preceeds expression of both A-type lamins, In a slightly distinct approach, SE may be considered a TGCT that follows a differentiation pathway along the spermatogenic lineage; their lamin expression pattern therefore resembles that of spermatogonia. In contrast, NS follow an embryonal or extra-embryonal differentiation, in which CIS is the most undifferentiated component, EC ar intermediate component expressing lamin C but not lamin $\mathrm{A}$, and YS, CH and TE fully differentiated components expressing lamins $A$ and $C$. Identification of human gern cell specific lamins and immunostaining of TGCT sections with antibodies to such lamins may give insight into this aspect of differentiation.

Regarding A-type lamin expression in SE, it should be kept in mind that the number of Ras+ SE in this study is much higher than the the actual incidence. Although Ras+ SE show reactivity with one of the A-type lamin antibodies and may therefore be considered as being more differentiated than Ras-SE, the transition from CIS to NS apparently does not occur via Rast 
SE as an intermediate, since the Ras+ NS incidence is much lower than the Ras+ SE incidence [28].

In TGCT, apparenty, expression of A-type lamins is dependent on the degree of differentiation, illustrated by the presence of lamin $A$ and lamin $C$ in the differentiated NS components, and the lack of one or both A-type lamins in $\mathrm{EC}$ and $\mathrm{SE}$, respectively. A correlation with proliferative activity is less obvious, since a similar expression was found in YS, CH and TE, while differences in proliferative activities have been found (unpublished observations).

Since lamin A detection in NS discriminates between EC on the one hand and $\mathrm{YS}, \mathrm{CH}$ and TE on the other hand, this may provide a usefull parameter of clinical relevance, since the percentage of EC cells together with the degree of vascular invasion have been described as a prognostic factor $[10,24,35]$.

\section{Carcinoma in situ}

The absence of A-type lamins in CIS can be explained by the highly proliferative character of these cells. Furthermore, in spite of the fact that CIS resembles early (primordial) germ cells [16], lamin expression in CIS was similar to lamin expression in more differentiated germ cells, i.e. spermatogonia. This indicates that early germ cells probably show a lamin expression pattern that is identical to that of the more differentiated spermatogonia.

The findings shown in table III, support a close interaction between normal cells, malignant germ cells and their nursing cells within the testis [14, 37], It has been claimed that the extracellular matrix plays an important role in the communication between cells, possibly resulting in differences in expression of nuclear lamins [4]. Whether certain factors of EC play a role in this phenomenon in the testis remains to be established.

In conclusion, lamin expression in CIS resembles, on the one hand, lamin expression in spermatogonia and on the other hand, lamin expression in SE, indicating a close relationship between these three cell types, which is confurmed by their morphological similarity. These cell types may follow a differentiation pathway along the spermatogenic lineage, and therefore dlo not express A-type lamins, but they might express an as yet unidentified germ cell specific lamin. In contrast, NS follow an embryonal or extra-embryonal differentiation pathway, resulting in A-type lamin expression in these cells. EC, the most undifferentiated NS component, expressed only lamin C and not lamin A. From a cell biological point of wiew, this would mean that lamin $C$ is expressed earlier in the process of differentiation than lamin $A$. From a clinical point of view, lamin immunostaining of NS sections may be used to identify clearly the EC component in NS, which may aid in the use of the percentage of EC in NS as a prognostic marker. 


\section{Acknowledgements}

The authors thank Dr. E.B. Lane, Dr. G. Krohne, Dr. Y. Raymond and Dr. G. Warren for providing the lamin antibodies used in this study. Dr. J.L.V. Broers is acknowledged for his helpful advice on the irimunostaining procedures.

\section{References}

(1) Andrews, P.W: Human teratocarcinoma. Biochem. Biophys. Acta 948, 17-36 (1988).

[2] Ausma, J, G.J.J.M. van Eys, J.L.V. Broers, F. Thone, W. Flameng, F.C. S. Ramaekers, M. Borgers: Nuclear lanin expression in chronic hibernating myocardium in man. J. Mol. Cell. Cardiol, 28, 1297-1305 (1996),

(3) Biamonti, G. M. Giacca, G. Perini, G. Contreas, L. Zentilin, F. Weighardi, M. Guerra, G. Della Valle, S. Saccone, S. Riva, A. Falasch: The gene for a novel human lamin maps at a thighly transcribed locus of chromosine 19 which replicates at the onset of S-phase. Mol. Cell. Biol 12, 3499-3506 (1992).

[4] Boudrenu, N. C. Myers, M.J. Bissell: From laminin to lamin: regulation of tissue-specilic gene expression by the ECM. Trends in Cell Biol. 5, 1-4 (1995).

[5] Boyle, P., D.G. Zaridze: Risk factors for prostate cancer and testicular cancer. Eur. I. Cancer 29A, 1048$1055(1993)$,

[6] Bridger, I.M.4 I. Kill "M. O'Farrell, C.J. Hutchison: Internal lamin structure within G1 nucle of human dermal fibroblasts. J. Cell Sci. 104, 297-306 (1993).

[7] Burke, B., G. Tooze, G. Warren: A monoclonal antibody which recognises each of the nuclear lamin polypeptides in mammalian cells. EMBO J. 2, 361-367 (1983).

[8] Ewing, J. "lleratoma testis and its derivates. Surg. Gynecol. Obstet. 12, 230(1911).

[9] Friedman, N.B.: The comparative morphogenesis of extragenital and gonadal teratoid tumors. Cancer 4 , 265-276 (1951).

[10] Fung, C.X., L.A. Kalish, G.L. Brodsky, J.P. Rilchie, M.B. Garnick: Stage I nonseminomatous germ call testicular tumor: prediction of metastatic potential by primary histopathology. J. Clin. Oncol. 6, 1467-1473 (1988).

[11] Furakawa, K., H. Inagaka, Y. Hotta: Identification and cloning of an WRNA coding for a germ coll-specific A-type lamin in mice. Exp. Cell Res. 212,426,430 (1994).

[12] Furukawa, K., Y. Hota: cDNA cloning of a gern celli specific lamin B3 from mouse spernatocytes and analysis of its fuction by cotopic expression in somatic cells. EMBO J. 12,97-106 (1993).

[13] Höger, TH., K. Zatloukal, I. Waizenegger, G. Krohne: Characterization of a second highly conserved $\mathbb{B}$ lype lamin present in cells previously thought to contain only a single B-type lamin. Chromosoma 99, 379. $390(1990)$.

[14] Holsteîn, A.F: Cellular components of early testicular cancer. Eur. Urol. 23, 9.18(1993).

[15] Hortk, P. M.J. Sasseville. Y. Raymond, P.R. Cook: Lamin proteins form an internal nucleoskelelon as well as a peripheral lamina inu human cells. J. Cell Sci. 108, 635-644 (1995).

[16] Jongensen. N., E. Raypert-de Meyts, N. Graem, Ni. Miller, A. Giwercman, N.E. Skakkebak: Expression of immunothistochemical matkers for testicular carcinoma in situ by normal human fetal germ cells. Lab. Invest. $72,223-231(1995)$

117) Kaufmann, S.H. M. Mabry, R. Jast, J.H. Shaper: Difterental expression of muclear enwelope lamins A and C in human lang cancer cell lines. Cancer Res. 51, 581-586 (1991).

[18] Laemmli, U.K. Cloavage of structural proteins during the assembly of the head of bacteriophage T4. Nature 227, 680-685 (1970).

[19] Lib, F., H.J. Worman: Structura organization of the human gene encoding nuclear lamin-A and nuclear Hmin -C. J. Biol. Chem, 268, 1632/-16326(1993).

[20] Machicts, B.M., J.L.V. Broers, Y. Raymond, L. de Ley, H.J.H. Küjpers, N.E.H. Caberg, F.C.S. Ramaekers: Abnormal A-type lamin organization in a human lung carcinoma cell line. Eur. J. Cell Biol. 67, 328-335 $(1995)$

[21] Manjulla, K., A. Karande, M.R.S. Rao: Behawiour of the germ cell specific lamin through mamalian spermatogenesis as probed with monoclonal antibodies. Cell Struct. Function 19, 207-218 (1994).

[22] Moir, R.D., R.D. Goldman: Lamin dynamics. Curr Opin. Cell Biol 5, 408-411 (1993).

[23] Mostofi, F.K., I.A. Sesterhenn, C.J.J. Davis: Immunopathology of germ cell tumors of the testis. Sem. Diagn. Pathol. 4, 320-341 (1987). 
[24] Mou, J.W, J.P. Foley, C.L. Hilchoock, W.F. MoCathy, I.A. Sesterheme, R.L. Berker, J.L. Griftin: Fiow cylometric and quantitatuve histological parameters 10 predict ocuth disease in chineral sqae 1

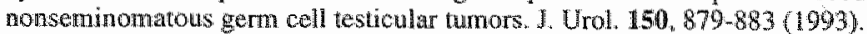

[25] Mulder, M.P. W. Keijzer, A. Verkerk, A.M. Boot, M.E.F. Prins, T.A.W. Splinter. J.L. Bos: Activated ras genes in human seminoma: Evidence for tumor heterogeneity. Oncogen 4, 1345-1351 (1989)

[26] Nigg, E.A.: Assembly-disassembly of the nuclear Iamina. Cur. Biol. 4, 105-109 (1992).

[27] OFarrell, P.H.: High resolution two dimensional electrophoresis of proteins, J. Biol Chem. 230, $4007-4021$ (1975).

[28] Olie, R.A. L.HJ, Loojjenga, L. Boerrigter, B. Top, S. Rodenthuis, A. Langeveld, M.P. Mulder, J.W. Oosterhuis: $\mathrm{N}$ - and K-Ras mutations in human festicular germ cell tumors: incidence and possible biological implications. Genes Chromosom. Cancer 12,110-116 (1995).

[29] Oliver, R.T.D.: HLA phenotype and clinicopathological behaviour of germ cell tumours: possible evidence for clonal evolution from seminomas to nonseminomas. Int J. Androl. 10, 85-93 (1987).

[30] Oosterhuis, J.W., S.M.M.J. Castedo, B. De Jong, C.J. Comelisse, A. Dam, D.T. Ste jler, H. Sehrahtordt Koops: Ploidy of primary germ cell tumors of the testis. Pathogeneric and clinical relewance. Lab. Invest. 60 , 14-21 (1989).

[31] Oosterhuis, J.W., L.H.J. Loojenga: The biology of human germ cell tumours: retrospective speculations and new prospectives. Eur, Urol. 23, 245-250 (1993).

[32] Pollard, K.M., E.K.L. Chan, B.J. Grant, K.F. Sullivan, E.M. Ta, C.A. Glass: In witro postranslational modification of lamin B cloned from a human T-cell line. Mol. Cell. Biol. 10, $2164-2175$ (1990).

[33] Raghavan, D., N.J. Vogellang, G.J. Bosl: Tumor chassification and size in gemn-cell lesticular cancer. Influence and occurence of metastases. Cancer 50, 1591-1595 (1982).

[34] Schafsma, H.E., F.C.S. Ramaekers: Cytokeratin subtyping in normal and acoplastic epithelium: Basic principles and diagnostic applications. In: Rosen, P.P. Fechner, R.E. ed. Pathology annual: 1994. Nonwalk: Appleton \& Lange, 1994: 21-62. vol 29

[35] Sesterhenn, I.A., R.B. Weiss, F.K. Mostofi, D.M. Stablein, R.G. Rowland, G. Falkson, S.E. Rivkind, N.J. Vogelzang: Prognosis and other clinical correlates of pathologic review in stage I and II vesticullar carcinoma: a report from the Testicular Cancer Intergroup Study. J. Clin. Oncol. 10, 69n78 (1992).

[36] Skakkebak, N.E., J,G. Berthelsen, A. Giwercman, J. Müller: Carcinoma-in-situ of the testis: posstble origin from gonocytes and precursor of all types of germ cell tumours except spenatocytona. Int. J. Androl. I0, $19-28(1987)$.

[37] Skinner, M.: Cell-cell interactions in the testis. Endocrine Reviews 12, 45-77 (1991)

[38] Swerdlow, A.I.: The epidemiology of testicular cancer. Eun. Urol. 23 (suppl2), 35-38 (1993).

[39] Towbin, H., T. Staehelin, J. Gordon: Electrophoretic transfer of proteins from polyecrylamide gels to nitrocellulose sheets: procedure and some applications Proc. Natl. Acad. Sci. USA 76, 4350-4354 (1979).

[40] Zatloukal, K., H. Denk, G. Spurej, H. Hituter: Modalation of protein composition of nuclear lamina reduction of lamins-BI and lamins-B2 in livers of griseofulvin-treated mice. Lab. Invest. 66, $589-597$ (1992). 


\section{Chapter 4}

Comparison of A- and B-type lamin expression in nodular sclerosing Hodgkin's disease and reactive lymph nodes

Maurice P.H.M. Jansen, Barbie M. Machiels, Anton H.N. Hopman, Jos L. V. Broers, Fredrik J.

Bot, Jan Willem Arends, Frans C.S. Ramaekers, and Harry C. Schouten

Histopathology (1997), in press. 


\section{Summary}

Lamins are a family of nuclear membrane-associated intermediate filament proteins, of which the A-type lamins are preferentially expressed in differentiated cells. The B-type lamins B 1 and B2 have long been considered to be constitutiwely expressed, but only recently we have come across several examples of a differential expression of these two latter lamin subtypes, with lamin $B 1$ being related to proliferation.

In order to clarify the differentiation and proliferation status of the Reed-Sternberg and Hodgkin cells we studied $A$ - and B-type lamin expression with specific monoclonal antibodies in Hodgkin's disease. Its normal counterpart, the reactive lymph node, was also examined for lamin subtype expression.

The CD20 positive centrocytes and centroblasts of the follicle centre in the reactive lymph nodes expressed lamin B1, but were not or only very weakly positive for lamin B2 or A-type lamin antibodies. Mantle zone lymphocytes displayed lamins $\mathrm{B} 1$ and $\mathrm{B} 2$, but were negative for A-type lamins. Furthermore, CD3- and CD20-positive lymphocytes in the medulla and paracortex lacked A-type lamins, but were positive for both B-type lamins. Finally, the proliferation marker $\mathrm{Ki}-67$ was mainly detected in the centroblasts, but also in a fraction of the A-type lamin negative cells in the paracortex and medulla.

In Hodgkin's disease, all cells expressed lamins B $\mathbb{l}$ and B2, whereas a small subpopulation of cells had A-type lamins. CD30-positive Reed-Sternberg and Hodgkin cells were primarily positive for A-type lamins and about $20 \%$ of the Reed-Sternberg and Hodgkin cells expressed $\mathrm{Ki}-67$, with co-expression of lamin $\mathrm{A}$ in most of these cells.

All in all, Ki-67 and A-type lamin positivity in general were mutually exclusive in lymph nodes, indicating that A-type lamin positive cells are not proliferative. This suggests also that the Atype lamin expression in Reed-Stemberg and Hodgkin cells is correlated with a relatively mature phenotype of these malignant cells. However, part of these differentiated malignant cells still have a capacity to proliferate as indicated by Ki-67 positivity. Our observation that lamin $\mathrm{B} 2$ expression in the follicle centre cells of the reactive lymph node is low or absent indicates that this lamin stibtype is not always expressed in nucleated cells, which is in clear contrast to the results obtained in previous studies in other diseases and in normal tissues. Absence of lamin B2 expression may be associated with the follicle centre stage of $B$-cells.

\section{Introduction}

Lamins belong to the intermediate filament protein family and are constituents of the nuclear lamina. In vertebrates two types of lamins have been recognized, i.e. lamins of the neutral A-subtype and lamins of the acidic B-subtype $[11,18,23]$. These subtypes differ in their primary sequences and $\mathrm{pl}$, and each subtype consists of several distinct phosphorylation isoforms $[2,15]$. The B-type lamins B1 and B2 (Mw $65-67 \mathrm{kDa})$ seem to be involved in the 
association of the nuclear lamina to the inner nuclear membrane, which may result in stabilisation of the nuclear envelope [26]. B-type lamins have long been thought to be constitutively expressed in all somatic nucleated cells of vertebrates $[6,22]$. During mitosis, the nuclear lamina disintegrates due to phosphorylation of the lamins, but B-type lamins remain associated with vesicles originating from the nuclear membrane [11].

Expression of the A-type lamins, consisting of lamin $A$ and lamin $C$, is largely restricted to differentiated cells and not extensively found in proliferating cells $[6,23]$. Recent results indicate that statin, an antigen associated with non-proliferative cells, is identical to A-type lamins [7]. Statin and the proliferation marker Ki-67 segregate to distinct populations in cytospins of lymphoid cell suspensions, confirming the anti-proliferative expression of statin or A-type lamins [30]. A-type lamins have intrinsic chromatin-binding capacity, and as a result may be involved in a topological organization of chromatin and in the regulation of replication and transcription [10-12, 24]. During mitosis the phosphorylated A-type lamins, in contrast to the B-type lamins, become soluble and disperse throughout the cytoplasm.

Human lymphocytes of the early differentiation stages, as well as the neoplastic cells in acute Jymphoblastic leukemia (ALL) and non-Hodgkin's Jymphomas (NHL), are known to lack A-type lamins [13, 25, 29]. Lamin expression in Hodgkin's disease has until now not been characterized. Next to lymphocytes, this latter tumor type contains macrophages and histiocytes, as well as the morphologically distinguishable Reed-Sternberg and Hodgkin cells. The multinucleated Reed-Stemberg cells and mononucleated Hodgkin cells are considered to represent the malignant fraction in Hodgkin's disease, although they amount to only $2-3 \%$ of the total cell population. So far, the origin and stage of differentiation of the Reed-Sternberg cells have not been completely elucidated $[14,19]$. A recent study, however, suggests on base of rearranged $\mathrm{V}_{\mathrm{H}}$ and $\mathrm{V}_{\mathrm{L}}$ genes that the malignant cells in Hodgkin's disease originate from germinal centre B-cells [20].

The aim of this studly was to analyse lamin expression in cells of Hodgkin's disease in relation to their proliferative capacity and to compare these reaction patterns to those found in reactive Jymph nodes, in an attempt to clarify the degree of differentiation of the malignant cells in Hodgkin's disease.

\section{Materials and Methods}

\section{Tissue specimens}

Frozen biopsy specimens of nine patients with Hodgkin's disease nodular sclerosis subtype were investigated. In addition, twelve frozen biopsy specimens of reactive lymph nodes were analysed. 


\section{Antibodies}

The following mouse monoclonal antibodies against $A$-and B-type lamins were used in this study for immunocytochemical analyses:

1. 133 A2 (IgG3) against lamin A [16], kindly provided by Dr. Y. Raymond (Montreal/Canada), mouse ascites diluted 1:1000;

2. 41CC4 (IgM) against lamin A/C [5], kindly provided by Dr. G. Warren (London/United Kingdom), culture supernatant used undiluted;

3. R27 (IgM) against lamins A/C [32], kindly provided by Dr. G. Krohne (Würzburg/Germany), culture supernatant used undiluted;

4. X223 (IgG1) against lamin B2 [15], kindly provided by Dr. G. Krohne, ascites diluted 1:100; 5. 101B7.2 (IgG1) against lamin B2 (Matritech Inc., Cambridge, MA), ascites diluted 1:100;

6. LN43 (IgG1) against lamin B2 [3] kindly provided by Dr. E.B. Lane (Dundee/UK), culture supernatant used undiluted"

7. 119D5 (IgG1) against lamin B1, kindly provided by Dr. Y. Raymond, ascites diluted 1:750.

The leucocyte common antigen antibody (LCA), diluted 1:200 was used as a positive control. Phosphate buffered saline (PBS) pH 7.2-7.4 without primary antibodies was used as a negative control. The secondary antibody for the immunocytochemical detection of antibody binding was a peroxidase conjugated rabbit anti mouse immunoglobulin (DAKO A/S, Glostrup, Denmark), diluted 1: : 100.

Primary antibodies recognizing lymphocyte subtypes and used for the double label immunofluorescence studies, are:

1. anti-CD3, a rabbit polyclonal antiserum recognizing T-lymphocytes (DAKO), diluted 1: 100;

2. Anti-CD20, a mouse monoclonal IgG2a binding B-lymphocytes (L26; DAKO), diluted $1: 1000$;

3. Anti-CD30 (Ber-H2 clone; DAKO), a mouse monoclonal IgG1 detecting Reed-Sternberg cells, Hodgkin cells and activated lymphocytes [28], diluted 1:25.

Finally, a rabbit polyclonal antiserum recognizing the proliferation marker Ki-67 (DAKO) was used in combination with lamin antibodies and/or anti-CD30. The secondary antibodies used in the clouble-label immunofluorescence analyses were: fluorescein isothiocyanate (FITC) conjugated goat anti rabbit (Sigma, St. Louis, MO, USA), diluted 1:100, for the detection of anti-CD3; FITC labeled goat anti mouse IgG2a (Southem Biotechnology Associates, Inc., Birmingham, USA (SBA)), diluted 1:40, for the detection of anti-CD20; FITC labeled goat anti mouse IgGl (SBA), diluted 1:40, for the detection of anti-CD30; biotin labeled horse anti mouse (DAKO), diluted 1:200, with AMCA conjugated avidin (Vector, Brunschwig Chemis, Amsterdam, The Netherlands), diluted 1:100, for detection of CD30; Texas Red conjugated goat anti mouse IgM (SBA), diluted 1:40, for the detection of lamin $\mathrm{A} / \mathrm{C}$ antibody $\mathbb{R} 27$. For signal enhancement FITC labeled antibodies were reincubated with rabbit anti FITC (DAKO), diluted 1:100 and FITC conjugated swine anti rabbit immunoglobulins (DAKO), diluted 1:100. Finally, Ki-67 antigen was detected with FITC conjugated swine anti rabbit antibody (DAKO). 


\section{Immunoperoxidase staining procedure}

Five $\mu \mathrm{m}$ thick sections were cut with a cryostat (Cryocut 1800 , Reichert-Jung, Leical) from all frozen biopsy specimens, brought onto poly-L-lysine coated glass slides and fixed in acetone for five minutes at $4^{\circ} \mathrm{C}$. After fixation, slides were washed three times five minutes in PBS at room temperature (RT). Slides were incubated with appropriately diluted monse monoclonal antibodies for one hour at RT, followed by three times five minutes washing with PBS at RT. Thereafter, peroxidase conjugated secondary rabbit anti mouse Ig was incubated for one hour at RT. After another series of washing steps in PBS at RT (three times five minutes), peroxidase activity was wisualized with a diaminobenzidine (DAB; Sigma) staining reaction $(0.5 \mathrm{mg} / \mathrm{ml}$ $\mathrm{DAB}$ in $\mathrm{PBS} / 0.1 \mathrm{M}$ imidazol $\mathrm{pH} 7.6$ and $0.03 \% \mathrm{H}_{2} \mathrm{O}_{2}$ ), for four minutes at $\mathrm{RT}$. Thereafter, slides were rinsed with MilliQ-water, counterstained, dehydrated and mounted in Entellan (Merck, Darmstadt, Germany). Control incubations included omission of the primary antibodies and incubation with all secundary antibodies.

\section{Immunofluorescence procedure}

For double-label immunofluorescence studies $5 \mu \mathrm{m}$ thick frozen tissue sections from 3 cases, fixed for 5 minutes in acetone, were simultaneously incubated with mouse monoclonal $\operatorname{IgM}$ antibodies against lamin $\mathrm{A} / \mathrm{C}$, together with either anti-CD3, anti-CD20 or anti-CD30 antibodies for 45 minutes at $37^{\circ} \mathrm{C}$. Furthermore, monoclonal antibodies against lamin subtypes were also combined with the polyclonal antibody against the Ki-67 antigen. The slides were washed with PBS at RT and for detection of the CD-markers incubated with FITC conjugated goat anti rabbit IgG, FTTC labelled goat anti mouse IgG2a, or FITC conjugated goat anti mouse IgGI antibody, respectively, at $37^{\circ} \mathrm{C}$ for 30 minutes. $\mathrm{Ki}-67$ antigen was stained with FITC conjugated swine anti rabbit and the lamins were detected with Texas Red labeled goat anti mouse IgM. After each incubation step, slides were washed with PBS at RT. Finally, FTTC was amplified with rabbit anti FITC and FITC conjugated swine anti rabbit Ig. Slides were delnydrated and nuclei were connterstained with 4",6-diamidino-2-phenylindole (DAPI; Sigma; $1.25 \mathrm{ng} / \mathrm{ml}$ ) in $90 \%$ glycerol, $0.02 \% \mathrm{NaN}_{3}, 10 \% 0.2 \mathrm{M}$ Tris-HCl $(\mathrm{pH} 8.0)$, and 2.0\% 1,4-diazobicyclo-(2.2.2)-octane (DABCO; Sigma) (pH8.0), to reduce photobleaching.

For triple-label immunofluorescence, anti-CD30, followed by biotin labeled horse anti mouse and AMCA conjugated avidin were first incubated, than the Ki-67 antigen was detected by the polyclonal antiserum, followed by FITC conjugated swine anti rabbit, and finally lamin $\mathrm{A} / \mathrm{C}$ antibody R27 followed by Texas Red labeled goat anti mouse IgM were applied. Incubations were performed under similar conditions as described above for double-label immunofluorescence. Control incubations included omission of the primary antibodies and incubation with all secundary antibodies. The staining reactions were recorded with a CCD camera, using bright field and fluorescence filters. 


\section{Results}

The immunophenotyping results obtained with the lamin antibodies, lymphocyte subtype markers, and Ki-67 as proliferation marker in reactive lymph nodes and of Hodgkin's disease are summarized in table 1 and illustrated in figures 1-8. Antibodies R27 and $41 \mathrm{CC} 4$, both recognizing lamin $A$ and lamin $C$, showed similar reactivity patterns when compared to antibody $133 \mathrm{~A} 2$, recognizing only $\operatorname{lamin} \mathrm{A}$. The results of the $B$-type lamins were extrapolated by combining results of the lamin immunoperoxidase staining reactions with those from immunofluorescence microscopy for lymphocyte markers and Ki-67.

\section{Reactive lymph nodes}

In the follicle centre few cells scattered through the follicle centre were positive for all three Alype lamin antibodies (fig. 1), while virtually all cells expressed lamin B 1 as detected by 1 19D5 (fig. 2). The centrocytes and centroblasts of the follicle cemtre were not or very weakly positive for the lamin B2 antibodies (figs. 3 and 4). Mantle zone cells exhibited lamin B1 and B2 expression, but were completely negative for the lamin $\mathrm{A}$ and $\mathrm{A} / \mathrm{C}$ antibodies. The paracortical and medullar cells of reactive lymph nodes showed similar lamin expression patterns, i.e. strong expression of B-type lamins in all cells and A-type lamins in a smaller population of cells (fig. 1). To further specify the A-type lamin expression patterns for the different types of lymphocytes, we performed double- and triple-label immunofluorescence microscopy on the tissue sections. All CD20-positive B-cells in the follicle centre, but also the CD20-positive B-cells outside the follicle, lacked A-type lamins. Additionally, CD3-positive T-lymphocytes in the paracortex and medulla were also negative for A-type lamins. However, activated lymphoid cells with CD30 expression, sparsely seen in the paracortex and medulla, displayed lamins $A / C$, although a small subpopulation ( $\pm 10 \%$ ) of CD30 positive cells lacked A-type lamins. Another fraction of the A-type lamin positive cells in the paracortex and medulla remained unidentified by the lymphocyte markers, and mainly represent histiocytes, reticulum, dendritic and endothelial cells but not plasma cells.

Proliferative cells were identified by staining with the Ki-67 antibody. Centroblasts in the follicle centre were positive for Ki-67, whereas centrocytes and the cells of the mantle zone, paracortex and medulla were predominantly negative (fig. 4). In general, A-type lamin expression was mutually exclusive with $\mathrm{Ki}-67$ positivity.

\section{Hodgkin's disease}

The Reed-Stemberg and Hodgkin cells and all surrounding lymphocytes were positive for lamins $B 1$ and B2 in all cases (fig. 5), although the staining intensity of the Reed-Sternberg and Hodgkin cells with the lamin B1 antibody seems lower than the staining intensity of the surrounding cells. A-type lamins were observed in most Reed-Stemberg and Hodgkin cells, 
while also a small population of the cells in the background displayed this lamin subtype ffig. 6).

Again, double- and triple-label immunocytochemistry was used to correlate A-type lamin expression with the cellular subtype (Table 2). CD20 positive B-lymphocytes and CD3 positue T-lymphocytes in Hodgkin's disease lacked lamins $A$ and $C$, which was comparable to the patten observed in reactive lymph nodes. Again, A-type lamin expression commonly excluded Ki-67 positivity (fig. 7).

Furthermore, the majority of CD30 positive lymphoid cells and Reed-Stenberg or Hodgkin cells expressed A-type lamins (Table 2). However, a subpopulation of about $20 \%$ of the lamin A/C and CD30 positive malignant cells showed also Ki-67 expression (fig. 8).

Table 1 Summary of the immunophenotypes of the different cell types in reactive lymph nodes and Hodgkin's disease

\begin{tabular}{|c|c|c|c|c|c|c|c|}
\hline & CD3: & CD2O & CD30 & $\mathrm{Ki}-67$ & $\operatorname{lamin} \mathrm{A} / \mathrm{C}$ & $\operatorname{lamin} B 2$ & $|\operatorname{amin} B|$ \\
\hline \multicolumn{8}{|l|}{ Reactive Iynph node: } \\
\hline folliclo centre: & & & & & & & \\
\hline centroblasts & - & + & - & + & - & - & + \\
\hline centrocyles & - & + & - & - & - & - & + \\
\hline mantle zone cells & - & + & - & - & - & + & + \\
\hline \multirow[t]{4}{*}{ paracortex/medella cells } & + & - & - & - & - & + & + \\
\hline & - & \# & - & - & - & + & + \\
\hline & - & - & - & - & + & + & + \\
\hline & nd & nd & + & - & + & + & + \\
\hline \multirow{3}{*}{$\begin{array}{l}\text { Hodgkin's disease" } \\
\text { Hodgkin/Reed-Sternberg } \\
\text { cells }\end{array}$} & & & & & & & \\
\hline & nd & nd & + & - & + & + & * \\
\hline & nd & nod & + & + & + & + & * \\
\hline \multirow[t]{2}{*}{ surrounding cells } & nd & nd & - & - & - & + & * \\
\hline & “ & - & . & - & + & + & + \\
\hline
\end{tabular}

Results obtained after bright field microscopy with peroxidase staining $(\mathrm{n}=9)$, double and uriph - label immunofluorescence microscopy $(n=3)$, and extrapolation. Expression of antigen is indicated by + whereas lack is represented by -, nd is not determined. When differen expression patterns for a certain cell lypo occur., than the most common pattern is described first. in order of significance. 


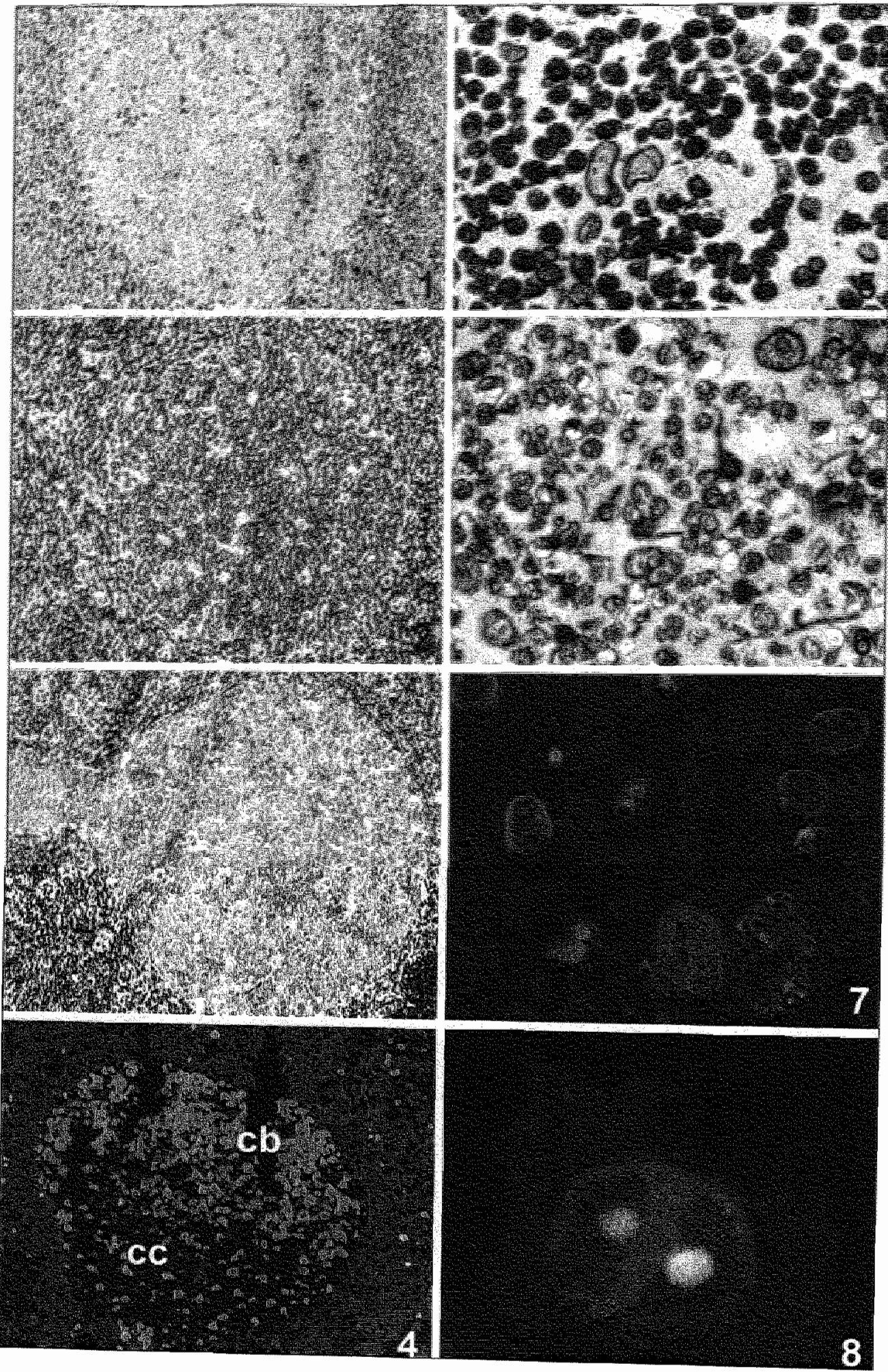


Figure 1. Reactive lymph node stained with antibody $R 27$, showing that A-type lamins are present in a few cells of the follicle centre and a population of cells in the paracortex. For colour illustration see page 132-133.

Figure 2. Staining of the reactive lymph node with antibody 1 19D5 showing that cells of the follicle centre and the surrounding areas exhibit lamin B 1. Colour illustration page 132-133.

Figure 3. The reactive lymph node after antibody $\mathrm{LN} 43$ staining, showing that lamin $\mathrm{B} 2$ is not or very weakly expressed in the cells of the follicle centre. For colour illustration seepage 132 133.

Figare 4. Double-label fluorescence microscopy of a reactive lymph node showing that centroblasts of the follicle centre express the proliferation marker Ki-67 (in green) but not lamin B2 (in red), while the majjority of the surrounding cells in the mantle zone, paracortex and medulla show the reverse staining pattern. Centrocytes were negative for both $\mathrm{Ki}-67$ and lamin $\mathrm{B} 2$. cc: centrocyte region; $\mathrm{cb}$ : centroblast region. For colour illustration see page $132-133$.

Figure 5. Reed-Stemberg/Hodgkin cells do express lamin B2, as shown after staining with LN43. Note that surrounding cells stain more strongly. For colour illustration see page 132-133.

Figure 6. Hodgkin lymphoma stained with antibody R27 shows that Reed-Sternberg and Hodgkin cells express Atype lamins. For colour illustration see page 132-133.

Figure 7. Double-label fluorescence microscopy of Hodgkin lymphoma with the proliferation marker Ki-67 (in green) and antibody R27 for A-type lamins (in red), showing that in general Ki-67 and A-type lamin staining are mutually exclusive. DNA was counterstained with DAPI (blue). For colour illustration see page 132-133.

Figure 8. Triplle-label fluorescence microscopy of a CD30-positive Reed-Sternberg cell (in blue) expressing A-1ype lamins as detected. with antibody $\mathrm{R} 27$ (in red) and the proliferation marker $\mathrm{K}_{\mathrm{i}}-67$ (in green). For colour illustration see page 132-133.

Table 2

Frequency distribution of cells in Hodgkin's disease expressing multiple phenotypic parameters. Results represented as the percentage of 1000 cells counted in double-label immunofluorescence samples and of 50 counted Reed-Sternberg and Hodgkin cells in the triple-label study of three cases.

\begin{tabular}{|c|c|c|c|}
\hline \multicolumn{4}{|c|}{ Hodgkin's dissease } \\
\hline CD30 & lamin $\mathrm{A} / \mathrm{C}$ & K.67 & $\begin{array}{l}\text { Frequency } \\
\text { (in \%) }\end{array}$ \\
\hline & + & + & 1.0 \\
\hline & + & - & 15.3 \\
\hline & - & + & 7.1 \\
\hline & - & - & 76.5 \\
\hline+ & & + & 0.3 \\
\hline+ & & - & 1.0 \\
\hline- & & + & 7.6 \\
\hline- & & - & 91.1 \\
\hline+ & + & & 0.8 \\
\hline+ & $\infty$ & & 0.2 \\
\hline- & + & & 10.5 \\
\hline- & - & & 89.6 \\
\hline \multicolumn{4}{|c|}{ Hodlgkin and Reed-Sternberg cells } \\
\hline+ & + & + & 18 \\
\hline+ & + & - & 74 \\
\hline+ & - & + & 4 \\
\hline+ & - & $\sim$ & 4 \\
\hline
\end{tabular}




\section{Discussion}

In this study nuclear lamin subtype expression was investigated in specific cell populations of reactive lymph nodes and Hodgkin's disease. Lamin expression of the malignant cells in Hodgkin's disease was compared to the expression in reactive lymph node, in an attempt to obtain further insight into the biology of malignant Reed-Sternberg and Hodgkin cells.

\section{Differential expression of lamins $B 1$ and $B 2$ in reactive lympla nodes}

Distinct areas of reactive lymph nodes exhibit a differential staining pattern for lamins $B 1$ and B2. The CD20 positive centrocytes and centroblasts of the follicle centre, i.e. maturating Blymphocytes, express high llevels of lamin B1, but no or only very low levels of lamin B2, whereas cells of the mantle zone, the paracortex and medulla display both B-type lamins. Our observation implies that lamin B2 is not constitutively expressed in nucleated cells, in contrast to observations by other investigators $[6,22,23]$. The use of three different lamin $B 2$ antibodies, recognizing both the hypo- and hyperphosphorylated forms of lamin B2 in immunoblotting [4], makes it very unlikely that epitope masking has prevented lamin B2 recognition in our study [3, 15]. Furthermore, the strong reactivity of the surrounding cells with these antibodies supports the suggestion that the centrocytes and centroblasts of the follicle centre do indeed not or only very weakly express lamin B2. This suggests that the absence of lamin B2 may be correlated with certain stages of $\mathrm{B}$-cell maturation, because it is lacking only in centroblasts and centrocytes. In contrast, $\mathrm{CD} 20$ positive B-lymphocytes in the paracortex and medulla do express lamin $\mathrm{B} 2$.

Furthermore, it has been suggested that lamin B 1 expression is correlated with proliferation [4]. Staining with the proliferation marker $\mathrm{Ki}-67$ showed only positivity in the centroblasts and not in the centrocytes. However, lamin B 1 was found in both cell types, which is in contrast with the assumed proliferation dependent expression of lamin B1. In conclusion, our observations with respect to B-lype lamin expression in the reactive lymph nodes are striking in the light of recent observations in other normal human tissues $[1,4,6,21]$. Lamin $B 1$ is expressed constitutively in the lymphoid cell population, while lamin B2 expression seems correlated with lymphoid cell maturation of the B-cells.

\section{A-type lamin expression in reactive lymph nodes}

Several investigators have observed a lack of A-type lamins in early human hematopoietic cells, such as T-lymphobiasts and pre-B cells $[13,25,29]$. Cance et al. [6] also demonstrated that proliferating lymphocytes of the germinal centres of lymphoid tissue lacked lamins $A$ and $C$. In our study A-type lamins were expressed in a small proportion of cells in reactive lymph nodes. Double-label fluorescence microscopy revealed that $\mathrm{Ki}-67$ positive cells, CD20-positive B-Hymphocytes and CD3-positive T-lymphocytes lack A-type lamins, confirming the earlier observations. A few of the lymphoid cells in reactive lymph nodes were CD30 positive, and 
most of them expressed A-type lamins. The presence of A-type lamins in these CD30 positive. cells suggests that this type of lamin expression may correlate with cell maturation or activation, because CD30 is expressed on mature activated lymphocytes. Only a minor fraction of CD30 positive lymphoid cells lacks A-type lamins. Moreover, next to these cells a population of histiocytes, reticulum, dendritic and endothelial cells exhibited A-type lamin expression.

Recent studies suggest that, in general, A-type lamin expression is restricted to differentiated cel]s $[1,4,6,8,13]$. Mature B-and T-lymphocytes of peripheral blood, for example, do display A-type lamins according to Guilly et al. [13]. Our Ki-67 study supported the above findings, indicating that A-type lamin expression is limited to the non-proliferative and more mature cell fraction in lymph nodes. Therefore, the presence of A-type lamins in the CD30 positive cells may correlate with the degree of differentiation rather than activation of the cells.

\section{A-and B-type lamin expression in Hodgkin's disease}

In general, Reed-Sternberg and Hodgkin cells contain lamins A, C, B1 and B2, while the surrounding B- and T-lymphocytes were only positive for both B-type lamins. Reed-Sternberg and Hodgkin cells may be derived from lymphocytes, since recent studies proof the presence of lymphoid markers, such as $\mathrm{V}_{\mathrm{H}}$ and $\mathrm{V}_{\mathbb{L}}$ rearramgements, in Reed-Sternberg and Hodgkin cells [9, 14, 19]. The presence of lamin B2, A-type lamins and CD30 in the Reed-Sternberg and Hodgkin cells suggests that they show a more differentiated phenotype than the centrocytes and centroblasts or the cells in the mantle zone of a reactive lymph node. Strikingly, Reed-Sternberg and Hodgkin cells resembled the lamin phenotype of CD30 positive cells of the paracortex or medulla. This may seem in contrast to the results of Kanzler et al. (1996) [20], who suggested that the malignant cells in Hodgkin's disease were derived from (crippled) germinal centre Bcells based on $\mathrm{V}_{H}$ and $\mathrm{V}_{\mathrm{L}}$ gene rearrangements. We realize, however, that the Reed-Sternberg and Hodgkin cells may be derived from any lymphoid cell types by terminal differentiation, and hence show A-type lamin expression.

It should be noted that we did not detect centrocyte- and centroblast-like lamin B2 negative Bcells in Hodgkin lymph nodes. This population seems to be replaced by a population of rellatively undifferentiated cells, which may arise from crippled follicle cells and possibly representing the precursors of the Reed-Sternberg and Hodgkin cells. Such crippled cells may initiate differentiation rapidly and aberrantly, resulting in the lack of centrocyte- and centroblast-like lamin B2 negative cells in Hodgkin's disease, which upon terminal differentiation result in Reed-Sternberg and Hodgkin cells.

The finding of Ki-67 positive Reed-Sternberg and Hodgkin cells confirms that a subpopulation of these malignant cells may proliferate [14, 27, 31]. However, most Ki-67 positive ReedSternberg and Hodgkin cells expressed next to CD30 also A-type lamins, indicating that these proliferating cells have a differentiated phenotype. Therefore, these results suggest that several populations of Reed-Sternberg and Hodgkin cells may exist [17] which differ in their degree of 
differentution, activation or proliferative status as shown by the absence or presence of A-type lamins and $\mathrm{Ki}-67$ antigen.

In conclusion, Reed-Sternberg and Hodgkin cells express both A-type and B-type lamins in which they distinguish themselves from lamin B2 negative centroblasts and centrocytes and the A-type lamin negative mantle zone cells of the reactive lymph nodes. Furthermore, this staining pattern indicates that the malignant cells are more differentiated than these cell types although some of these cells still possess proliferative capacity.

\section{Aknowledgements}

We thank Annick Haesevoets and Petra Pasman for technical advise and staining of tissue sections. Dr. E.B. Lane, Dr. G. Krohne, Dr. Y. Raymond and Dr. G. Warren are acknowledged for providing the lamin antibodies. Furthermore, we are grateful to the Nijbakker-Morra Foundation for financial support.

\section{References}

11 Ausma, J., G.J.J.M. van Eys, J.L.V. Broers, W. Thone, W. Flameng, F.C.S. Ramaekers, M, Borgers: Nuclear lamin expression in chronic hibernating myocardium in man. J. Mol. Cell. Cardiol. 28, 1297-1305 (1996).

[2] Bimontä, G. M. Giacca, G. Perini, G. Contreas, L. Zentilin, F. Weighardi, M. Guerra, G. Della-Valle, S. Saccone, $\$$. Riva: The gene for a novel human lamin maps at a highly transcribed locus of chromosome 19 which replicates at the onset of S-phase. Mol. Cell Biol. 12, 3499-3506 (1992).

[3] Bridger, J.M., I.R. Kill, M. OFartell, C.J. Hutchison: Internall lamin structure within G1 nuclei of human dermal fibroblasts. J. Cell Sci. 104, 297-306 (1993).

[4.] Broers, J.L.V., B.M. Machiels, H.J.H. Kuijpers, F. Smedts, R. wan den Kieboon, Y. Raymond, F. C.S. Ramackers: $A$ and $B$-type lamins are differentially expressed in nomal thuman tissues. Histochem. Cell Buol. 107, 505-517(1997).

[5] Burke, B., G. "Wooze, G. Warren: A monoclonat antibody which recognises eqch of the nuclear lamin polypeptides in manmalian cells. $1 \mathrm{MMBO}, 2,361-367$ (1983).

[6] Cance, W.G., N. Chaudhary, H.J. Worman, G. Blobel, C. Cordon-Cardo: Expression of the nuclear lamins in nommal and neoplastic human tissues. J. Exp. Clin. Cancer Res. 11, 233-246 (1992).

[7] Costes, P.J., R.C. Hobbs, J. Crocker, D.C. Rowlands, P. Murray, R. Quinlan, P.A. Hall: Identification of the nntigen recognized by the monoclonal antibody BU31 as lamins A and C. J. Pathol. 178, 21-29 (1996).

181 Collard, J.F. J.L. Sencial, $Y$, Raymond: Redistribution of nuclear lamin-A is an early event associated with difrumentiation of human promyelocytic leukemia HL-60 cells. J. Cell Sci. 101, 657-670 (1992)

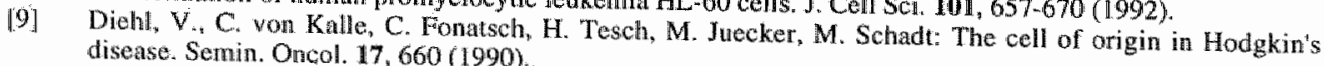

[10] Foister. R., L. Gerace: Integral membrane proteins of the nuclear envelope interact with lamins and chromosomes, and binding is modulated by mitotic phosphorylation. Cell 73, 1267-1279 (1993). [11.] Gerace, L.. B. Burke: Functional organization of the nuclear envelope. Anum. Rev. Cell Biol. 4, 335-374.
(1988).

112] Glass, JR. L. Gerace: Lamins A and C bind and assemble at the surface of mitotic chromosomes. J. Cell
Bioll. 111, 1047-1057 (1990).

[1.3] Guilly, M.N. I.P. Kolb, F. Gosti, F. Godeau, J.C. Courvalin: Lamins A and C are not expressed at early stages of human lymphocyte differentiation. Exp. Cell Res. 189, 145-147 (1990).

[14] Haluska, F., A.M. Brutsky, G.P. Canellos: The cellular biollogy of the Reed-Sternberg cell. Blood 84

[15] Höger, T.H., K. Zatoukal, I. Waizenegger, G. Krohne: Characterization of a second highly conserwed Blype lamin present in cells prewiously thought to contain only a single B-type lamin. Chromosoma 100, 67 -
69 (1990). 
[16] Hozak, P., M.-J. Sassevile, Y. Raymond, P.R. Cook: Lamin proteins form an internal nudeoskoloton as well as a peripheral lamina in human cells. J Cell 5 ci. 108,635 644 (1995).

[17) Hammel, M. R. Ziemann, H. Lammert, S. Pileri, E. Sabattini, H. Steñ: Hodgkin's disease with monoclonal andpolyclonal populations of Reed-Sternberg cells. N. Engl. J. Med. 333,901-906 (1995).

[18] Hutchison, C.J, J.M. Bridger, L.S. Cox , I.R. Kinl Wearing a pattern from disparate threads: Iamin function in nuclear assembly and DNA replication. I. Cell Sci. 107, 3259-3269 (1994).

[19] Jaffe, E.S.: The elusive Reed-Stermberg cell N. Engl. J. Med. 320, 529-531 (1989).

[20] Kanzler, H., R. Kuppers, M.L. Hansmann, K. Rajevsky: Hodgkin and Reed Sternberge cells in Hodgkin"s disease represent the owtgrowth of a dominant muor clone derived from (crippled) gerrminal center $\mathbb{B}$ colls. J. Exp. Med. 184, 1495-1505 (1996).

121] Machiels, B.M., F.C.S. Ramaekers, H.J.H. Kuijpers, J.S. Groenewoud, J.W. Oosterhuis, L.HJ. Looijemga: Nuclear lamin expression in nornal testis and testicular germ cell cumors of adolescents and adult. I. Pathol. 182, 197-204 (1997).

[22] Molr, R.D., R.D. Goldman: Lamin dynamics. Curr. Opiry. Cell Biol. 5, 408-411 (1993).

[23] Nigg, E A.: Assembly and cell cycle dynamics of the nuclear lamina. Semin. Cell Biol. 3, 245-253 (1992).

[24] Paddy, M.R., A.S. Belmont, H. Saumweber, D.A. Agard, J.W. Sedat: Interphase naclear envelope lamins form a discontinuous network that interacts with only a fraction of the chromatin in the nucleur periphery. Cell 62,89-106 (1990).

[25] Paulin-Levasseur, M., A. Scherbarth, U. Traub, P. Traub: Lack of lamins A and C in manmalian hemopoietic cell lines devoid of intermediate filament proteins. Eur. A. Cell Biol. 47. 121-13L (1988).

[26] Röber, R.A., H. Sauter, K. Weber, M. Osborm: Cells of the cellular immune and hemopotetic system of the mouse lack lamins A/C: distinction versus other somatic cells. J. Cell Sci, 95, 58.7-598 (1990).

[27] Sabattini, E., J. Gerdes, F. Ghertiazoni, S. Poggi, L. Zucchini, G. Melilli, F. Grigioni, M. T. Del-Vecchio, L. Leoncini, B. Falini: Comparison between the monocional antibodies Ki-67 and PC10 in 125 malignant Hymphomas. I. Pathol. 169, 397-403 (1993).

[28] Schwab, U., H. Stein, J. Gerdes, H. Lemke, H. Kirchner, M. Schaad, V. Dielal: Production of a monoclonal antibody specific for Hodgkin and Sternberg.Reed cells of Hodgkin's disease and a subset of normal lymphoid cells. Nature 299, 65-67 (1982).

[29] Stadelmann, B., E. Khandjian, A. Hirt, A. Luthy, R. Weil, H.P. Wagner: Repression of muclear lamin A and $C$ gene expression in human acute lymphoblastic leukemia and non-Hodgkin's lymphoma cells. Leuk, Res. 14, $815-821(1990)$.

[30] Trudel, M.A., L. Oligny, S. Caplan, C. Cetplan, H.M. Schipper, E. Wang: Statin a novel marker of nonproliferation (Expression in nonneoplastic lymphoid tissues and follicular lymphomas). Arn. J. Clin. Pathol. 101, 421-425 (1994).

131] Tsenga, A., P. Korkolopoulon, E. Patsounis, G.A. Pangalis, J. Oates, A. Skopelitou, J. Elemenoglou, C. Kittas: Proliferating cell nuclear antigen, $\mathrm{Ki}-67, \mathrm{c}$-rmyc p 62 oncoprotein, and nucleolar organizer regions in Hodgkin's disease. Appl. Immunohistochem. 2, 191-196 (1994).

[32] Zatloukal, K., H. Denk, G. Spurej, H. Hutter: Modulation of protein composition of nuclear lannina reduction of lamins-B1 and lamins-B2 in livers of griseofuvin-treated mice. Lab. Invest. 66, 589-597 (1992). 


\section{Chapter 5}

Abnormal A-type lamin organization in a human lung carcinoma cell line

Barbie M. Machiels, Jos L.V. Broers, Yves Raymond, Lou de Ley, Helma J.H. Kuijpers, Nicole E.H. Caberg, Frans C.S. Ramaekers.

European Journal of Cell Biology (1995), 67: 328-335. 


\section{Summary}

We have studied the expression of lamins A and C (A-type lamins) in a lung carcinoma cell line uging type-specific monoclonal antibodies. Using immunofluoresence and immunoblotting studies it was noted that seweral irregularities in lamin expression exist in the cell line GLC-A1, derived from an adenocarcinoma. First, the expression of the A-type lamins was lower than in other adenocarcinoma cell lines of the lung. Also the ratio between lamins $A$ and $C$ proteins was 1:8 instead of the 1:1 ratio seen in the other cell lines. Northern blotting confrmed the altered level of A-type lamin expression. Secondly, an abnormal localization of lamin A was observed. Intensely fluorescing lamin A aggregates were observed in the nucleus, rather than the typical perinuclear staining pattern. Confocal scanning laser microscopy revealed that the lamin $A$ aggregates were indeed present throughout the internal nucleus. When these cells were extracted with Triton $\mathrm{X}-100$ the nucleoplasmic aggregates disappeared, which indicates that the A-type lamins are not properly incorporated into the lamina. The A-type lamins in other cell lines derived from adenocarcinomas remained present in the nuclear periphery after extraction with the non-ionic detergent. Immunoblotting studies of the Triton X-100 soluble and insoluble fractions showed that lamin $\mathrm{A}$ and an apparently truncated product, which was detected with the lamin A antibody, were present in the insoluble fraction of GLC-A1. This truncated product is partly Triton X-100 soluble since it was also detected in the detergent soluble fraction. Thirdly, using an antibody to A-type lamins sporadic GLC-AI cells showed a filamentous cytoplasmic staining pattern, which was Triton $X$ - 100 resistant. Double labelling immunofluorescence studies revealed that these cytoplasmic lamins colocalized with the vimentin cytoskeleton in this cell line.

\section{Introduction}

Lamins are nuclear proteins, which belong to the family of intermediate filament proteins and consist of A-type lamins and B-type lamins. In mammalian cells, A-type lamins are represented by lamins $A$ and $C$, which are different transcripts arising from the same gene [11,29]. B-type lamins are represented by lamin $\mathrm{B} 1$ and $\mathrm{B} 2$ in mammalian cells and are encoded by different genes [17], while recently a third B-type lamin, denoted lamin B3, has been detected in mouse spermatocytes [13]. Lamins may have a significant impact on the expression of genes by interacting with the heterochromatin, directly or indirectly, by serving as a matrix for the attachment of nuclear matrix-associated proteins, which are thought to play important roles in gene regulation. In contrast to B-type lamins the expression of A-type lamins appears to be related to the state of cellular differentiation: well-differentiated cells do in general express Atype لlamins, while relatively undifferentiated cells or cells at early stages of embryonic development do not express detectable levels of A-type lamins (for reviews see [16, 22, 31]). In addition, it was shown that A-type lamins were not expressed in proliferating cells of some adult 
thuman tissues such as the basal keratinocytes of the skin [5] or certain cell lineages of the hematopoietic system [35].

Studies on the expression of nuclear lamins in neoplasms are relatively rare. In parallel to studies in embryonic cells, Lebel et al. [24] showed the absence of A-type lamins in undifferentiated teratocarcinoma cell cultures. In addition, Kaufmann et al. [21] have shown that A-type lamins were decreased by more than $80 \%$ in small cell lung cancer (SCLC) cell lines compared to non-SCLC cell lines. The findings were confirmed in our recent study on the expression of lamins in solid SCLC and non-SCLC [3], which showed the absence or reduction of A-type lamins in SCLC as compared to non-SCLC. In addition, striking aberrations in the organization patterns of A-type lamins were observed in some non-SCLC, in particular adenocarcinomas, which showed cytoplasmic rather than nuclear lamin staining patterns in a part of the tumour cells. In this study we have examined an adenocarcinoma cell line of the lung, which showed irregularities in A-type lamin expression.

\section{Materials and Methods}

\section{Cell Lines}

Three adenocarcinoma cell lines, i.e. NCI-H125 [6, 14], GLC-A1, GLC-A2 [9] were used. The characteristics and growth conditions of these cell lines have been described previously. All cell lines were maintained in a humidified incubator at $37^{\circ} \mathrm{C}$ in $5 \% \mathrm{CO}_{2}$ and were grown in Roswell Park Menorial Institute Medium 1640 (RPMI-1640, ICN Flow, Irvine, UK) containing $2 \mathrm{~g} / 1 \mathrm{NaHCO}_{3}$, supplemented with $10 \%$ newborn calf serum (ICN Flow). Cells were grown to almost confluency before harvesting.

\section{Antibodies}

The following mouse monoclonal antibodies were used in this study:

- LN43 (IgG1) directed against lamin B2 and not cross-reacting with lamin B1 [1], kindly provided by Dr. E.B. Lane (Dundee, U.K.).

- X223 (IgG1) directed against lamin B2 and not cross-reacting with lamin B1 [17], kindly provided by Dr. G. Krohne (Heidelberg, Germany).

- 19D5 (IgGl) directed against lamin B1. and not cross-reacting with lamin B2 (umpublished).

- 41CC4 (IgM) [4] kindly provided by Dr. G. Warren (Heidelberg, Germany). This antibody recognizes human lamins $\mathrm{A}$ and $\mathrm{C}$ in immunoblotting.

- R27 (IgM) was a gift from Dr. G. Krohne (Heidelberg, Germany). This antibody recognizes both lamins $A$ and $C$ and does not react with human $B$-type lamins [40].

- 133A2 (IgG3) raised against the carboxy-terminus of 98 amino acids present in lamin A and absent from lamin $\mathrm{C}$. This antibody recognizes lamin $\mathrm{A}$ but not lamin $\mathrm{C}$. Epitope 
mapping using several deletion mutants of lamin A showed that the amino acids 598-611 form the epitope recognized by $133 \mathrm{~A} 2$ [20]

- RV202 (IgG1) directed againgt vimentin [34].

- RCK102 (IgG1) directed against keratin 5 and 8 [34].

- pNF160, a rabbit polyclonal antibody, directed to neurofilaments, kindly provided by Dr. Y. Nakazato [30].

In immunofluoresence and immunoblotting studies LN43, X223, 41CC4, R27, RV202 and RCK 102 were used as unduluted culturing supernatant, while 119D5 (mouse ascites) was used 1:750 in immunofluorescence and 1:250 in immunobloting and 133A2 (mouse ascites) 1:2500 in immunofluorescence and 1:1000 in immunoblotting, pNF160 (rabbit serum) was used 1:600 in immunofluorescence.

The antibodies $41 \mathrm{CC} 4$ and $\mathrm{R} 27$ both recognize lamin $A$ and $C$ and will be referred to as lamin $\mathrm{A} / \mathrm{C}$ antibodies unless otherwise specified. Since the antibodies LN43 and X223 both recognize lamin B2 they will be referred to as lamin B2 antibodies unless otherwise specified. 133A2 will be referred to as lamin $A$ antibody and $119 D 5$ will be referred to as lamin B1 antibody.

\section{Indirect immunofluorescence technique}

The indirect immumofluorescence technique that was applied to the cell lines has been previously described [2]. Briefly, cells were grown on glass coverslips for 1-2 days. After washing in phosphate bufferd saline (PBS, containing $8 \mathrm{~g} / 1 \mathrm{NaCl}, 0.2 \mathrm{~g} / 1 \mathrm{KCl}, 1.15 \mathrm{~g} / \mathrm{l} \mathrm{Na} 2 \mathrm{HPO}_{4}$ and $0.2 \mathrm{~g} / 1 \mathrm{KH}_{2} \mathrm{PO}_{4}$ at $\mathrm{pH} 7.4$ ) the cells were fixed in methanol ( $-20^{\circ} \mathrm{C}$ for 5 seconds) followed by acetone (room temperature, 3 times five seconds) and air dried. For single labelling immunofluorescence cells were then incubated with the primary antibody for $30-45$ minutes, and after several washes with PBS, incubated with fluorescein isothiocyanate (FITC)conjugated rabbit anti-mouse Ig (1:100, DAKO A/S) for $30-45 \mathrm{~min}$. For double labelling immunoflourescence the cells were incubated with a lamin $\mathrm{A} / \mathrm{C}$ antibody of the $\operatorname{lgM}$ subclass for 30-45 minutes and after several washes with PBS incubated with FITC conjugated goat antimouse IgM (diluted 1/80, Southern Biotechnology associates (SBA), Birmingham, Alabama). Then after several washes with PBS, the antibody RV202 was applied for 5-10 minutes and after several washes with PBS the cells were incubated with Texas Red conjugated goat anti-mouse IgG1 (diluted 1/80, SBA). Thereafter, cells were washed again in PBS, mounted in 90\% glycerol containing $0.02 \mathrm{M}$ Tris $-\mathrm{HCl} p \mathrm{H} 8.0,0.002 \% \mathrm{NaN}_{3}, 2 \% 1,4$ diazabicyclo $(2,2,2)$-octane (DABCO; Merck) and $0.5 \mu \mathrm{g} / \mathrm{ml} \mathrm{4}, 6$ diamino-2 phenylindole (DAPI; Merck) for DNA staining, and photographs were taken with an automatic camera using 400 ASA Tri-X pan film (Kodak, England).

\section{Triton $X-100$ extraction of cells for immunofluorescence studies.}

Prior to Triton $X-100$ treatment the cells on the coverslips were rinsed with $P B S$ at room temperature (RT). Then the coverslips were placed on ice for Triton X-100 extraction. 
Precooled $\left(4^{\circ} \mathrm{C}\right.$ ) PBS containing $1 \mathrm{mM}$ EDTA (Titriplex III, Merck), $1 \mathrm{mM}$ EGTA (Titriplex VI, Merck), 0.4 mM PMSF (Aldrich, Steinheim, Germany) and 0.1\% Triton X-100 (BDH) was used for a 5 minute extraction. The coverslips wete then waslaed three times with cold PBS containing i mM EDTA, $1 \mathrm{mM}$ EGTA, 0.4 mM PMSF and the cells were fixed and immunostained as described above.

\section{Sample preparation for one-dimensional gel electrophoresis}

Samples of non-extracted cells:

The cells were rinsed with PBS at RT and the culture flask was placed on ice. Then $10 \mathrm{ml}$ PBS containing $1 \mathrm{mM}$ EDTA, I mM EGTA, 0.4 mM PMSF was added and the cells were collected by scraping with a rubber policeman from the bottom of the culture flask. The cell suspension was centrifuged at $4100 \mathrm{~g}$ and the pellet and the supernatant were separated. The proteins in the supernatant were precipitated with trichloroacetic acid (TCA, Merck), which was added to a final concentration of $10 \%(\mathrm{w} / \mathrm{v})$ and allowed to precipitate on ice for $30-60$ minutes. The precipitated proteins were pelleted by centrifugation at $2500 \mathrm{~g}$ for 10 minutes, washed twice with ice cold acetone $\left(-20^{\circ} \mathrm{C}\right)$ and air dried. The $4100 \mathrm{~g}$ cell pellet and the TCA-pellet of the PBS soluble fractions were resuspended in $200 \mu$ SDS-sample buffer and boiled for 5 minutes.

Samples of Triton X-100 extracted cells:

The cells were washed twice with PBS at RT. Then the flasks were placed on ice and the cells were extracted for 5 minutes with cold $\left(4^{\circ} \mathrm{C}\right) \mathrm{PBS}$ containing $1 \mathrm{mM}$ EDTA, $1 \mathrm{mM}$ EGTA, 0.4 mM PMSF and $0.5 \%$ Triton $X-100(B D H)$. The supernatant was discarded and the cell remainders were rinsed twice with cold PBS containing $1 \mathrm{mM}$ EDTA, $1 \mathrm{mM}$ EGTA and 0.4 $\mathrm{mM}$ PMSF. The cell remainders were collected by scraping in cold PBS containing $1 \mathrm{mM}$ EDTA, $1 \mathrm{mM}$ EGTA and 0.4 mM PMSF, the culture flasks were rinsed with the same buffer and the two fractions were pooled. These pooled fractions were centrifuged at $4100 \mathrm{~g}$ and the pellet and supernatant were separated. The proteins in the supernatant were TCA-precipitated as described above. All samples were dissolved by boiling for 5 minutes in $200 \mu$ SDS-sample buffer.

As a result of this approach equal sample volumes of different cellular fractions correspond with equal cell numbers.

\section{Sample preparation for two-dimensional gel electrophoresis}

Cells were washed with cold PBS $\left(4^{\circ} \mathrm{C}\right.$ ) containing $0.5 \mathrm{mM}$ PMSC (phenyl methyl sulfonyl chloride, Merck, Hohenbrunn, Germany) and collected by scraping in cold PBS containing 0.5 $\mathrm{mM}$ PMSC. They were centrifuged for 5 minutes at $1500 \mathrm{~g}$ and the pellet was Triton $\mathrm{X}-100$ extracted for 10 mimutes by stirring the pellet in Tris-buffer containing $10 \mathrm{mM}$ Tris- $\mathrm{HCl} \mathrm{pH} \mathrm{7.4}$, $10 \mathrm{mM} \mathrm{NaCl}, 1.5 \mathrm{mM} \mathrm{MgCl}_{2}, 0.5 \mathrm{mM}$ PMSF and $0.5 \%$ Triton $X-100$. The extracted cells were centrifuged at $1500 \mathrm{~g}$ and the pellet was treated with RNase/DNase mix ( $1 \mathrm{mg} / \mathrm{ml}$ DNase I, 0.5 $\mathrm{mM}$ PMSF, $0.05 \mathrm{mg} / \mathrm{ml}$ RNase A in $10 \mathrm{mM}$ Tris- $\mathrm{HCl} \mathrm{pH} 7.4,110 \mathrm{mM} \mathrm{NaCl}$ and $1.5 \mathrm{mM}$ 
$\mathrm{MgCl}_{2}$ ) for 20 minutes at $\mathrm{RT}$. Then cold Tre-buffer was added and the cells were centrifuged at $1500 \mathrm{~g}$. The supermatant was discarded and the pellet was bolled in SDS-sample buffer for 5 minutes. These samples were stored at $-20 \mathrm{C}$. Before loading onto an isoelectric focusing (IEF) gel an equal volume of buffer containing $2 \%$ Nonider P40 (Fluka, Buchs, Switzerland), $5 \%$ mercaptoethanol (Merck), 5\% Bio-Lyte 3/10 carrier ampholytes (Bio-Rad Laboratories, Hercules, Califomia) and $9 \mathrm{M}$ urea (Merck) was added followed by addition of $1 / 5$ volume $1 \mathrm{M}$ 3-[(3-cholamidopropyl)dimenylammonio] -propanesulfonate (CHAPS, Sigma) followed by addition of urea (Merck) until saturation.

\section{Gel electrophoresis and immunoblotting}

One-dimensional SDS-gel electrophoresis in polyactylamide was performed according to Laemmi [23] using gels containing $10 \%$ polyacrylamide (Bio-Rad Laboratories, Hercules, Cahifornia) and $0.1 \%$ SDS (Merck). Gels were run on the Mini-Protean II system (Bio-Rad Laboratories) for approximately 45 minutes at $200 \mathrm{~V}$.

Two-dimensional gels were run essentially as described by OFarrell [32], with the following modifications. Isoclectric focusing (IEF) was performed in $4 \%$ polyacrylamide gels containing $8 \mathrm{M}$ urea, $1.4 \%$ Bio-Lyte $3 / 10$ carrier ampholytes (Bio-Rad) and $25 \mathrm{mM}$ CHAPS (Bio-Rad Laboratories). Gels were run on the Mini-Protean II 2-D system (Bio-Rad Laboratories) and for IEF no pre-electrophoresis was performed. Gels were run at increasing voltages starting at 500 $V$ for 10 mimutes, followed by $1000 \mathrm{~V}$ for 20 minutes and $1500 \mathrm{~V}$ for 100 minutes.

In the second dimension, $10 \%$ polyacrylamide SDS gels were run similar to the onedimensional gel electrophoresis as described above.

Westem blotting was performed essentially according to Towbin [38] using the Mini Trans-Blot Cell (Bio-Rad) at $100 \mathrm{~V}$ for 1 hour. Proteins were blotted onto nitrocellulose (BA85, Schleicher and Schüh, Dassel, Germany). After blotting nitrocellulose sheets were air-dried and stored until immunochemical detection.

Prior to application of the primary antibodies the westemblots were blocked for 1 hour at RT in buffer containing $10 \mathrm{mM}$ Tris- $\mathrm{HCl} \mathrm{pH} 7.6,0.35 \mathrm{M} \mathrm{NaCl}$ and $3 \%$ bovine serum albumin (BSA, Sigma, St. Louis, Missouri). Thereafter the blots were incubated with the primary antibodies for 30-60 minutes at RT in appropriate dilutions in buffer containing $10 \mathrm{mM}$ TRIS-HCI pH 7,6, $0.15 \mathrm{M} \mathrm{NaCl}, 0.3 \% \mathrm{BSA}, 1 \%$ Triton X-100, 0.5\% DOC (Merck) and 0.1\% SDS (Merck). Then the blots were washed three times with PBS containing $0.5 \%$ Triton $\mathrm{X}-100(\mathrm{BDH})$. The secondary peroxidase conjugated rabbit anti-mouse Ig antibody (DAKO A/S) was diluted 1: 1000 in PBS containing 0.5\% Triton X-100 and 0.5\% BSA and the blots were incubated with this antibody for 30-60 minutes at RT. Then the blots were extensively washed with PBS containing $0.5 \%$ Triton $X-100$ and peroxidase activity was detected by chemiluminescence (ECL-kit, Amersham, Buckinghamshire, UK), RX Fuji medical X ray films (Fuji, Tokyo, Japan) were used for the visualisation of the luminescent signals. 


\section{Messenger ( $m$ )RNA isolation and northern blotting analysis}

Total RNA was isolated from the cell lines by the guanidine isothiocymate procedure as described previously [7, 8]. The RNA was dissolved in 200-400 $\mu 1$ DEPC (Diethyl pyrocarbonate, Sigma) treated $\mathrm{mQ}$ water, two volumes of ethanol p.a. (Merck) was added and the samples were stored at $-70^{\circ} \mathrm{C}$.

Twenty $\mu \mathrm{g}$ of total RNA, as determined at OD 260 , was size fractionated on a formaldehyde agarose gel [25] and blotted onto Hybond-N+ membrane (Amersham Life Science, Little Chalfont, United Kingdom). The blots were air dried for several hours and then the RNA was crosslinked with 120 Joules/ $\mathrm{cm}^{2}$ in an U.V. Stratalinker 1800 (Stratagene, La Jolla, California). The blots were prehybridized for 3 hours at $65^{\circ} \mathrm{C}$ in a hybridization mix containing $7 \%$ SDS, $1 \%$ BSA, 2 mM EDTA, $0.5 \mathrm{M} \mathrm{Na}_{2} \mathrm{HPO}_{4}$ at pH 7.0 and an excess of single stranded sheared salmon sperm DNA. Then the [32P] radioactive labeled probe (see below) was added to this mixture and hybridized overnight at $65^{\circ} \mathrm{C}$. After hybridization the blots were washed with saline citrate buffer (SSC, $0.15 \mathrm{M} \mathrm{NaCl}$ and $0.015 \mathrm{M}$ sodium citrate $\mathrm{pH} 7.0$ ) containing $0.1 \%$ SDS. Stringency conditions were optimized for each DNA probe. Autoradiography was done on RX Fuji medical X ray films (Fuji) at $-70^{\circ} \mathrm{C}$ using an intensifying screen. Densitometry of the autoradiograms was performed using a Computing Densitometer 300 (Molecular Dynamics, Sunnyvale, California) with the Quantity one (PDI, Protein Databases Inc., Huntington Station, New Yorky software on a Sun Sparc $1+$ station.

\section{Probes}

Hybridization was performed with $50-200 \mathrm{ng}$ probe DNA. The lamin A/C probe, kindly provided by Dr. F McKeon [29], was labeled with [32P] $\alpha$-dATP by random priming labeling [10] and purified over a Sephadex G50 fine (Pharmacia) column. A GAPDH probe [12] was used as a control for the amount mRNA loaded onto the gel.

\section{Results}

\section{Subcellular lamin localization as detected by immunofluorescence}

Representative reactivity patterns of perinuclear lamin expression in the lung adenocarcinoma cell lines with the different lamin antibodies are shown in figure $1 \mathrm{a}, \mathrm{b}, \mathrm{c}$.

The antibody to lamin A showed strong decoration of the nuclear lamina in the cell lines, but in GLC-A1 (Fig. 1e) an aberrant A-type lamin protein distribution pattern was observed in the immunofluorescence assay, in that intensely stained aggregates were detected in the nucleus. Confocal scanning microscopy revealed that the nuclear aggregates were localized throughout the whole nucleus and not only on the perinuclear lamina (Fig. 2). In addition to the clustered appearance, a normal lamina was stained in these cells with lamin A/C antibodies (Fig. 1f), but the fluorescence intensity was only very weak compared to the signal obtained in the other cell 

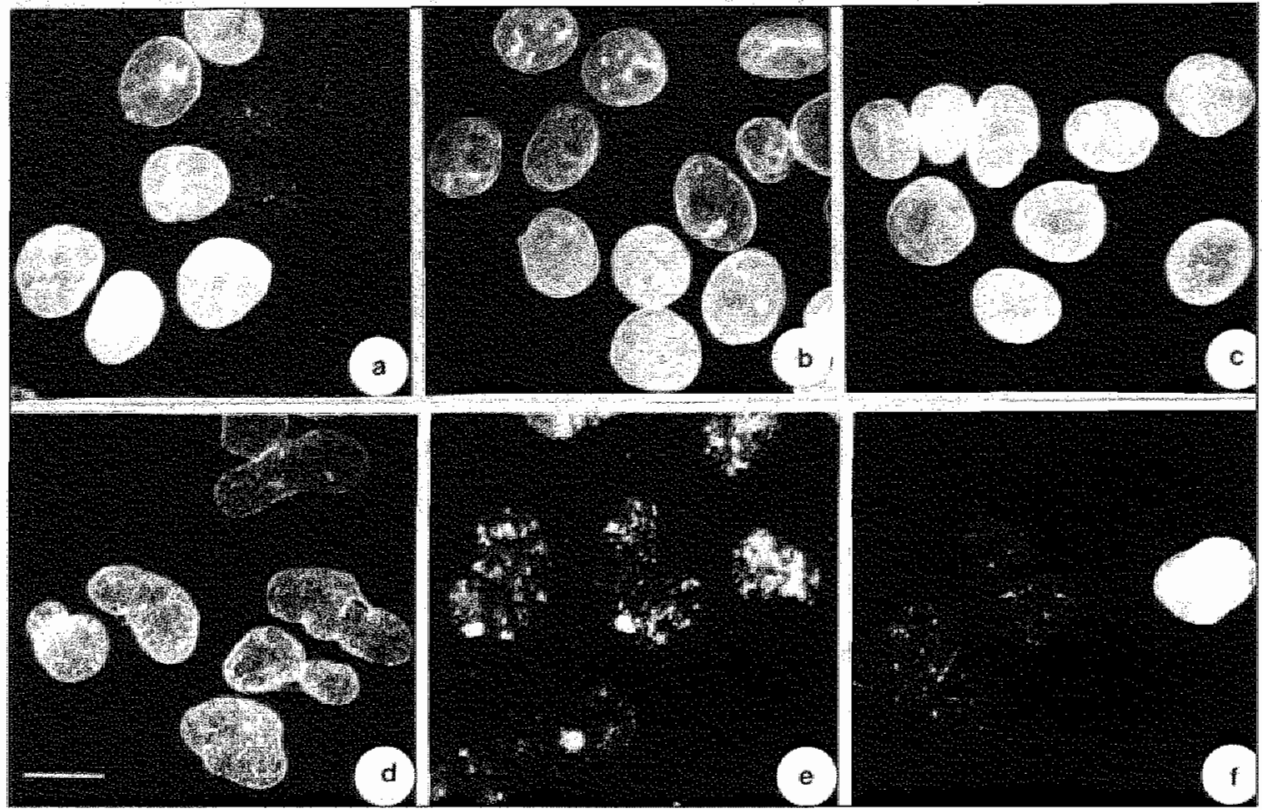

Figure 1. Immunofluorescence micrographs of cell lines GLC-A2 $(a, b, c)$ and GLC-A1 $\left(d_{1}, \mathrm{e}, \mathrm{f}\right)$, stained with the lamin $B 1$ antibody $119 D 5$ (a), the lamin B2 antibody LN43 (d), the lamin $A$ antibody $133 \mathrm{~A} 2(\mathrm{~b}, \mathrm{e})$, the lamin $\mathrm{A} / \mathrm{C}$ antibody $41 \mathrm{CC} 4$ (c) and the tamin $\mathrm{A} / \mathrm{C}$ antibody $\mathrm{R} 27$ (f). Bar indicates approximately $12 \mu \mathrm{m}$.

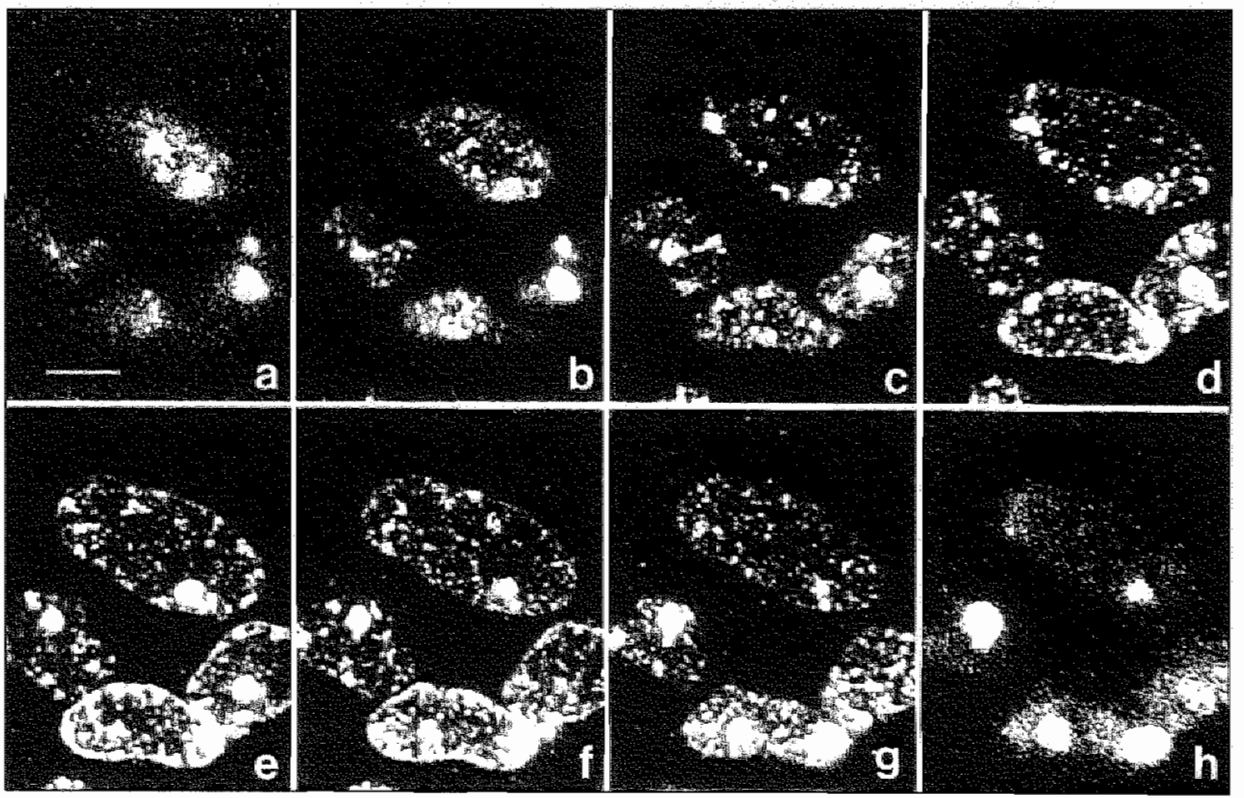

Figure 2. Z-series of confocal images of GLC-Al cells, stained with the lamin A antibody 133A2. The series goes from the top (a) to the bottom (h) of the cells. Bar indicates $10 \mu \mathrm{m}$. 
lines. Also when compared to the reaction with B-type lamin antibodies in GLC-A1 (Fig 1 d) the

perinuclear A-type lamin staining has to be interpreted as weak. The nuclear aggregates were dissolved when the cells were treated with $0.1 \%$ Triton X-100 prior to fixation (Fig. 3). However, the normal lamina staining with A-type and B-type lamin antibodies persisted treatment with Triton $X-100$ and was still detectable in the cells that had lost the aggregates.

Furthermore in GLC-A1 another aberrant lamin distribution pattern was detected when stained with the lamin $\mathrm{A} / \mathrm{C}$ antibody $\mathrm{R} 27$. In most cells the lamina was only very weakly stained. However, in some cells an apparent normal intensity of A-type lamin perinuclear staining was observed (Fig. 1f). Additionally, in a small fraction of the cells strongly staining extranuclear aggregates, next to a faint filamentous staining was observed with the antibody R27 (not shown). These A-type lamins appeared to be stably incorporated in cytoskeletal filaments, since they persisted treatment with $0.1 \%$ Triton $X-100$. Double labelling immunofluorescence studies with antibodies to cytoskeletal proteins revealed colocalization of the cytoplasmic A-type lamins with vimentin. Colocalization of A-type lamins with neurofilaments and cytokeratins did not seem to occur.
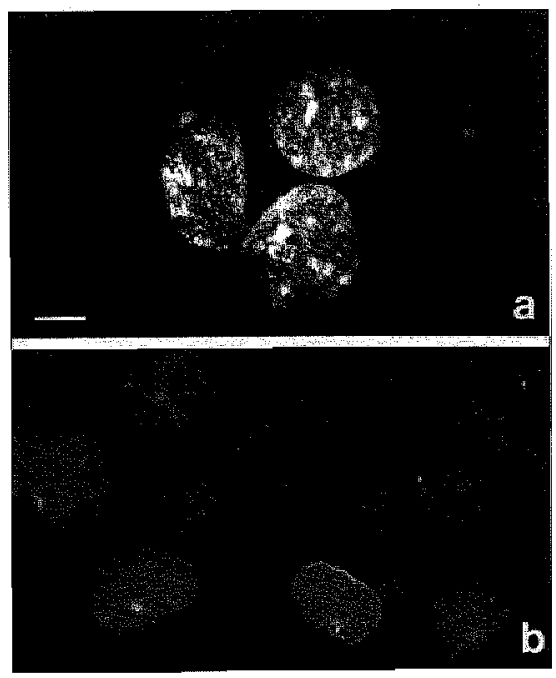

Figure 3. Immunofluorescence staining patterns of GLC-A1 cells with the lamin A antibody $133 \mathrm{~A} 2$ before (a) and after (b) treament with $0.1 \%$ Triton $\mathrm{X}-100$. Bar indicates $10 \mu \mathrm{m}$.

\section{Solubility properties of lamins as detected by immunobloting}

In order to further characterize the Triton $X-100$ soluble and Triton $X-100$ insoluble lamin fractions in the cell lines, one-dimensional immunoblotting studies were performed of pellet and supermatant fractions after Triton X-100 extraction of the cells. Immunoblots of these fractions. were tested with the six lamin antibodies.

After the Triton X-100 extraction step most of the cells were still attached to the bottom of the culture flask. These cells were scraped from the bottom and collected; this cell suspension was centrifuged and the Triton X-100 supernatant and Triton $\mathrm{X}-100$ cell pellet were prepared for gel 

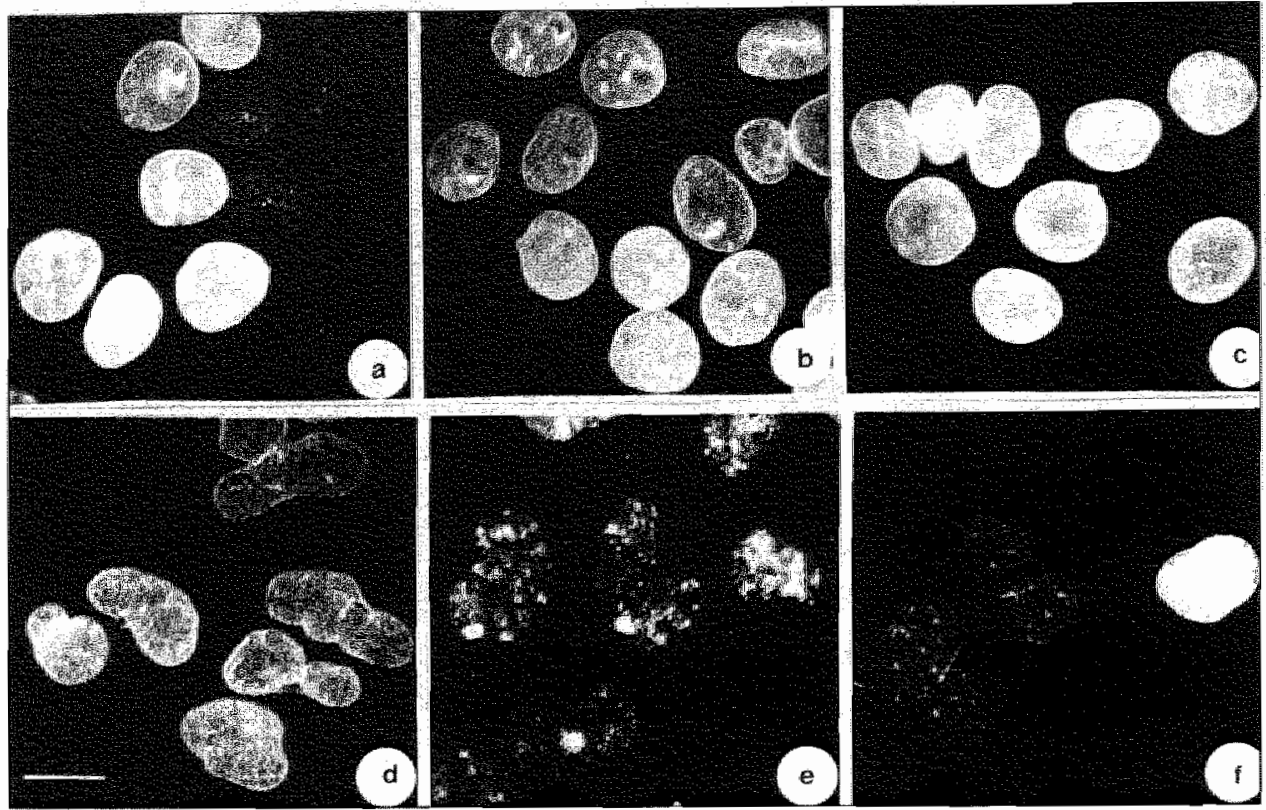

Figure 1. Imnunofluorescence micrographs of cell lines GLC-A2 $(\mathrm{a}, \mathrm{b}, \mathrm{c})$ and $\mathrm{GLC}-\mathrm{A} 1$ (d,e, $)_{1}$ stained with the lanin Bil antibody 11905 (a), the lamin B2 antibody LN43 (d), the lamin $\mathrm{A}$ antibody $133 \mathrm{~A} 2$ (b, e), the lamin $\mathrm{A} / \mathrm{C}$ antibody $41 \mathrm{CC} 4$ (c) and the lantin $\mathrm{A} / \mathrm{C}$ antibody $\mathrm{R} 27$ (f). Bar indicates approximately $12 \mu \mathrm{m}$.

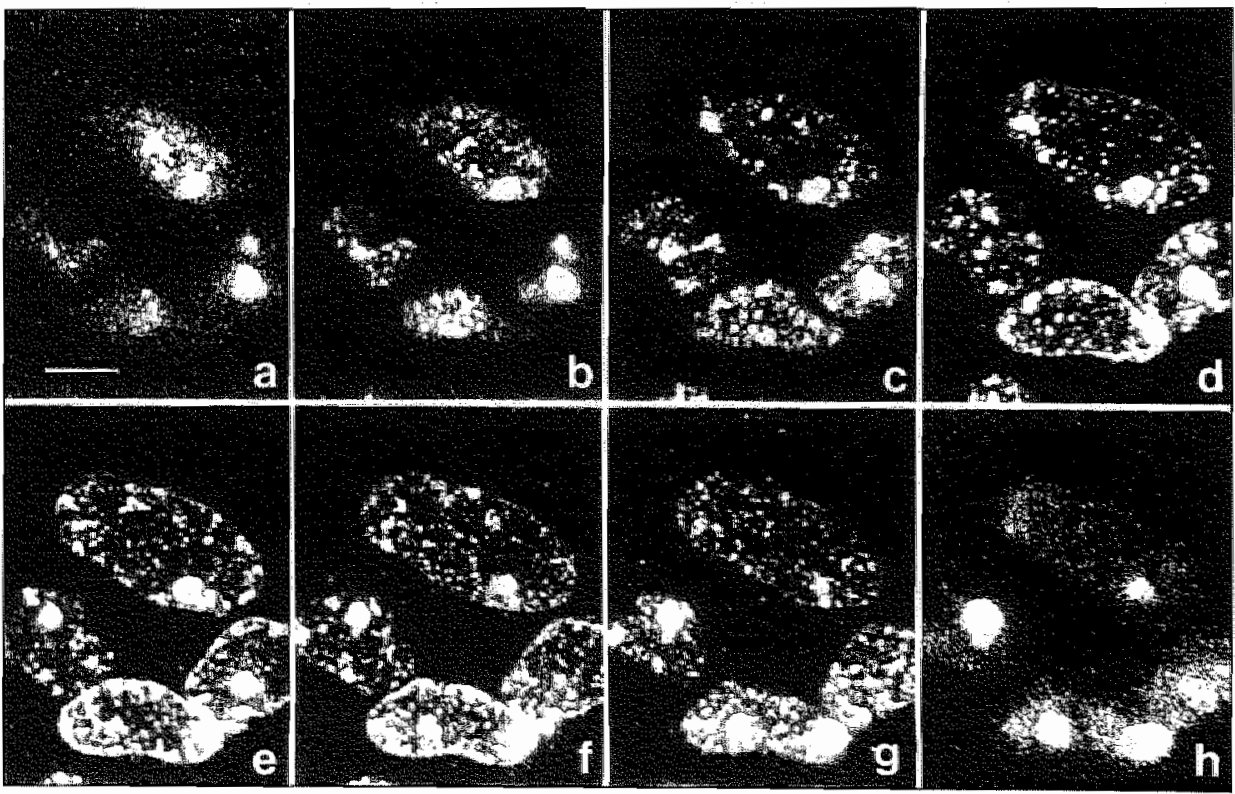

Figure 2. $Z$-series of confocal images of GLC-Al cells, stained with the lamin A antibody 133A2. The series goes from the top (a) to the bottom (h) of the cells. Bar indicates $10 \mu \mathrm{m}$. 
lines. Also when compared to the reaction with B-type lamin antibodies in GLC-A1 (Fig Id) the

perinuclear A-type lamin staining has to be interpreted as weak. The nuclear aggregates were dissolved when the cells were treated with $0.1 \%$ Triton $X-100$ prior to fixation (Fig. 3). However, the normal lamina staining with A-type and B-type lamin antibodies persisted treatment with Triton X-100 and was still detectable in the cells that had lost the aggregates.

Furthermore in GLC-A1 another aberrant lamin distribution pattern was detected when stained with the lamin $\mathrm{A} / \mathrm{C}$ antibody $\mathrm{R} 27$. In most cells the lamina was only very weakly stained. However, in some cells an apparent normal intensity of A-type lamin perinuclear staining was observed (Fig. 11). Additionally, in a small fraction of the cells strongly staining extranuclear aggregates, next to a faint fillamentous staining was observed with the antibody $\mathrm{R} 27$ (not shown). These A-type lamins appeared to be stably incorporated in cytoskeletal filaments, since they persisted treatment with $0.1 \%$ Triton X-100. Double labelling immunofluorescence studies with antibodies to cytoskeletal proteins revealed colocalization of the cytoplasmic A-type lamins with vimentin. Colocalization of A-type lamins with neurofilaments and cytokeratins did not seem to occur.

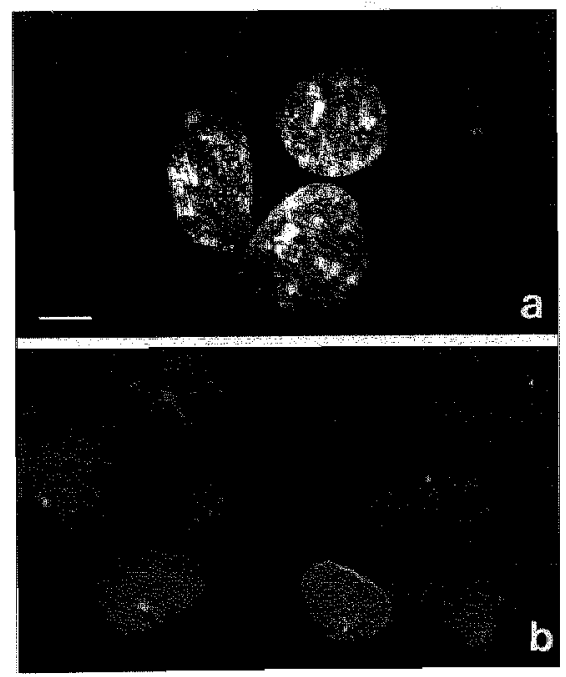

Figure 3. Immunofluorescence staining patterns of GLC-A1 cells with the lamin A antibody $133 \mathrm{~A} 2$ before (a) and after (b) treatment with $0.1 \%$ Triton X-100. Bar indicates $10 \mu \mathrm{m}$.

\section{Solubility properties of lamins as detected by immunoblotting}

In order to further characterize the Triton $X-100$ soluble and Triton $X-100$ insoluble lamin fractions in the cell lines, one-dimensional immunoblotting studies were performed of pellet and supernatant fractions after Triton X-100 extraction of the cells. Immunoblots of these fractions were tested with the six lamin antibodies.

After the Triton X-100 extraction step most of the cells were still attached to the bottom of the culture fask. These cells were scraped from the bottom and collected; this cell suspension was centrifuged and the Triton $\mathrm{X}-100$ supernatant and Triton $\mathrm{X}-100$ cell pellet were prepared for gel 
electrophoresis. A similar fractionation was done with cells that were not Triton X-100 extracted and the PBS supernatant and PBS cell pellet were prepared for gel electrophoresis.

When the fractions the cell lines were incubated with a lamin B1 or lamin B2 antibody, onlly one band was detected in the Triton X-100 cell pellets and PBS cell pellets (Fig. 4, lanes 1-4). These results matched with the results obtained in the immunofluorescence studies, in which no aberrant patterns for lamin $\mathrm{B} 1$ and $\mathrm{B} 2$ were detected in the cell lines.

Blots of the same samples were also incubated with antibody $R 27$, reacting with both lamins $A$ and $C$. The results of the cell lines NCL-H125 and GLC-A2 were comparable (illustrated for NCI-H125 in Fig. 4, lanes 5-8), in that the Triton X-100 cell pellets and PBS cell pellets of the cell lines showed both lamin $A$ and lamin $C$ as two strong bands in an approximate $1 / 1$ ratio. The lamin $A$ band is actually a doublet, which is seen as a single band after prolonged exposure in chemiluminescence.

In GLC-AIt the intensity of both lamin A and lamin $C$ bands of the Triton $X-100$ cell pellet and PBS cell pellet was completely different from those seen in the other cell lines, while also the ratio of lamin $A$ over lamin $C$ was aberrant (Fig. 4, lanes 8-12). The lamin $A$ band was hardly detectable in the GLC-A1 Triton X-100 cell pellet and PBS cell pellet, while the lamin C band was clearly visible, but weaker when compared to the other cell lines. In addition, when examined closer this lamin $\mathrm{C}$ band appeared to be a doublet. The overall weaker reaction of lamin A/C antibodies on blots of GLC A1 samples matched with the results of the

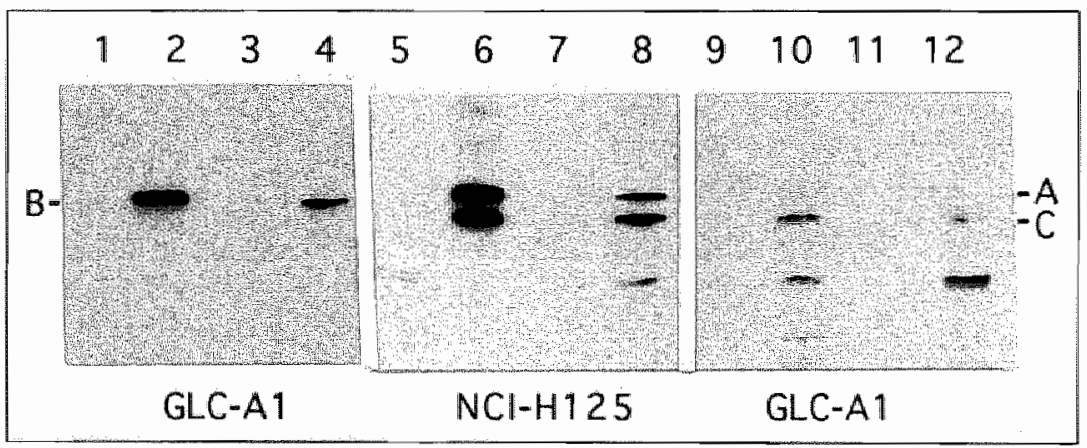

Figure 4. One-dimensional immunoblotting of lamin B2 and lamin $A / C$ in the Triton $X-100$ supernatants (lanes 1,5,9), Triton $X-100$ cell pellets (lanes $2,6,10)$, PBS supernatants (lanes $3,7,11)$ and PBS cell pellets $($ anes4,8,12). Blots of these fractions of GLC-A1 (lanes $1-4$ ) cells were inctbated with the lamin B2 antibody LN43, blots of these fractions of NCl-H125 (lanes 5-8) and GLC-Al (lanes a-12) cells were incubated with the lamin $\mathrm{A}$ C antibody $\mathrm{R} 27$.

immunofluorescence studies, in which the lamin staining with these antibodies was also weak and aberrant. In the soluble fractions of the cell lines no reactivity was detected with the lamin A/C antibodies (Fig. 4, odd numbered lanes).

When stained with lamin A antibody 133A2 the blots of the soluble and insoluble fractions of the cell lines showed distinct differences between the cell lines (Fig. 5). The blotting results for 
the cell lines NCI-H125 and GLC-A2 were identical (fig. 5, lanes 1-8). In the Triton X-100 cell pellet and PBS cell pellet of these two cell lines a lamin A doublet of approximately $72 \mathrm{kDa}$ was detected (Fig. 5, lanes $2,4,6,8$ ). Furthermore a relative faint additional band with a lower molecular mass of approximately $63 \mathrm{kDa}$ was detected with the antibody to lamin $\mathrm{A}$. In the Triton X-100 supernatant of NCI-H125 and GLC-A2 four bands were detected (Fig. 5, lanes 1 and 5). The upper two bands were at the same molecular weight levels as the bands detected in the Triton X-100 cell pellets (Fig. 5, lanes 2 and 6), while the two additional bands showed a lower molecular weight. In the PBS soluble fractions no bands were detected (Fig. 5, lanes 3 and 7 ).

The immunoblots with the GLC-Al samples showed again that the lamin A expression level was much lower as compared to the other cell lines (Fig. 5, lanes 9-12). In the Triton X-100 cell pellet and PBS cell pellet of GLC-A1 identical bands were detected as in NCI-H125 and GLCA2, but the intensity ratio between the two bands was changed (Fig. 5, lanes 2,4,6,8, 10,12). Furthermore in the Triton X-100 supernatant of GLC-A1 cells only the three lower molecular weight bands, indicated as A' (Fig. 5, lane 9), were detected, while the band at the normal lamin A level was missing in this sample. Again no bands were detected in the PBS soluble fractions (Fig. 5, lane 11). It is remarkable that with the antibodies to lamins A and C (R27 and $41 C C 4)$ never any band was detected at the lamin A level in the Triton X-100 soluble fractions.

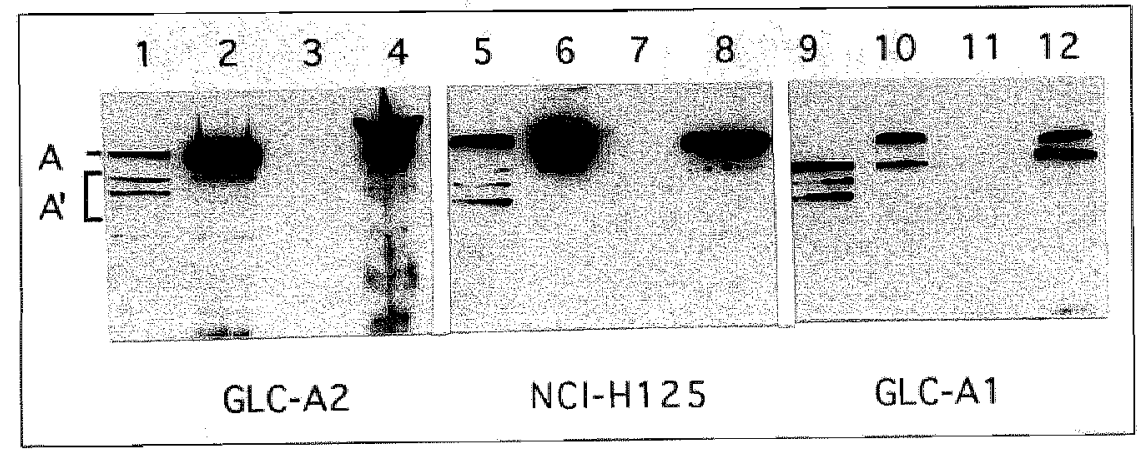

Figure 5. One-dimensional immunoblotting of lamin $A$ in the Triton $X-100$ supenatants (lanes $1,5,9)$, Tritom $X$ 100 cell pellets (lanes 2,6,10), PBS supernatants (lanes $3,7,1$ ) and PBS cell pellets (lanes $4,8,12$ ). The fractions of the cell lines GLC-A2 (lanes 1-4), NCW-H125 (lanes 5-8) and GLC-A1 (lanes 9-12) were incubated with the lamin A antibody $133 \mathrm{~A} 2$.

Immunostaining of two-dimensional blots of the insoluble fraction of GLC-A1, showed that after applying the lamin $\mathrm{A}$ antibody $133 \mathrm{~A} 2$ and using an exposure time as used for the other cell lines and antibodies, only one very small spot was visible for lamin A. After relatively long exposure it became evident that two arrays of several isoforms of lamin A could be detected in GLC-A1 (Fig. 6a). However, the protein with the lower molecular weight, as detected in onedimensional blotting (Fig. 5, lane 10 indicated as lamin $A^{\prime}$ ), was not visible in this twodimensional blotting. When the two-dimensional immunoblots of GLC-A1 were stained with 
the lamin $A / C$ antibody $R 27$ a strong reaction was seen with lamin $C$ and only a faint spot was cletected for lamin $A$ under these exposure conditions (fig. 6b). The signal for lamin $\mathbb{C}$ was a doublet of arrays with little difference in molecular masses and distinct phophorylation isoforms. When the different lamins were detected simultaneously in one immunoblot, the relatiwe abundance of each component became apparent. The relatively high abundance of $B$ type lamins is obwious from figure $6 c$, while also the extremely low concentration of A-type lamins is evident as compared to idlentical blots of the other cell lines (Fig. 6d).

The lamin A signals were seen as doublets, with only small differences in molecular masses. The isoelectric mobilities of both arrays of lamin A isoforms were identical. Several spots with lower molecular masses were consistently detected by the lamin antibodies. The most prominent of these have molecular masses of approximately $46 \mathrm{kDa}$, most likely representing degradation products of the lamins [33].

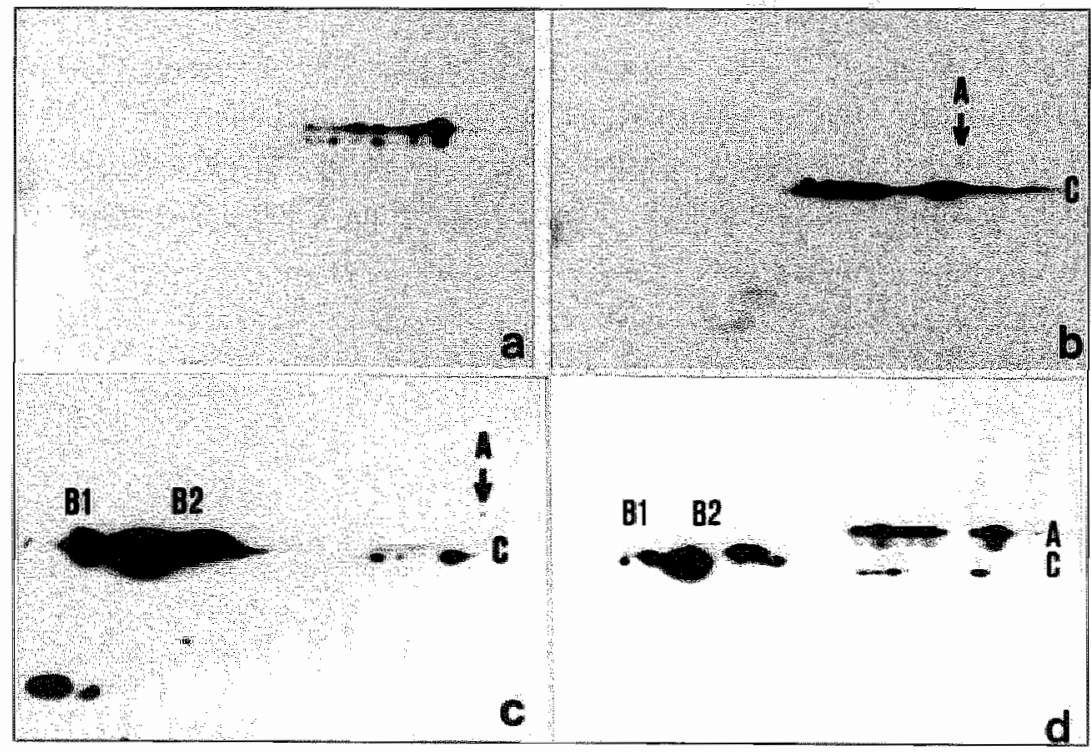

Figure 6. Two dimensional immunoblotting of Triton $X-100$ extracted cells of GLC-A1 (a,b,c) and GLC-A2 (d) The immunoblots were incubated with the lamin $\mathrm{A}$ antibody $133 \mathrm{A2}$ (a), the lamin $\mathrm{A} / \mathrm{C}$ antibody $\mathrm{R} 27$ (b), or simultancously with the lamin B1 antibody $119 \mathrm{DS}$, the lamin B2 antibody LN43, the lamin A antibody $133 \mathrm{A2}$ and the lamin $\mathrm{A} / \mathrm{C}$ antibody $41 \mathrm{CC} 4\left(\mathrm{O}_{8} \mathrm{~d}\right)$.

\section{Messenger RNA levels of lamins as detected by Northern blotting}

RNA isolated from the three cell lines was subjected to Northern blotting analysis (Fig. 7). Hybridization with an A-type lamin probe showed major differences in lamin A and C mRNA expression between the cell lines. In the cell lines NCI-H125 and GLC-A2 both lamin A and Lamin C mRNA were detected. The lamin A over lamin C mRNA ratio varied from $1: 1.5$ to $1: 2$ as measured by densitometry. However in the mRNA samples isolated from GLC-A1 the total 
A-type lamin mRNA expression was 5 tol0 fold decreased compared to the A-typa lamin MRNA expression in the other cell lines. Moreover, the expression ratio of lamin A over lamin $C$ was changed to 1:8. Consequently, the lamin A mRNA was hardly detectable. No abnormally sized mRNA was detected in the cell lines. The decreased A-type lamin mRNA level and altered ratio of lamin A over lamin C in GLC-A I was in concordance with the immunoblotting results. The Northern blot was rehybridized with a GAPDH probe as a control for the amount of RNA blotted onto the membrane. This confirmed that the amount of mRNA from GLC-Al loaded onto the gel was comparable to that of the other cell lines.

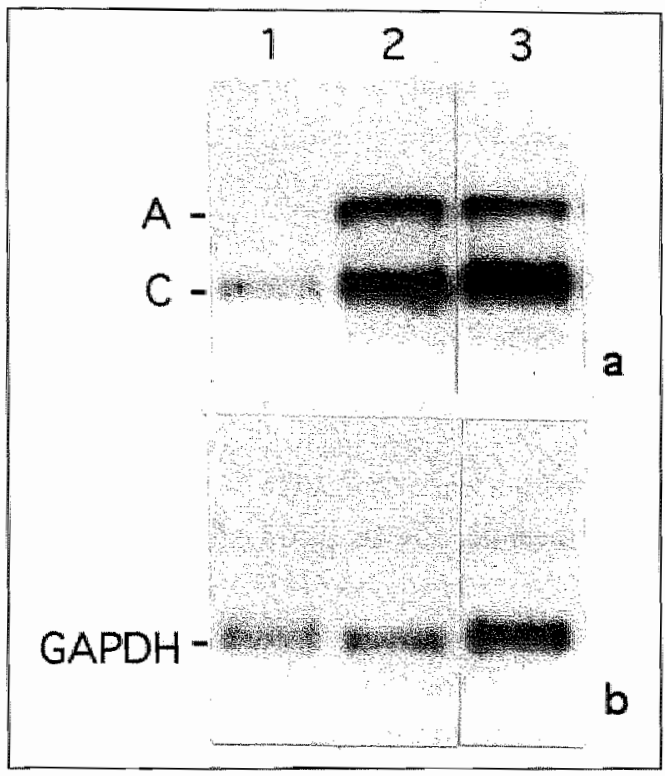

Figure 7. Northern blotting of mRNA isolated from cell limes GLC-A1 (lane 1), GILC-A2 (lame 2) and NCI-H125 (lane 3). The blot was hybridized with a lamin AV probe (a) and a GAPDH probe (b).

\section{Discussion}

In this study the molecular basis of an aberrant expression pattern of lamins in a human lung carcinoma cell line has been investigated. Previous studies on lamin expression in normal lung tissues and lung tumours showed that B-type lamins seem to be ubiquitously expressed in cells of normal tissues and most lung cancers [36,39], but that in adenocarcinomas of the lung they could not be detected in certain areas of these malignancies. Furthermore, cytoplasmic instead of nuclear localization of A-type lamins in adenocarcinomas has been reported [3]. In the study presented here the A-type lamin expression showed aberrancies at the protein and mRNA levels in an adenocarcinoma cell line.

In immunofluorescence studies with antibody $133 \mathrm{~A} 2$, directed to the carboxy-terminal tail of lamin $A$, which is lacking in lamin $C[20]$, an aberrant lamin $A$ llocalization was seen in GLC. A 1 cells. The perinuclear lamina was only slightly stained, while heavily stained aggregates 
were detected throughout the nucleoplasm. Our experiments showed that the majority of the nuclear aggregates were removed upon Triton X-100 treatment. These results indicate that a soluble form of lamin $\mathrm{A}$ is present in these aggregates. It has been described that non-prenylated prelamin $A$ accumulates as nucleoplasmic inclusions in the nuclei of cells that have been blocked in prenylation [28]. However, the possibility of accumulation of prelamin $A$ in the nuclei of GLC-A1 could be excluded by using an antibody specific for prelamin $A$ (kindly prowided by Dr. M. Sinenski [37]), which did not show any nuclear reactivity in GLC-Al (data not showit).

In order to identify the protein that was responsible for the aggregate like staining pattern, inmunoblotting studies were performed. In one-dimensional immunoblots of GLC-A1, that were incubated with the lamin $\mathrm{A}$ antibody $133 \mathrm{~A} 2$, a protein band with a lower molecular weight than mature lamin $A$ was detected. This lamin $A^{\prime}$ appeared to be preferentially extracted, as compared to lamin $\mathrm{A}$. Probably this lamin $\mathrm{A}^{\prime \prime}$ is responsible for the Triton $\mathrm{X}$ - 100 soluble nuclear aggregates that were detected in GLC-Al cells. However, lamin A" was also present in the other cell lines, but the ratio of normall lamin A over the smaller lamin $\mathrm{A}^{\prime}$ protein was completely different in these cell lines, in that the lamin A' was expressed at relatively very low levels. Therefore, the relative excess of normal lamin A might obscure the presence of the lamin $A^{\prime}$ protein in these cell limes.

Loewinger and Mckeon [27] have described abnormal nuclear aggregation of lamin A lacking the carboxy terminal part distal to amino acid 444 , indicating that this part of lamin $A$ is necessary for correct incorporation into the lamina. Additional studies [18] have shown that not. only the carboxy terminal CaaX motive is responsible for the incorporation, but that additional sequences of lamin $A$ are required for proper incorporation. The fact that lamin $A$ ' is recognized by the antibody $133 \mathrm{~A} 2$ indicates that at least part of the carboxy terminal region is intact, since the epitope for this antibody is localized between amino acid 598 and 611 . However, the decreased molecular weight might predict that deletions within the molecule occur.

'The observation that lamin $A$ ' is not detectable under our standard isoelectric focusing conditions, encompassing a pll range of $\mathrm{pH} 4-8$, might indicate that such a deletion causes an extreme shift in the isoelectric point. The exact nature of lamin $A^{\prime}$ remains, however, to be established.

The absence of the typical aggregate-like reactivity with the lamin $\mathrm{A} / \mathrm{C}$ antibodies may be explained by the observation that in two-dimensional blottings the lamin $\mathrm{A} / \mathrm{C}$ antibodies have a stronger reactivity with lamin $C$ than with lamin $A$, while the lamin $A$ antibody showed a very strong reactivity with lamin $A$. Therefore preferential staining of lamin $C$ with the lamin $A / C$ antibodies might also occur in immunofluorescence assays, through which nucleoplasmic lamin A aggregates remain invisible.

Furthermore total A-type lamin expression levels were decreased in GLC-A 1. and the ratio of lamin $A$ over lamin $C$ was altered, as detected in immunoblotting and northern blotting. Since lamins $A$ and $C$ arise from the same gene by alternative splicing [26] an explanation for the 
altered ratio of lamin $A$ over lamin $C$ may be an altered relative preference for alternative splicing. However, the mechanism behind the regulation of the lamin $A$ to $C$ MRA ratio is still unclear [26].

The shift in lamin A over lamin $C$ protein ratio in the GLC-Al cell line probably has consequences for lamina assembly, in particular for the incorporation of lamin $C$ into the lamina, since it has been reported that the absence of lamin A disturbs proper assembly of lamin $C$ into the lamina [19]. Most likely, in some cells the relative excess of lamin $C$ becomes stably integrated in newly formed cytoplasmic filaments or into the pre-existing vimentin cytoskeleton, which leads to a Triton X-100 insoluble cytoplasmic localization. This would explain why the cytoplasmic filaments, that were seen in some GLC-Al cells, were detected with an antibody directed to both lamin $A$ and $C$ and not with the antibody that recognized only lamin $A$. Unincorporated lamin $C$ will not remain for long in the cytoplasm, since it has been found that unassembled lamins have a short half-live [15].

In summary, we have described an abnormal nuclear and cytoplasmic localization of A-type lamins in the adenocarcinima cell line GLC-A1, and by additional immunoblotting and northern blotting studies we have tried to elucidate the nature of these aberrancies. To further validate and confirm our present results additional two-dimensonal immunoblotting and molecular biology studies have been initiated.

\section{Acknowledgements}

The authors thank Dr. M. Sinenski, Dr. E.B. Lane, Dr. G. Krohne, Dr. G. Warren and Dr. Y. Nakazato for providing the antibodies and Dr. F. Mckeon for providing the lamin A/C probe.

\section{References}

(1) Bridger, J.M., 1. Kill, M. OFartell, C.J. Hutchison: Internal lamin structure within Gl nuclei ol luman dermal fibroblasts. J. Cell Sci. 104, 297-306 (1993).

[2] Broers, J.L.V., D.N. Carmey, M. Klein Rot, G. Sehaar, E.B. Lane, G.P. Vooijs, F.C.S. Ramaekers: Intermedate filament proteins in classic and variant types of small cell lung carcinoma cell lines. a biochemical and immumochemical analysis using a panel of monoclonal and polyclonal antibodies. I, Cell Sci. 83, 37-60 (1986).

[3] Broers, J.L.V. Y. Raymond, M. Klein Rot, H. Kuijpers, S. Wagenaar, F. S. Ramackers: Nuclear A-type lamins are differentially expressed in human lung cancer subtypes. Am. J. Pathol 143, 211-220 (1993).

[4] Burke, B., G. Tooze, G. Warren: A monoclonal antibody which recognises each of the muclear liamin polypeptides in mammalian cells. EMBO J. 2, 361-367 (1983).

[5] Cance, W.G. N. Chaudhary, H.J. Woman, G. Blobel, C. Cordon Cardo: Expression of the nuclear lamins in mormall and neoplastic human tissues. J. Exp. Clin. Cancer Res. 11, 233-246 (1992).

[6] Carney, D.N., A.F. Gazdar, G. Bepler, J.G. Guccion, P.J. Marangos, T.W. Moody, M.H. Zweig, I.D. Minna: Establishment and identification of small cell lung cancer cell lines having classic and variant features. Cancer Res. 45, 2913-2923 (1985).

[7] Chirgwin, J.M., A.E. Pruybyla, R.J. Macdonald, W.J. Rutter: Isolation of biologically actiwe ribonucleic acid from sources enriched in ribonuclease. Biochemistry 18,5294-5299 (1979).

[8] Davis, L.G., M.D. Dibner, J.F. Bartey: Basic methods in molecular biology. pp. 130 135 . Elsevier. Ansterdan 1986. 
(9) De Leij, L., P.E. Postmus C.H.C.M. Buys, J.D. Elema, F. Ramaekers, S. Poppema, M. Brouwer, A.Y. wan der Veen, G. Mesander, "T.H. The: Characterization of three new, "variant-type" cell lines derived from small cell carcinoma of the lung. Cancer Res. 45, 6024-6033 (1985).

[10] Feinberg, A.P. B. Wogellstein: A technique for radiolabeling DNA restriction endonuclease fragments to high specific acuivity. Anal Biochem. 132, 6-13 (1983).

[11] Fisher, D.Z., N. Chaudhary, G. Blobel: CDNA sequencing of nuelear lamins A and C revealls primary and secondary structural homology to intermediate filament proteins. Proc. Natl. Acad. Sci. USA 83, 6450-6454 (1986).

[12] Fort, P., L. Marty, M. Piechaczyk, S.E. Sabrouty, C. Dani, P. Jeanteur, J.M. Blanchard: Various rat adult tissues express only one major mRNA species from the glyceraldehyde-3-phosphate-dehydrogenase multigenic family. Nucleic Acids Res. 13, 1431 (1985).

[13] Furukawa, K., Y. Hotta: cDNA cloning of a germ cell specific lamin B3 from mouse spermatocytes and analysis of its function by ectopic expression in somatic cells. EMBO J. 12, 97-106 (1993).

[14] Gazdar, A.F., P.A. Bunn, I,D. Minna, S.B. Baylin: Origin of human small cell lung cancer. Science 229, $679-680(1985)$.

[15] Gerace, L.: Nuclear lamina and organization of nuclear architecture. Trends Biochem. Sci. 11, 443-446 (1986).

[16] Gerace, L., B. Burke: Functional organization of the nuclear envelope. Annu. Rev. Cell Biol. 4, 335-374 (1988).

[17] Höger, T.H., K. Zatloukal, I. Waizenegger, G. Krolne: Characterization of a second highly conserved Btype lamin present in cells previously thought to contain only a single B-type lamin. Chromosoma 99, 379$390(1990)$.

[18] Holtz, D., R. Tanaka A, J. Fartwig, F. McKeon: The CaaX motif of lamin A functions in conjunction with the nuclear localization signal to target assembly to the nuclear envelope. Cell 59,969-977 (1989).

[19] Horton, H., I. Mcmorrow, B. Burke: Independent expression and assembly properties of heterologous laminA and lamin-C in murine embryonal carcinomas. Eur. J. Cell Biol. 57, 172-183 (1992).

120】 Hozák, P., M.-J. Sasseville, Y. Raymond, P.R. Cook: Lamin proteins form an internal nucleoskeleton as well as a peripheral lamina in human cells. J. Cell Sci. 108, (1995).

[21] Kaufmann, S.H., M. Mabry, R. Jasti, J.H. Shaper: Differential expression of nuclear envelope lamins A and $\mathrm{C}$ in human lung cancer cell lines. Cancer Res. 51, 581-586 (1991).

[22] Krohne, G., R. Benavente: The nuclear lamins. A multigeme familly of proteins in evolution and differentiation. Exp. Cell Res. 162, 1-10 (1986).

[23] Laemmli, U.K.: Cleavage of structural proteins during the assembly of the head of bacteriophage T4. Nature 227, 680-685 (1970).

[24] Lebel, S., C. Lampron, A. Royal, Y. Raymond: Lamins A and C appear durimg retinoic acid-induced differentiation of mouse embryonal carcinoma cells. J. Cell Biol. 105, 1099-1104 (1987).

[25] Lehrach, H., D. Diamond, J.M. Wozney, H. Boedtker: RNA molecular weight determinations by gel electrophoresis under denaturating conditions, a critical reexamination. Biochemistry 16, 4743-4751 (1977).

[26] Lin, F., H.J. Worman: Structural organization of the human gene encoding nuclear lamin $\mathrm{A}$ and nuclear lamin C. J. Biol. Chem. 268, 16321-16326 (1993).

127] Loewinger, L. F. Mckeon: Mutations in the nuclear lamin proteins resulting in their aberrant assembly in the cyroplasm. EMBO J. 7, 2301-2309 (1988).

[28] Lutz, R.L., M.A. Trujillo, K.S. Denham, L. Wenger, M. Sinensky: Nucleoplasmic localization of prelamin A: implications for prenylation-dependent lamin A assembly into the nuclear lannima. Proc. Natl. Acad. Sci. USA 89, 3000-3004 (1992).

[29] McKeon, F.D. M.W. Kirschner, D. Caput : Homologies in both primary and secondary structure between nuclear envelope and intermediate filament proteins. Nature 319, 463-468 (1986).

[30] Nakazato, Y.. A. Sasaki, J. Hirato, I. Ishida: Immunohistochemical localisation of neurofilament protein in neuronal degenerations. Acta Neuropath. 64, 30-36 (1984).

31] Nigg, E.A.: Assembly - disassembly of the nuclear lamina. Curr. Opin. Cell Biol. 4, 105-109 (1992).

[32] O'Farrell, P.H.: High resolution two-dimensional electrophoresis of proteins. J. Biol Chem. 230, 4007-4021 (1975).

[33] Oberhammer, F.A., K. Hochegger, G. Froschl: Chromatin condensation during apoptosis is accompanied by degradation of lamin $\mathrm{A}+\mathrm{B}$, without enhanced activation of cdc2 kinase. J. Cell Biol. 126, 827-837 (1994).

[34] Ramackers, F., A. Huysmans, G. Schaart, O. Moesker, P. Vooys: Tissue distribution of keratin 7 as monitored by monoclonal antibody. Expl. Cell Res. 170, 235-249 (1987).

[35] Röber, R.-A., H. Sauter, K. Weber, M. Osborn: Cells of the cellular immune and hemopoietic system of the mouse lack lamins A/C: distinction versus other somatic cells. J. Cell Sci. 95, 587 598 (1990).

[36] Röber, R.A., K. Weber, M. Osborn: Differential timing of nuclear lamin A/C expression in the various organs of the mouse embryo and the young animal: a developmental study. Development 105, 365-378 (1989).

[37] Sinensky, M. K. Fantle, M. Trujillo, "T. McLain, A. Kupfer, M. Dalton: The processing pathway of prelamin A. J. Cell Sci. 107, 61-67 (1994). 
[38] Towbin, H., T. Stzehelin, J. Gordon: Elecurophorectic transfer of proteins from polyhcrylamide gels to nitrocellinlose sheets: procedure and some applications. Proc. Natl. AGat. Sci. USA 76, 4350-4354 (1979).

[39] Worman, H.I., I. Lazaridis, S.D. Georgatos: Nuclear lamina heterogemeity in mammallan cells. J. Biol. Chem. 263, 12135-12141(1988).

[40] Zatloukal, K., H. Denk, G. Spurej, H. Hutter: Modulation of protein composition of nuclear lamina. reduetion of lamins-B 1 and lamins-B2 in livers of griseoful vin-treated Mice. Lab. Invesi. 66, 589-597 (1992). 


\section{Chapter 6}

\section{An alternative splicing product of the lamin $\mathrm{A} / \mathrm{C}$ gene lacks exon 10}

Barbie M. Machiels, Antoine H.G. Zorenc, Jorike M. Endert, Helma J.H. Kuijpers, Guillaume J.J.M. van Eys, Frans C.S. Ramaekers, Jos L.V. Broers.

Journal of Biological Chemistry (1996), 271: 9249-9253. 


\section{Summary}

Expression of the A-type lamins was studied in the lung adenocarcinoma cell line GLC-A. Atype lamins, consisting of lamin $\mathrm{A}$ and $\mathrm{C}$, are two products arising from the same gene by alternative splicing. Northern blotting showed in GLC-A1 a relatively low expression level of lamin $C$ and an even lower expression level of lamin $A$ as compared to other adenocarcinoma cell lines. Immunofluorescence studies revealed highly irregular nuclear inclusions of $\operatorname{lamin} A$, suggesting protein or gene expression abnormalities. Reverse transcriptase-PCR based cDNA analysis followed by sequencing indicated the presence of an as yet unidentified alternative splicing product of the lamin $\mathrm{A} / \mathrm{C}$ gene. This product differs from lamin $\mathrm{A}$ by the absence of the 5 part of exon 10 (90 nucleotides). Therefore we propose to designate this product lamin A $\Delta 10$. Deletion of the 30 amino acids encoded by exon 10 was predicted to result in a shift in pI of the protein from 7.4 to approximately 8.6 , which was confirmed by two-dimensionall immunoblotting. mRNA analysis in a variety of cell lines, normal colon tissue as well as carcinomas demonstrated the presence of lamina $A \Delta 10$ in all samples examined, suggesting its presence in variety of cell types.

\section{Introduction}

Lamins are intermediate filament type proteins which form the major components of the nuclear lamina. Two main types of lamins are known in mammals; i.e. A-type lamins and B-type lamins. The B-type lamins, B1 and B2, are encoded by two distinct genes [21], while lamin B3 is a recently discovered alternative splicing product of the lamin B2 gene in embryonic cells [17]. At least one of the B-type lamins is ubiquitously expressed in mammalian cells and their expression appears to be independent of the state of cellular differentiation $[38,42]$. The A-type lamins, represented by lamins $\mathrm{A}$ and $\mathrm{C}$, are products arising from one gene by alternative splicing $[14,28,32]$. A-type lamin expression appears to be related to the state of cellullar differentiation. In general, well-differentiated cells express A-type lamins, whereas undifferentiated cells synthesize low or nndetectable levels of A-type lamins $[6,19,25]$. In addition it is shown that A-type lamins are not expressed in proliferating cells of some adult tissues such as basal cells of the skin [8] or certain lineages of the hematopoietic system [37]. The recent unravelling of the complete human lamin $\mathrm{A} / \mathrm{C}$ gene [28] has provided a better insight into the mechanism by which lamins $\mathrm{A}$ and $\mathrm{C}$ are generated from the same gene. The site for alternative splicing has been demonstrated to be located within exon 10. While exon 1 through 9 of the lamin A and C mRNAs are identical, lamin A mRNA further contains the 5' 90 bases of exon 10 , followed by exon 11 and 12 . In contrast the lamin $C$ messenger contains the complete 111 base sequence of exon 10 , but not exon 11 and 12 . In this paper we describe a third splicing product of the lamin $\mathrm{A} / \mathrm{C}$ gene, identical to lamin $\mathrm{A}$ with the exception of the absence of exon 10. 


\section{Materials and Methods}

\section{Cell Lines}

Adenocarcinoma cell lines NCI-H125, NCI-H23 [9, 18], GLC-A1, GLC-A2 [12] and NL-Ac1 [5], the neuroendocrine non-small cell lung carcinoma NCI-H460 [7], the large cell undifferentiated lung carcinoma cell line LCLC-103H [1], the breast carcinoma cell line T47D [16], and the (bladder) transitional carcinoma cell line T24 [36] were grown in Roswell Park Memorial Institute Medium 1640 (RPMI-1640, ICN Flow, Irvine, UK) containing 2 g/l $\mathrm{NaHCO}_{3}$, supplemented with $10 \%$ newborn calf serum (ICN Flow). The epitheloid lung carcinoma cell line MR65 [30] was grown in DMEM in 10\% newborn calf serum, while the neuroblastoma cell line SK-N-SH [3] was grown in RPMI with 15\% fetal bovine serum. All cell lines were maintained in a humidified incubator at $37^{\circ} \mathrm{C}$ in $5 \% \mathrm{CO}_{2}$.

\section{Human tissue specimens}

Human lung adenocarcinoma specimens and a specimen of normal collon were obtained after" surgery and snap frozen in liquid nitrogen. Samples were homogenized in ice-cold guanidine isothiocyanate buffer [11] using a Omni 1001 mixer (Omni, Waterbury, CT, USA) at 20,000 rpm for $15-60$ seconds and stored at $-70^{\circ} \mathrm{C}$ until use.

\section{Immunofluorescence}

The procedure for immunofluorescence has been described [31]. Primary antibodies used include 133A2 [23] recognizing lamin $A$ and $L N 43$ [4] recognizing lamin B2. As secondary antibody FITC-labeled rabbit anti-mouse immunoglobulins (DAKO, Glostrup, Denmark) was used.

\section{RNA isolation and Northern blotting analysis}

Total RNA was isolated from cell lines and tissue specimens by the guanidine isothiocyanate procedure $[10,11]$. Twenty $\mu$ g of total RNA was size-fractionated on a formaldehyde agarose gel [27], blotted onto Hybond-N+ membrane (Amersham Life Science, Little Chalfont, UK) and cross-linked with 120 Joules/ $\mathrm{cm}^{2}$ in an U.V. Stratalinker 1800 (Stratagene, Lua Jolla, CA/USA). Blots were hybridized overnight at $65^{\circ} \mathrm{C}$ in a hybridization mix containing $7 \%$ sodium dodecyl sulphate (SDS, BRL Life Technologies, Gaitherburg, MD/USA), $1 \%$ bovine albumin (BSA, Sigma, St. Louis, MO/USA), $2 \mathrm{mM}$ EDTA, $0.5 \mathrm{M} \mathrm{Na}_{2} \mathrm{HPO}_{4}$ (pH 7.0) and $0.1 \mathrm{mg} / \mathrm{mll}$ sheared salmon sperm DNA (Boehringer Mannheim GmbH, Mannheim, Germany), to which [32P]dATP labeled probe (see below) was added. After hybridization the blots were washed with saline citrate buffer (SSC, $0.15 \mathrm{M} \mathrm{NaCl}$ and $0.015 \mathrm{M}$ sodium citrate $\mathrm{pH} 7.0$ ) containing $0.1 \%$ SDS. Stringency conditions were optimized for each DNA probe. Autoradiography was performed with RX Fuji rnedical X ray films (Fuji) at $-70^{\circ} \mathrm{C}$ using intensifying screens. 


\section{Probes}

The lamin A/C probe, kindly provided by Dr. F McKeon [32], and the lamin BI probe, a kind gift of Dr. Pollard [35], were labeled with [32P] $\alpha$-dATP (Amersham) by random priming [13] and purified over a Sephadex G50 fine (Pharmacia, Uppsala, Sweden) column. Each hybridization was performed with 50-200 ng probe DNA. A GAPDH probe [15] was used as a control for the amount mRNA loaded onto the gel.

\section{CDNA synthesis and PCR analysis}

The reverse transcriptase (RT) reaction was performed with $25 \mu \mathrm{g}$ of total RNA or $5 \mu \mathrm{g}$ of poly A+ RNA. Samples were incubated for 1.5 hours at $37^{\circ} \mathrm{C}$ in a reaction mixture containing $10 \mu \mathrm{g}$ oligo dT primers (Pharmacia), $1 \mathrm{mM}$ of each dNTP (Pharmacia), 40 units RNAsin (Promega, Madison, WI, USA), $0.01 \mathrm{M}$ dithiothreitol (Sigma) and 600 units MMV reverse transcriptase (Gibco/BRL) in a total volume of $50 \mu \mathrm{l}$. After completion of the RT reaction $5 \mu \mathrm{l}$ of this reaction mixture was used for PCR in a total reaction volume of $50 \mu$, containing $50 \mathrm{mM} \mathrm{KCl}$ (Merck), $10 \mathrm{mM}$ Tris- $\mathrm{HCl}$ pH 8,3 (Merck), $4 \mathrm{mM} \mathrm{MgCl} 2$ (Merck), $0.001 \%$ gelatin, $1 \mathrm{mM}$ of each dNTP (Pharmacia), $1.5 \mu \mathrm{g}$ of primer 1 (sense, 5'-GCCTACCGCAAGCTCTTGGA-3" (Eurogentec, Seraing, Belgium), corresponding to lamin A codon 375-381 (nucleotides 1123-1142, see Fig. $2 \mathrm{~A}$ ) and $1.5 \mu \mathrm{g}$ of primer 2 (antisense, 5'-GGTGAGGAGGACGCAGGAAG-3', lamin A non coding region, nucleotides $2030-2049$ ). This mixture was heated to $95^{\circ} \mathrm{C}$ for 5 minutes, cooled to $80^{\circ} \mathrm{C}$ for 5 minutes and thereafter 0.2 units of Taq polymerase (Super Taq, HT Biotechnology LTD, Cambridge, UK) was added. The mixture was overlaid with $60 \mu 1$ mineral oil (Sigma) heated at $94^{\circ} \mathrm{C}$ for 2 minutes and carried through 30 cycles of denaturation $\left(94^{\circ} \mathrm{C}, 1 \mathrm{~min}\right.$.), annealing $\left(54-58^{\circ} \mathrm{C}, 2 \mathrm{~min}\right.$.) and elongation $\left(72^{\circ} \mathrm{C}, 2 \mathrm{~min}\right.$.), followed by a final extension step of $72^{\circ} \mathrm{C}$ for 10 minutes. PCR products were used for subcloning (see below) or for a second round of PCR. For this latter purpose, samples were first run on $1.5 \%$ agarose gel. Bands at the $800-$ $900 \mathrm{bp}$ level corresponding to the predicted size of products of lamin A and not lamin C cDNA were excised and (electro-)eluted. Next, PCR was performed under identical conditions as described above with primers 3 (sense, 5'-AGCCTGCGTACGGCTCTCAT-3', lamin A codon 525-531, nucleotides 1573-1592) and 4 (antisense, 5'-GCTCCTGAGCCGCTGGCAGA-3', lamin A codons 599-605, nucleotides 1795-1814).

\section{Oligonncleotide hybridization}

PCR products were run on a $2 \%$ alkaline agarose gel [39], blotted onto Hybond $\mathrm{N}+$ (Amersham) and hybridized with ${ }^{32} \mathrm{P}-\gamma$ ATP end-labelled aligonucleotides. 5 -End labelling of 10 pmoles of oligonucleotides was performed using the USB T4 Polynucleotide Kinase system (USB, Cleveland, Ohio) Oligonucleotides comprised primer 3 (see above), hybridizing to a region within exon 9 , and an oligonucleotide complementary to the last 11 bases of exon 9 and the first 11 bases of exon 11 (oligo 5: 5'-CAGTGGGAGCCTTCCCCAGTGG-3'), thus enabling a 
specific hybridization to lamin A CDNA, in which exon 10 is lacking. Hybridization was performed at $46^{\circ} \mathrm{C}$ in $5 x S S P E$ buffer containing $0.3 \%$ SDS. Washes were at $52^{\circ} \mathrm{C}$ in the same buffer. The same blot was first hybridized with primer 3 , stripped and rehybridized with oligo 5 .

\section{Genomic DNA analysis}

DNA was isolated from human leukocytes, human placenta and cell lines GLC-AI and NL-Acl using standard procedures [39]. Purified genomic DNA was subjected to a single round of PCR using either primers 3 and 4 (see above) or primer 3 and primer 6 , 5GAAAAGATTTTTGGCACGG-3; complementary to the sequence in the untranslated region of exon 10. The use of primers 3 and 4 in PCR is supposed to produce a $1405 \mathrm{bp}$. fragment for the lamin $\mathrm{A} / \mathrm{C}$ gene, while primers 3 and 6 will yield a $649 \mathrm{bp}$. fragment for this gene.

\section{Plasmid subcloning, restriction analysis and sequencing}

Two products of 927 and 837 bp resulting from PCR with primers 1 and 2 were subcloned into the pGEM-T vector (Promega) and used to transform E. Coli TGI cells by electroporation. Cloned plasmids were analysed by restriction fragment analysis. The restriction digestions were performed with a combination of the endonucleases Ncol and SstII, or SstI and PstI (Promega). Relevant restriction sites are indicated in Fig. 2A. Cloned fragments of the PCR reaction with primers 1 and 2 were digested with PstI and the fragment from nucleotide 1496 to 1707 was subcloned in pUC 19. Subsequently these fragments were sequenced using the dideoxynucleotide chaim termination method [40] with $1.5-2 \mu \mathrm{g}$ template plasmid using a T7 sequencing kit (Pharmacia).

\section{Two-dimensional gel electrophoresis and immunoblotting.}

Cytoskeletal preparations of cell line GLC-A1 were prepared as described [31] and subjected to non-equilibrium $\mathrm{pH}$ gel electrophoresis [34]. Electrophoresis was performed for $1800 \mathrm{Vh}$ using 2\% Bio-Lyte 3 10 carrier ampholytes (Bio-Rad Laboratories, Hercules, CA/USA). In the second dimension $10 \%$ SDS/polyacrylamide gels were used according to Laemmli [26].

Proteins were immunoblotted onto nitrocellulose and the presence of lamin $\mathrm{A}$ was detected by antibody 133A2 [23] using enhanced chemiluminescence (ECL kit, Amersham, Buckinghamshire, England) as described before [31].

\section{Results}

\section{Immunofluorescence.}

In cell line GLC-A1 an abnormal localization of lamin A has been detected using immunofluorescence microscopy (Fig. 1 A, see also [31]). Instead of a perinuclear localization, as seen for the B-type lamins, nuclear aggregates of lamin $A$ were seen in these cells, when stained with an antibody directed to lamin $A$. In contrast, lamin B2 appears to be organized in a 
perinuclear lamina (Fig. IB) in the same cell line. Another adenocarcinoma cell line GLC-A2 cxpressed a normal fuorescence staining pattern with the lamin $\mathrm{A}$ antibody (fig. 1C)

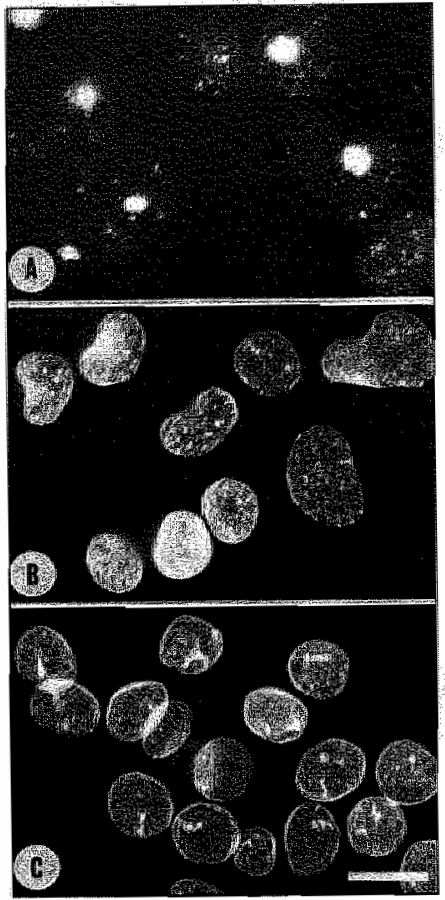

Figure 1. Immunofluorescence of cell line GLC-A1 (Panel $A, B)$ and GLC-A2 (C), using an antibody to lamin A (Panel A,C) or lamin B2 (Panel B). Bar represents $20 \mu \mathrm{m}$

\section{Northern blotting.}

Northern blotting studies, comparing lamin expression in several adenocarcinoma cell lines of the lung revealed that in the cell line GLC-A1 A-type lamin mRNA levels were largely reduced as compared to the other cell lines (Fig. 2). Lamin C mRNA levels in GLC-A1 were much lower than in the other cell lines and the lamin A messenger was barely detectable on Northern blot. No obvious abnormalities in the predicted sizes of the A-type lamin mRNAs were observed.

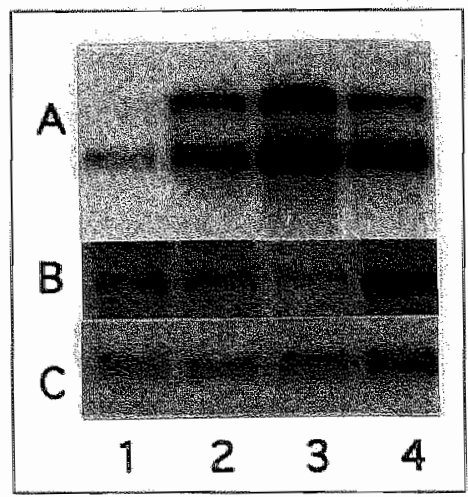

Figure 2. Northern blotting of cell lines GlC-All, GLC-A2, NL-Acl and NCL-Hil25 (lanes 1-4), bybridized with the lamin A probe: (Panel A) Note the reduced expression of A-type lamins in GLC-AI (lane 1). Panel B: lamin B I probe, Panel C: GAPDH probe. 


\section{Detection of a new type of $\operatorname{lamin} A / C$ mRNA}

To examine whether minor mRNA abnormalities could be detected, RT-PCR was performed. Special emphasis was put in the region coding for the carboxy-terminus since the structure of the lamin tail is crucial for correct nuclear assembly. Therefore, we designed primers 1 and 2 (Fig. $3 \mathrm{~A})$, starting at nucleotide $\mathbb{1} 123$ and terminating 55 bases into the $3^{\prime \prime}$ untranslated region of lamin A. Gel electrophoretic analysis of the PCR fragments of GLC-A1 showed two bands of about the predicted $927 \mathrm{bp}$ (Fig. 3B, double arrows). Only one band was found in a control PCR using a lamin $\mathrm{A}$ cDNA clone (not shown). In addition, RT-PCR was performed with primer 1 and primer 6, complementary to part of the $3^{t}$ untranslated region of lamin C mRNA, resulting in a single band around $630 \mathrm{bp}$, as predicted from the known cDNA sequence (data not shown). Subcloning of the two PCR-products using primers 1 and 2 showed that one band was of the correct size (927 nucleotides), whereas the other product was approximately 100 bp shorter (Fig. 3B). Restriction fragment length analyses of the latter product showed that fragments containing exons 9,10 and 11 were reduced by approximately $100 \mathrm{bp}$ (Fig. 3, Panel C, arrows). Sequencing of both the normal and the short products revealed that in both products the nuclear localization signal and the CaaX motif were present (not shown), but that the 90 bp of exon 10 were missing in the short product. The predicted mRNA structure of this shortened lamin A, which we suggest to designate lamin $A \Delta 10$, is outlined in Fig. 3D. To map which region is missing from the normal lamin A, we have included a schematic drawing indicating the most important characteristics of lamin A (Figure 3E). The amino acid region encoded by exon 10 is located in the carboxy-terminal region, which forms the tail of the protein. This region contains a stretch of amino acids rich in aspartic acid and glutamic acid (E/D), followed by a sequence of four consecutive histidines ( $\mathrm{H} 4)$.

\section{Presence of lamin $\mathrm{A} \Delta 10$ in other cell types}

To determine whether lamin $A \triangle 10$ was unique for a single cell line, nested PCR was performed using primers 1 and 2, followed by PCR with primers 3 and 4 (Fig. 3A) on cDNA of several lung cancer cell lines, other carcinoma cell lines and a neuroblastoma cell line. In addition, CDNA derived from tissues of normal colon and adenocarcinomas of the lung were examined (Figs. 4A and B). PCR of plasmid lamin A cDNA yielded the expected 242 bp product of lamin $A$, whereas the lamin A $\triangle 10$ plasmid cDNA yielded a fragment of 152 bp (Fig. 4A, lanes 1 and 2). Analysis of cDNA from different sources on ethidium bromide stained agarose gels (A and $B$, upper panels) showed in addition to the expression of the 242 bp product a band of 152 bp of variable intensity in most samples. The identity of the stained bands was confimed by an alkaline agarose gel, and PCR products were hybridized to the end-labelled primer 3 (Fig. 4A and $B_{*}$ middle panels) or oligo 5 (Fig. $4 \mathrm{~A}$ and $\mathrm{B}$, lower panels). Hybridization to primer 3 showed that lamin $A$ and lamin $A \Delta 10$ occur in all samples, except for the controls (lanes 1,2 and 7 of panel $A)$. However, the ratio of lamin $A / A \Delta 10$ expression showed a large variation amongst samples. Hybridization with oligo 5 allowed the positive identification of lamin $A \Delta 10$ in all 
samples tested, except for the two controls in panel A (lanes 2 and 7 ). No detectable crosshybridization with nomal lamin $\mathrm{A}$ was observed.

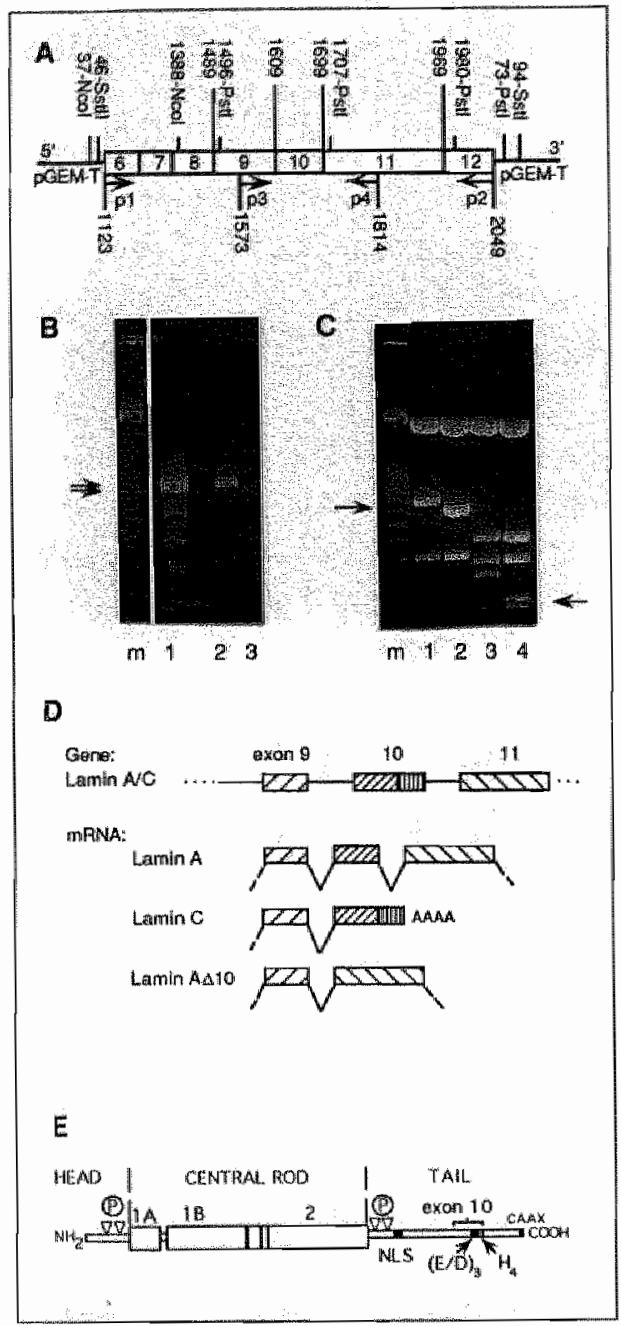

Figure 3. Panel A: Region of interest of the lamin A cDNA. Numbering started from nucleotide 1 . Upper numbers indicate restriction sites and exon boundaries of interest. Lower numbers correspond to first nucleotide recognized by primers 1 through 4 (p1-p4). Numbers in boxes correspond to exon numbering according to Lin and Worman [28].

Panel B: Agarose gel electrophoretic analyses of PCR products resulting from primers 1 and 2 on cell line GLC-AI (lane 1). Note the presence of two bands with sizes between 800 and $900 \mathrm{bp}$ (double arrow). Excision and purification of each band, followed by electrophoresis, resulted in two bands with distinct molecular weights (lanes 2 and 3 ).

Panel C. Restriction fragment length analysis of the normal lamin A (lanes 1 and 3) and lamin AA10 (lanes 2 and 4) using SstI and Ncol (Lanes 11 and 2), or PstI and SstII (lanes 3 and 4). Note that after digestion with the first set of restriction enzymes the fragment of $704 \mathrm{bp}$ (lane I) is shortened in lamin A $\Delta 10$ (lane 2, arrow), and after digestion with the second set of restriction enzymes the expected fragment of $211 \mathrm{bp}$ is shortened by approximately 100 bp (compare lanes 3 and 4, arrow). These results indicate a deletion between the PstI sites of exon 9 and 11 .

Panel D. Structure of the three different mRNAs resulting from alternative splicing of the lamin $A / C$ gene.

Panel E. Schematic diagram (adapted from [33]) showing the impact of the missing exon 10 in lamin $A$ at the protein level for lamin A AlO. P, phosphorylation site; NLS, nuclear localization signal; (E/D) 3, triple repeat of glu and asp: $\mathrm{H} 4 \mathrm{a}$ sequence of four histidines; CAAX, motif for isoprenylation of lamin $\mathrm{A}$.

\section{Genomic DNA analysis}

To investigate the possibility that lamin $A \Delta 10$ is a transcript from an as yet unidentified lamin A-like gene, PCR was performed on genomic DNA samples from carcinoma cell lines and normal tissues. Figure 5 shows that DNA from placenta, lleukocytes, and from cell lines GLC$\mathrm{Al}$ and NL-Acl all show a single band at the predicted levels of 649 and $1409 \mathrm{bp}$. 

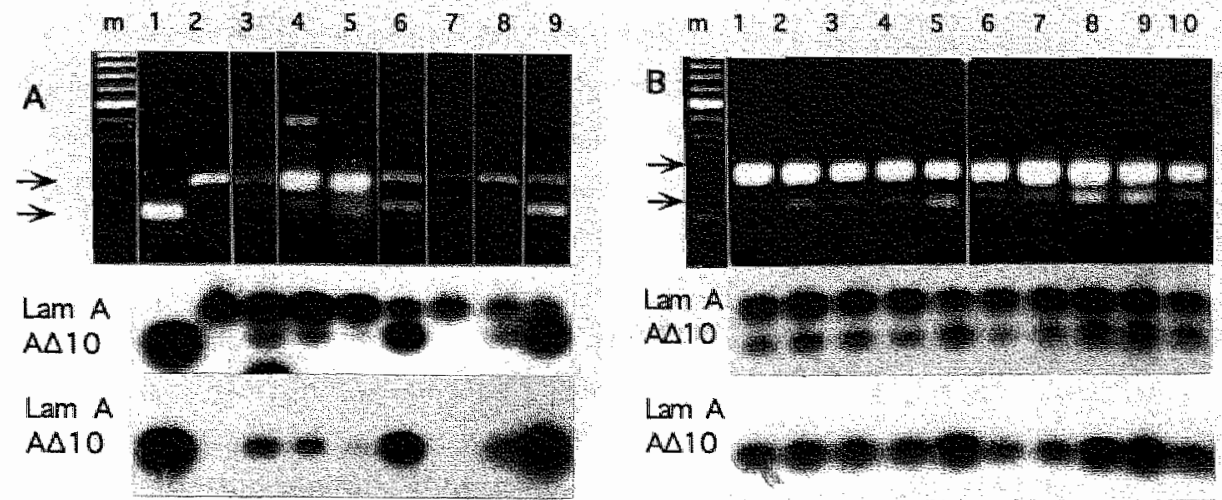

$\operatorname{Lam} A$

$A \triangle 10$

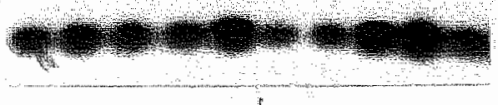

Figure 4. Analysis of PCR products for the presence of lamin A and lamin AD10 CDNA. PCR using primers 1 and 2 was followed by a PCR using primers 3 and 4 in all cases, except for cell lines LCLC-103H and NCI-H125, which were subjected to a single round of PCR-reactions using primer 3 and 4 .

A: cDNA from lamin A $\triangle 10$ (lane 1), mormall lamin A (lane 2), GLC-Al (lane 3), LCLC-103 (lane 4), NCl-H125 (lane 5), NCI-H23 (lane 6), normal lamin A (lane 7), GLC-A2 (lane 8), and NL-Acl (lane 9)

B: cDNA from cell the T24 (lane 1), T47D (lane 2), NCI-H460 (lane 3), MR65 (lane 4), SK-N-SH (lawe 5), normal colon (lane 6), and four different adenocarcinomas of the lung (lames 7-10).

The upper panel shows ethidium bromide stained agarose gels with beight of the expected lamin $A$ and lamin $A \Delta 10$ bands denoted by arrow.

Middle panel: hybridization with ${ }^{32} \mathrm{P}$ end-labeled primer 3, hybridixing to both lamin $\mathrm{A}$ and lamin ADIO cDNA.

Lower panel: hybridization with ${ }^{32} \mathrm{P}$ end-labeled oligonucleotide 5, specifically hybridizing to lamin AA10 CDNA only. $\mathrm{m}=100$ bp ladder markers

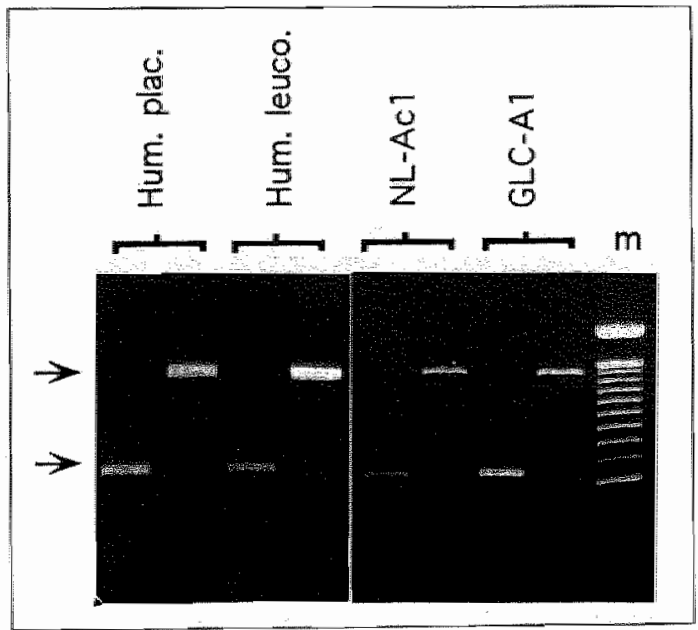

Figure 5. PCR-based analysis of genomic DNA of human placenta, human leukocyles, and cell lines NL-Acl and GLC-A1. In the first lane for each sample primers 3 and 6 were used and in the second lane primers 3 and 4 . Arrows indicate the level of the 1404 bp band (upper) and 649 bp. fragment (lower arrow). Note that in $100 \mathrm{bp}$. ladder markers lane $(\mathrm{m})$ bands below $500 \mathrm{bp}$ are barely visible. 


\section{Two-dimensional immunoblotting}

Two-dimensional immunoblotting of GLC-A1 using the antibody to lamin A showed the presence of a lamin $\mathrm{A}$ doublet at the predicted position (approximately $70 \mathrm{kDa}, \mathrm{pl} 7.0$, Figure 6). In addition, however, a clear protein spot recognized by this antibody was observed with a molecular mass. of around $65 \mathrm{kDa}$ and a pI value that was shifted approximately one $\mathrm{pH}$ unit to the basic site (arrow). No such protein spot was observed in immunoblots of cell line NCI-H125 (not shown).

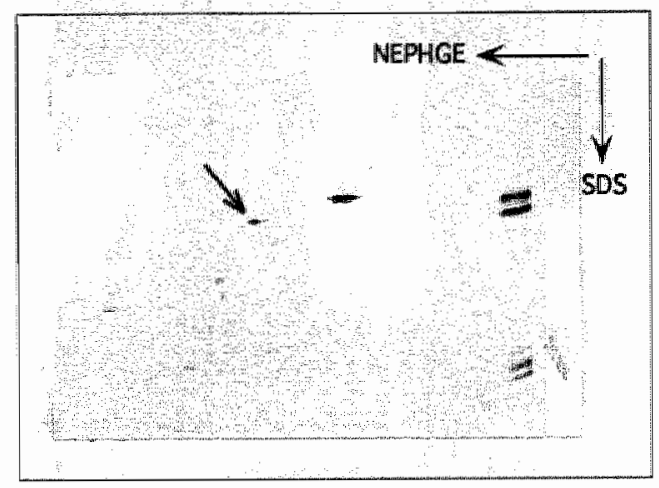

Figure 6. Immunoblot detection of lamin $A$ and lamin $A \Delta 10$ after two-dimensional non-equilibrium gel electrophoresis. Nate the presence of normalsized lamin A with the expected pI of around 7.0 , while an additional spot with lower molecular weight and more basic pl is also found (arrow).

\section{Discussion}

In this paper we describe the widespread occurrence of an as yet unidentified splicing product of the lamin $\mathrm{A} / \mathrm{C}$ gene, which we designate lamin $\mathrm{A} \Delta 10$, since exon 10 is absent in this transcript. In a previous report we have demonstrated the presence of an A-type lamin protein, which forms intranuclear aggregates in cell line GLC-A1 [31]. In contrast to normal, perinuclear Atype lamins these intranuclear aggregates could be largely extracted by Triton X-100, indicating that these aggregates are not assembled into the nuclear matrix [2]. This abnormal nuclear localization of the protein suggested a distortion in the mRNA region coding for the carboxyterminal part of the protein, since this part is known to govern targeting to the nucleus by the nuclear localization signal, and the CaaX-motif, the isoprenylation site of (pre)lamin A, which is essential for a proper incorporation into the nuclear lamina $[20,22,29]$. The structure of this region of the mRNA was examined by RT-PCR. Sequencing showed that the correct sequence for both motifs was present in the cDNA examined. However, gel analysis showed the presence of an additional shortened PCR product. Restriction fragment analysis, followed by sequencing showed that in the otherwise normal lamin A CDNA sequence exon 10 was lacking. Therefore we designated this novel protein lamin $A \Delta 10$.

Hybridization with oligonucleotides hybridizing to either lamin $\mathrm{A} \Delta 10$ alone or both lamin $\mathrm{A} \Delta 10$ and lamin $A$ showed that lamin $A \Delta 10$ is extensively expressed in a variety of tissues, since all samples examined were positive. In addition, we found that the ratio of expression levels of 
lamin A $\Delta 10$ and lamin A varied significantly between samples. Especially in the lung cancer cell lines the relative concentration of the lamin A $\Delta 10$ can be high. Similar differences in the expression ratio were observed between lamin $A$ and lamin $C$ at both protein and mRNA level $[6,31]$. Which mechanism is involved in regulating the relative expression of the three alternative splicing products of the lamin $\mathrm{A} / \mathrm{C}$ gene, remains to be elucidated. Preliminary studies show that different cultures from the same cell line can express different ratios of lamin A to lamin $\mathrm{A} \Delta \mathrm{ID}$, which might be explained by differences in cell density.

A positive identification of the protein encoded by the lamin A $\triangle 10$ mRNA is not yet possible since no antibody specific for this product is available. Therefore we cannot yet state that the abnormal lamin A expression patterns as seen in GLC-AI are represented by the lamin A $\triangle 10$ protein. However, evidence that indeed lamin A 10 mRNA is translated into protein comes from one-dimensional [31] and two-dimensional gel electrophoresis followed by immunobloting studjes. Computer assisted calculation of the pl of the lamin A $\triangle 10$ protein indicates a value of 8.58 as compared to a theoretical pI of 7.4 for nomal lamin A (PepStats, Caos/CAMM, Nijmegen, The Netherlands). Furthermore, a deletion of 30 amino acids should give rise to an approximately $3.5 \mathrm{kDa}$ smaller protein. In one dimensionall gel electrophoresis a protein smaller than lamin $A$ was detected with the lamin $A$ antibody $133 \mathrm{~A} 2$ [23, 31]. The additional protein spot detected in two-dimensional immunoblotting is significantly more basic (approx. $1 \mathrm{pI}$ value) and about $5 \mathrm{kDa}$ smaller than the normal lamin and fulfils the predicted electrophoretic characteristics of lamin $A \Delta 10$. The possibility that the lamin $A \Delta 10$ is a result from a translocation or deletion of lamina $\mathrm{A} / \mathrm{C}$, or is a transcript from a closely related as yet unknown gene has been examined. A previous study suggests that such a gene might exist [24]. Our PCR analysis within the region between exon 9 and 11 of genomic DNA provides no evidence for an additional gene. Thus, a single gene is responsible for lamins $A, A \Delta 10$ and $C$. The possibility that lamin $A \Delta 10$ is the result of a mutated lamin $A / C$ gene has been eliminated by our finding that lamin $A \Delta 10$ occurred in all samples examined.

It is feasible that the presence of lamin A $\triangle 10$ mRNA has been overlooked in previous studies because of its relatively low abundance as compared to lamins $A$ and $C$ expression. $A$ cell line with a low expression of normal lamins $A$ and $C$ has enabled us to identify this lamin $A \Delta 10$ mRNA by RT-PCR. The same holds true for protein analyses, in which lamin ADIO is easily overlooked, especially because of the relatively large pI shift. Furthermore, only in a cell expressing low levels of the normal A-type lamins an aberrant lamin can induce visible effects on the structure of the lamina. Apparently, in GLC-AL the concentration of lamin A $\triangle 10$ can reach relative high levels resulting in a distorted nuclear phenotype. The lamin $A \Delta 10$ protein may be localized in the nuclear inclusions seen in this cell line [31]. This would be in agreement with transfection studies [29] which showed that different types of nuclear distortions can be induced with constructs of lamin A containing carboxy-terminal deletions either starting at codon 456 (within exon 7) or starting at codon 550 (within exon 10). An altered localization of the lamin $A \Delta 10$ protein is likely, since the deletion of the first part of exon 10 results in loss of 
an acidic domain (7 consecutive Glu or Asp residues) and a poly-histidine domain. This is bound to have impact on the interaction of lamin A.A10 with other nuclear components. Although suggested, it is not yet shown that this particular highly charged region is involved in chromatin binding [41]. If the protein extracted by Triton $X-100$ from GLC-A1 indeed represents lamin $A \triangle 10$, then it is possible that this protein is not or only partially bound to the nuclear matrix and may be involved in other intranuclear interactions.

\section{Acknowledgements}

The authors wish to thank Dr. Y Raymond (Montreal, Canada) and E. Birgitte Lane (Dundee, UK) for providing antibodies, Dr. F McKeon (Boston, MA, USA) and Dr. C Glass (La Jolla, CA, USA) for allowing the use of the lamin A and B1 probes, and Dr. G. Bepler (Durham, NC, USA), Dr. L. de Leij (Groningen, The Netherlands) and Dr. D. Carney (Dublin, Ireland) for providing cell lines used in this study.

\section{References}

[1] Bepler, G., A. Koehler, P. Kiefer, K, Havemann, K. Beisenherz, G. Jaulues, C. Gropp, M. Haeder: Characterization of the state of differentiation of six newly established human non-small-cell lung cancer cell lines. Differentiation 37, 158-17\(1988).

12] Berezney, R. D.S. Coffey: Biochem. Biophys. Res. Commun. 60, 1410-1417 (1974).

[3] Biedler, J.L. . L. Helson, B.A. Spengler" Morphology and growth tumorigenicity, and cytogenetics of human neuroblastoma cells in continuous culture. Cancer Res. 33, 2643-2652 (1973).

[4] Bridger, J.M., I. Kill, M. OFarrell, C.J. Hutchison: Internal lamin structure within Gl nuclei of human dermal fibroblasts. I. Cell Sci. 104, 297-306 (1993).

[5] Broers, J.L.W., M. Klein Rot, T. Oostendorp, G. Bepler, L. de Leij, D.N. Carney, G.P. Vooijs, F.C.S. Ramaekers: Spontaneous changes in intermediate fulament protein expression patterns in lung cancer cell. lines. J. Cell Sei. 91, 91-108 (1988).

[6] Broers, J.L.V., Y. Raymond, M. Klein Rot, H. Kuijpers, S. Wagenar, F.C.S. Ramaekers: Nuclear A-type lamins are differentially expressed in human lung cancer subtypes. Am. J. Pathol. 143, 21 1-220 (1993).

[7] Brower, M., D.N. Caney, H.K. Oie, A.F. Gazdar, J.D. Minna: Growh of cell hines and clinical specimens of huminn non-small cell lung cancer in a serum-free defined medium. Cancer Res 46, 798.806 (1986).

[8] Cance, W.G., N. Chaudhay, H.J. Woman, G. Blobel, C. Cordon Cardo: Expression of the nuclear lamins in normal and neoplastic humant tissues. J. Exp. Clin. Cancer Res. 11, 233-246 (1992).

191 Carnoy, D.N. A.F. Gazdar, G. Bepler, J.G. Guccion, P.J. Marangos, T.W. Moody, M.H. Zweig, J.D. Minna: Establishmert and identification of small cell lung cancer cell lines having classic and variant features. Cancer Resi 45, 29l3-2923(1985).

[10] Chingwin, J.M. A.E. Przybyla, R.J. Macdonald, W.J. Ruatter." Isolation of biologically active ribonucleic acid from sounces enriched in ribonuclease. Biochemistry 18,5294-5299 (1979).

IIII Davis, L., G., M.D. Dibner, J.F. Battey: Basic methods in molesular biology. pp. 130-135. Elsevier. Amsterdani 1986.

[12] De Leij, L., P.E. Postmus, C.H.C.M. Buys, J.D. Elema, F. Ramaekers, S. Poppema, M. Brouwer, A. Y, van. der Veen, G. Mesander, T.H. The: Characterization of three new, "variant-type" cell lines derived from small cell carcinoma of the lung. Cancer Res. 45, 6024-6033 (1985).

[13] Feinberg, A.P., B. Vogelstein: A technique for radiolabeling DNA restriction endonuclease fragments to high specifie actiwity. Anal. Biochem. $132,6-13$ (1983).

114] Fisher, D.Z., N. Chaudhary, G. Blobel: cDNA seguencing of nuclear lamins $A$ and $C$ reveals primary and secondary structural homology to intermediate filament proteins. Proc. Natl. Acad. Sci. USA 83, 6450-6454 (1986). 
[15] Fort, P., L. Marty, M. Piechaczyk, S.E. Sabrouty, C. Dani, P. Jeanteur, J.M. B lanchard: Various rat adult tissues express only one major $\mathrm{mRNA}$ species from the glyceraldehyde-3-phosphate-dehydrogenase multigenic family. Nucleic Acids Res. 13, 1431 (1985).

[16] Freake, H.C., C. Marcocci, J. Itwasaki, I. Maclntyre: 1,25-dihydroxywitamin D3 specifically binds 10 . human breast cancer cell line (T47D) and stimulates growth. Biochem. Biophys. Res. Commun. 101, 1131$1138(1981)$.

[17] Furukawa, K., Y. Hotka: cDNA cloning of a germ cell specific lamin B3 from mouse spermatocytes and analysis of its function by ectopic expression in somatic cells. EMBO J. 12, 97-106 (1993),

[18] Gazdar, A.F., P.A. Bunn, J.D. Minna, S.B. Baylin: Origin of human small cell lung cancer. Science 229, 679-680 (1985).

[19] Gerace, L., B. Burke: Functional organization of the nuclear envelope. Annu. Rev. Cell Biol. 4, 335-374 (1988).

[20] Heitlinger, E., M. Peter, A. Lustig, W. Villiger, E.A. Nigg, U. Aebi: The role of the head and tail domain in lamin structure and assembly - analysis of bacterially expressed chicken lamin-A and trubicated B2-lamins. $\mathrm{J}$. Struct. Biol. 108, 74-91 (1992).

[21] Höger, T.H., K. Zatloukal, I. Waizenegger, G. Krohne: Characterization of a second highly conserved Btype lamin present in cells prewiously thought to contain only a single B-type lamin. Chromosoma 99, 379$390(1990)$.

[22] Holtz, D., R. Tanaka A, J. Hartwig, F. Mckeon: The CaaX motif of lamin A functions in conjunction with the nuclear localization signal to target assembly to the nuclear envelope. Cell $59,969-977$ (1989).

[23] Hozák, P., M.-J. Sasseville, Y. Raymond, P.R. Cook: Lamin proteins form an internal nucleoskeleton as well as a peripheral lamina in human cells. J. Cell Sci. 108, 635-644 (1995).

[24] Kamat, A.K., M. Rocchi, D.I. Smith, O.J. Miller: Lamin A/C gene and a related sequence map to human chromosomes 1q12.1-q23 and 10. Somat. Cell Mol. Genet. 19, 203-8 (1993).

[25] Krohne, G., R. Benavente: The nuclear lamins. A multigene family of proteins in evolution and differentiation. Exp. Cell Res, 162, 1-10 (1986).

[26] Laemmli, U.K.: Cleavage of structural proteins during the assembly of the head of bacteriophage T4. Nature 227, 680-685 (1970).

[27] Lehrach, H., D. Diamond, J.M. Wozney, H. Boedtker: RNA molecular weight determinations by gel electrophoresis under denaturating conditions, a critical reexamination. Biochemistry 16, 4743-4751 (1977).

[28] Lin, F., H.J. Worman: Structural organization of the human gene encoding nuclear lamin $A$ and nuclear lamin C. J. Biol. Chem. 268, 16321-16326 (1993).

[29】 Loewinger, $L_{\text {. }}$ F. McKeon: Mutations in the muclear lamin proteins resulting in their aberrant assembly in the cytoplasm. EMBO J. 7, 2301-2309 (1988).

[30] Luster, W., C. Gropp, K. Havemann: Peptide hormone synthesizing lung turnor cell lines Establishment and first characterization of biosynthetic products. Acta Endocr. 253 (Suppl), 24-25 (1983).

[31] Machiels, B.M., J.L.V. Broers, Y. Raymond, L. de Ley, H.J.H. Kuijpers, N.E.H. Caberg, F.C.S. Ramackers: Abnormal A-type lanin organization in a human lung carcinoma cell line. Eur. J. Cell Biol. 67, 328-335 (1995).

[32] McKeon, F.D., M.W. Kirschner, D. Caput : Homologies in both primary and secondary structure between nuclear envelope and intermediate filament proteins. Nature 319, 463-468 (1986).

[33] Nigg, E.A.: The nuclear envelope. Curr. Opin. Cell Biol. 1, 435-440 (1989).

[34] O'Fartel, P.Z., H.M. Goodman P.H. O'Farrell: High resolution two-dimensional gel electrophoresis of bassic as well as acidic proteins. Cell 12, 1133-1142 (1977).

[35] Pollard, K.M. E.K.L. Chan, B.J. Grant, K.F. Sullivan, E.M. Tan, C.A. Glass: In witro posttranslational modification of lamin B cloned from a human T-cell line. Mol. Cell. Biol. 10, $2164-2175$ (1990).

[36] Rigby, C.C., L.M. Franks: A human tissue culture cell line from a transittional turmour of the urinary bladder: growth, chromosome pattern and ultrastructure. Br. J. Cancer 24, 746-754. (1970).

[37] Röber, R.-A., H. Sauter, K. Weber, M. Osborn: Cells of the cellular immune and hemopoietic system of the mouse lack lamins A/C: distinction versus other somatic cells. J. Cell Sci. 95, 587-598 (1990).

[38] Röber, R.A., K. Weber, M. Osborn: Differential liming of nuclear lamin A/C expression in the variouss organs of the mouse embryo and the young animal: a fevelopmental sudy. Development $105,365-378$ (1989).

[39] Sambrook, J., E.F. Fritsch, T. Maniatis: Molecular cloning: A laboratory manual. pp. Cold Spring Harbor Laboratory Press. Cold Spring Harbor N.Y. 1989.

[40] Sänger, F., S. Nicklen, A.R. Coulson: DNA sequencing with chain-terminating inhibitors. Proc. Natl. Acad. Sci. USA 74, 5463-5467 (1977).

[41] Taniura, H., C. Glass, L. Gerace: A chromatin binding site in the tail domain of nuclear lamins that interacts with core histones. J. Cell Biol. 131, 33 44 (1995).

[42] Worman, H.J., L. Lazaridis, S.D. Georgatos: Nuclear lamina heterogeneily in mammalian cells. đ. Biol. Chem. 263, 121:35-12441 (1988). 


\section{Chapter 7}

Lamin $\mathbf{A}$ is not required for incorporation of lamin $\mathrm{C}$ in the nuclear lamina as demonstrated by GFP-tagged lamins

Barbie M. Machiels, Guillaume J.J.M. van Eys, Helma J.H. Kuijpers, Jos L.V. Broers, Frans C.S. Ramaekers 


\section{Summary}

Chimeric proteins of A-type lamins and green fluorescent protein (GFP) were used to study the mutual dependence of A-type lamins for incorporation into the nuclear lamina, and to elucidate the localization of lamin $A \Delta 10$, a recently described alternative splicing product of the lamin A/C gene. Two distinct cell lines, CHO and GLC-A1, were transfected with cDNA constructs encoding fusion proteins of lamin A-, lamin $\mathrm{C}$ - and laminA $\triangle 10-$ GFP. CHO cells express high levels of endogenous A-type lamins, while the GLC-Al cells express low levels of A-type lamins of which Iamin A does not seem to associate with the nuclear membrane, but assembles into intranuclear aggregates. Fusion of GFP to the amino-terminus of A-type lamins had no effect on their localization and incorporation into the lamina as proven by confocal immunofluorescence microscopy and resistance to extraction with detergents. None of the lamin-GFP proteins did incorporate into the intranuclear aggregates in GLC-Al, but all localized in the nuclear envelope, regardless of the expression levels. Also lamin $C$, which is not isoprenylated at its carboxy-terminus and therefore has no site for targetting and anchorage to the nuclear envelope, displays proper incorporation into the lamina. Contrary to previous suggestions (Loewinger and McKeon (1988) EMBO J., 7: 2301-2309) we conclude that incorporation of lamin $\mathrm{C}$ into the nuclear Jamina is not dependent on the presence of lamin $\mathrm{A}$. Removal of exon 10 by alternative splicing has also no effect on the incorporation of A-type lamins in the nuclear lamina.

\section{Introduction}

Lamins form the major constituents of the nuclear lamina. Two main types of lamins can be distinguished, i.e. A-type lamins and B-type lamins. While lamins B1 and B2 are encoded by distinet genes [1,37], A-type lamins, lamins A, A $\Delta 10$ and C, arise from one gene by alternative splicing $[11,23,29]$. A-type lamin expression is differentiation dependent, with absence from for instance embryonic cells $[12,20,34]$, cells of several epithelia [3] and spermatogonia [28], and presence in many other cell-types $[3,5]$. Recently, we described a new splicing product of the $\operatorname{lamin} \mathrm{A} / \mathrm{C}$ gene, which is identical to lamin $\mathrm{A}$ except for exon 10 , which is missing in the newly described product. The new protein was therefore designated lamin A $\Delta 10$ and is present in many cell lines and human tissues [29].

A number of authors have indicated that isoprenylation of lamin A, and presumably also of lamin $A \Delta 10$, is required for proper incorporation into the lamina $[21,26]$. Lamin $C$ does not contain a site for isoprenylation, and has consequently no site for targetting and anchorage to the nuclear envelope. It has been suggested that lamin $\mathrm{C}$ needs association with lamin $\mathrm{A}$ for proper incorporation into the lamina [24], and that lamins $A$ and $C$ are expressed in a 1/1 ratio [13]. CHO and GLC-A1 cells were used for transfection with cDNA fusion constructs of lamins and green fluorescent protein (GFP) to study the mutual dependence of A-type lamin expression on 
their incorporation into the lamina. CHO cells express high levels of endogenous A-type lamins, but GLC-A 1 cells express very low levels of lamin $A$ and higher levels of lamin $C$, which are however still low as compared to other cell lines examined [27].

Wild type GFP and several mutants displaying brighter emissions $[9,14]$ thave been expressed and detected by their fluorescent properties in bacteria [6], yeast [33], plants [8], and mammalian cells [7, 43]. GFP requires no substrates, cofactors or other proteins to fluoresce [6] and its CDNA is relatively short, making it a convenient reporter gene [7]. Chimeric proteins of GFP with several distinct target proteins have shown their usefuiness for localization and trafficking studies in a variety living cells $[10,25,35,38]$, since GFP appears not to impair the function of GFP-tagged target proteins [30,36].

Transfection assays of lamin A-GFP, lamin C-GFP and lamin ADIO-GFP in GLC-AI allowed us to address the following two questions: (1) do A-type lamins show mutual dependence for their incorporation into the nuclear lamina, and (2) does lamin A $\Delta 10$ locallize at the nuclear membrane.

\section{Materials and Methods}

\section{Plasmids}

Lamin A-cDNA, kindly provided by Dr. F, McKeon [31], was cloned to the $3^{\prime}$ end of GFP in the mammalian expression vector pS65T-CI (Clontech Laboratories Inc., Palo Alto, CA/USA) using the SstII and BamHI sites, generating pS65T-lamA. Lamin A $\triangle 10-\mathrm{cDNA}$ was constructed by replacement of the 344 bp lamin A BsiWI/BstEII fragment by the 254 bp lamin A $\Delta 10$ BsiWI/BstEII fragment, obtained by BsiWI and BstEII digestion of a subcloned 837 bp RT-PCR

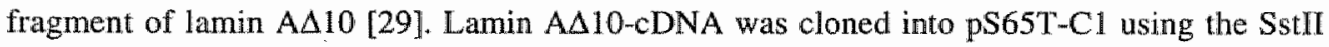
and BamHI sites, generating pS65T-lamA $\Delta 10$.

pS65T-lanC was generated by replacement of the 3' BsiW//BamHI fragment of pS65T-Lam.A, encoding part of exon 9 and exon 10,11 and 12 of lamin $A$, by the $3^{\prime \prime}$ end of lamin $C$. The $3^{\prime}$ end of lamin $C$ was obtained by reverse transcription [29], followed by two rounds of PCR. In the first round of PCR primer A22 (sense, 5'-GCCTACCGCAAGCTCTTGGA-3', corresponding to nt 1123-1142 of lamin $A$ and $C_{\text {; }}$ Eurogentec, Seraing, Belgium) and primer $X 37$ (antisense, 5" TGAAAAGATTTTTGGCACGG-3', corresponding to nt 1779-1798 of the untranslated region of lamin C; Eurogentec), followed by a second round of PCR with primer Aprl (sense, 5'AGCCTGCGTACGGCTCTCAT-3'; BsiWI site underlined; corresponding to nt 1573-1592 of lamin $A$ and $C$; Eurogentec) and primer Bar30 (antisense, 5TATAGGATCCCGGCCTCAGCGGCGGCTACC-3"; BamHI site underlined; the 3 ' 20 bases are complementary to nt 1705-1724 of lamin C, the 5'10 bases are non-complementary, but contain a BamHI site for cloning; Gibco Life Technologies Ltd., Paisley, Scotland). The BsiWI and BamHI sites were used for cloning of the 3' lamin C PCR product into pS65T-IamA, resulting in $\mathrm{pS65T}$-lamC. 


\section{Cell culture and transfections}

CHO cells were grown on HAM's F12 medium (ICN Biomedicals Inc., Costa Mesa, CA/USA) supplemented with 10\% foetal calf serum (Gibco Life Technologies Ltd.) and $2 \mathrm{mM} \mathrm{L-glutamin.}$ GLC-A1, a cell line derived from an adenocarcinoma of the lung, was grown on RPMI (ICN Biomedicals Inc) containing $2 \mathrm{~g} / \mathrm{NaHCO}_{3}$ supplemented with $10 \%$ newborn calf serum (Gibco Life Technologies Ltd.) and $2 \mathrm{mM} \mathrm{L-glutamin.} \mathrm{Cell} \mathrm{cultures} \mathrm{were} \mathrm{maintained} \mathrm{in} \mathrm{an} \mathrm{incubator} \mathrm{at}$ $37^{\circ} \mathrm{C}$. For transfections cells were grown to $25-30 \%$ confluency in 6 well plates. A mixture of 2.5 $\mu \mathrm{g}$ plasmid DNA, Hepes $20 \mathrm{mM}$ and DOTAP (Boehringer Mannheim GmbH, Mannheim, Germany) was added to $2.5 \mathrm{ml}$ culture medium, according to the manufacturers specifications. The cells were grown overnight in the DOTAP/DNA containing culture medium. The medium was then replaced and after 6 hours geneticin (Gibco Life Technologies Ltd.) was added to a final concentration of $500 \mu \mathrm{g} / \mathrm{ml}$. Transfected $\mathrm{CHO}$ cultures were subcloned and further maintained in geneticin containing medium in an incubator at $30^{\circ} \mathrm{C}$. Transfected GLC-A1 cultures were not subcloned, and maintained on geneticin containing medium at $37^{\circ} \mathrm{C}$, and were placed at $30^{\circ} \mathrm{C} 2$ or 3 days before handling.

\section{Antibodies}

The following mouse monoclonal antibodies were used in this study:

- LN43 (IgG1), recognizing lamin B2 and not cross reacting with lamin B1 or A-type lamins [2]. LN43 was used as undiluted culture supernatant and will be referred to as the lamin B2 antibody.

- 41CC4 (IgM), recognizing lamins $A$ and $C$ and not reacting with human B-type lamins, will be referred to as lamin $\mathrm{A} / \mathrm{C}$ antibody [4] and was used as undiluted culture supernatant.

- R27 ( $\operatorname{IgM}$ ), recognizing lamins $A$ and $C$ was used as undiluted culture supernatant in immunoblotting [44].

- 133A2 (IgG3) was a kind gift of Dr. Y. Raymond (Montréal, Canada). It was raised against the carboxy-terminus of 98 amino acids present in lamin $\mathrm{A}$ and absent from lamin $\mathrm{C}$. This antibody recognizes lamin A, reacting with the epitope consisting of amino acids 598-611 [19] and will be referred to as the lamin A antibody. Antibody 133A2 (mouse ascitis) was diluted 1:2500 for immunofluorescence and 1:1000 for immunoblotting.

\section{Indirect immunofluorescence technique}

The indirect immunofluorescence assay was applied to cell cultures that were grown on coverslips for several days at $30^{\circ} \mathrm{C}$. After washing in phosphate buffered saline (PBS, containing $8 \mathrm{~g} / \mathrm{NaCl}, 0.2 \mathrm{~g} / \mathrm{KCl}, 1.15 \mathrm{~g} / 1 \mathrm{Na}_{2} \mathrm{HPO}_{4}$ and $0.2 \mathrm{~g} / 1 \mathrm{KH}_{2} \mathrm{PO}_{4}$ at $\mathrm{pH}$ 7.4) the cells were either immediately fixed, or first detergent extracted (see below) and than fixed in methanol $\left(-20^{\circ} \mathrm{C}\right.$ for 5 seconds), followed by acetone (room temperature, 3 times five seconds) and air dried. Cells were then incubated with the primary antibody for 30-45 minutes, and after several washes with PBS, incubated with Texas Red-conjugated goat anti-mouse Ig (1:80, Southern Biotechnology 
Associates; SBA/TK; Birmingham, ALUSA) for $30-45 \mathrm{~min}$, or with Texas Red conjugated goat anti-mouse IgM (diluted 1:80, SBA/TTK). Thereafter, cells were washed in PBS, mounted in $90 \%$ glycerol containing $0.02 \mathrm{M}$ Tris $\mathrm{HCl}$ pH $8.0,0.002 \% \mathrm{NaN}_{3}, 2 \% 1,4$ diazabicyclo (2,2,2)-octane (DABCO; Merck, Darmstadt, Germany) and $0.5 \mu \mathrm{g} / \mathrm{ml} 4,6$ diamino-2 phenylindole (DAPI; Merck) for DNA staining. Immunofluorescence micrographs were taken with an automatic camera using Kodak 400 ASA Tri-X pan film.

\section{Preparation of nuclear matrices}

Cells grown on coverslips were rinsed three times 5 mimutes at $0^{\circ} \mathrm{C}$ with buffer containing 130 $\mathrm{mM} \mathrm{NaCl}, 5 \mathrm{mM} \mathrm{KCl}, 7.5 \mathrm{mM} \mathrm{MgCl}, 0.5 \mathrm{mM}$ phenylmethylsulphonyl chloride (PMSC, Merck) and $5 \mathrm{mM}$ N-ethylmaleimid (NEM, Sigma, St. Louis, MO/USA). Then the cells were submerged in buffer containing $10 \mathrm{mM}$ Tris-HCl pH 7.4, $10 \mathrm{mM} \mathrm{NaCl}, 1.5 \mathrm{mM} \mathrm{MgCl}, 0.5 \mathrm{mM}$ PMSC, $5 \mathrm{mM} \mathrm{NEM}$ and $300 \mathrm{mM}$ sucrose, and after two minutes of incubation at $0^{\circ} \mathrm{C}$ a $10 \%$ solution of Triton X-100 (BDH, Poole, UK) was added to a final concentration of $0.5 \%$. The slides were incubated with this buffer for 10 minutes at $0^{\circ} \mathrm{C}$. The cells were washed twice with buffer containing $10 \mathrm{mM}$ Tris- $\mathrm{HCl} \mathrm{pH} 7.4,10 \mathrm{mM} \mathrm{NaCl}, 1.5 \mathrm{mM} \mathrm{MgCl}, 0.5 \mathrm{mM}$ PMSC and 5 MM NEM (RSB buffer) and subsequently extracted with RSB buffer containing $0.5 \%$ sodium deoxycholate (DOC; Merck) and $1 \%$ Tween 40 (Sigma). Thereafter the cell remnants were washed twice with RSB buffer and incubated in buffer containing $10 \mathrm{mM}$ Tris-HCl $\mathrm{pH} 7.4,110$ $\mathrm{mM} \mathrm{NaCl}, 1.5 \mathrm{mM} \mathrm{MgCl} 2,0.5 \mathrm{mM}$ PMSC , $1 \mathrm{mg} / \mathrm{ml}$ DNase 1 (Sigma) and $50 \mu \mathrm{g} / \mathrm{mI}$ RNase A (Sigma), and incubated for 20 minutes at RT. Then the cells were washed with RSB buffer and subsequently extracted with $400 \mathrm{mM}\left(\mathrm{NH}_{4}\right)_{2} \mathrm{SO}_{4}, 50 \mathrm{mM}$ Tris-acetate, $2.25 \mathrm{mM} \mathrm{MgCl}, 0.5$ $\mathrm{mM}$ PMSC and $5 \mathrm{mM} \mathrm{NEM} \mathrm{for} 10$ minutes at $0^{\circ} \mathrm{C}$. Finally the obtained muclear matrices [42] were rinsed with RSB buffer.

\section{Confocal scanning laser microscopy}

For confocal immunofluorescence microscopy, the cells were analysed using a MRC 600 confocal scanning laser microscope (Bio-Rad, Hemel Hempstead, UK), equipped with an aircooled Argon-Krypton mixed gas laser and mounted onto an Axiophote microscope (Zeiss). The laser scan microscope was used in the dual parameter set-up, according to the manufacturers specifications, using dual wavelength excitation at $488 \mathrm{~nm}$ and $568 \mathrm{~nm}$. Emission specira were separated by the standard sets of dichroic mirrors and barrier filters. AJll scans were recorded in the Kalman filtering mode. Stacks of 5-12 confocal images were recorded using a step size of 0.5 - $1 \mu \mathrm{m}$. Photographs were taken with an automatic camera using Kodak 400 ASA Tri-X pan film.

\section{Sample preparation for gel electrophoresis}

Cells were rinsed with PBS at RT, scraped from the bottom of the culture flask in PBS and centrifuged at $1200 \mathrm{rpm}$. The supernatant was discarded and the pellet was stored at $-20^{\circ} \mathrm{C}$ until 
usage. Cell pellets were resuspended in buffer containing $10 \mathrm{mM}$ Tris-HCl pH 7.4, $10 \mathrm{mM}$ $\mathrm{NaCl}, 1.5 \mathrm{mM} \mathrm{MgCl}$, $0.5 \mathrm{mM}$ phenylmethylsulphonyl fluoride (PMSF, Merck) and $0.5 \%$ Triton $X-100$ (BDH, Poole, England), and stirred for 10 minutes at $0^{\circ} \mathrm{C}$. The cell remnants were collected by centrifugation at $1500 \mathrm{x}$ at $4^{\circ} \mathrm{C}$ and the pellet was washed with buffer containing $10 \mathrm{mM}$ Tris-HCl pH 7.4, $10 \mathrm{mM} \mathrm{NaCl}, 1.5 \mathrm{mM} \mathrm{MgCl} 2,0.5 \mathrm{mM}$ PMSF (Merck). Thereafter, the cell remnants were collected by centrifugation at $1500 \times \mathrm{g}$ at $4^{\circ} \mathrm{C}$, resuspended in buffer containing $10 \mathrm{mM}$ Tris- $\mathrm{HCl} \mathrm{pH} 7.4,110 \mathrm{mM} \mathrm{NaCl}, 1.5 \mathrm{mM} \mathrm{MgCl} 2,0.5 \mathrm{mM}$ PMSF (Merck), $\mathrm{mg} / \mathrm{ml}$ DNase 1 (Sigma) and $50 \mu \mathrm{g} / \mathrm{ml}$ RNase A (Sigma), and incubated for 20 minutes at RT. Then the pellet was washed with $10 \mathrm{mM}$ Tris- $\mathrm{HCl}$ pH $7.4,10 \mathrm{mM} \mathrm{NaCl}, 1.5 \mathrm{mM} \mathrm{MgCl}_{2}, 0.5$ mM PMSF (Merck). After centrifugation and discarding of the supernatant, the pellet was resuspended in SDS-sample buffer [22] and boiled for 5 minutes.

\section{Gel electrophoresis and immunoblotting}

One-dimensional SDS-gel electrophoresis in 10\% polyacrylamide (Bio-Rad Laboratories, Hercules, CA/USA) slab gels containing 0.1\% SDS (Merck), was performed according to Laemmli [22]. Gels were run on the Mini-Protean II system (Bio-Rad Laboratories) for approximatelly 45 minutes at $200 \mathrm{~V}$.

Western blotting was performed essentially according to Towbin et al. [41] using the Mini Trans-Blot Cell (Bio-Rad Laboratories) at $100 \mathrm{~V}$ for 1 hour. Proteins were blotted onto nitrocellulose (BA85, Schleicher and Schüll, Dassel, Germany), the filters were air-dried and blocked for 1 hour at RT in buffer containing $10 \mathrm{mM}$ Tris-HCl $\mathrm{pH} 7.6,0.35 \mathrm{M} \mathrm{NaCl}$ and $3 \%$ BSA (Sigma). Thereafter the blots were incubated with the primary antibodies in appropriate dilutions for 30-60 minutes at RT in buffer containing $10 \mathrm{mM}$ TRIS-HCl pH 7,6, 0.15 M NaCl, $0.3 \% \mathbb{B S A}, 1 \%$ Triton $\mathrm{X}-100(\mathrm{BDH}), 0.5 \%$ DOC (Merck) and $0.1 \%$ SDS (Merck). The blots were washed three times with PBS containing $0.5 \%$ Triton X-100 (BDH), and incubated for 3060 minutes at RT with the secondary peroxidase conjugated rabbit anti-mouse Ig antibody (DAKO A/S, Glostrup, Denmark), diluted 1:1000 in PBS containing 0.5\% Triton X-100 (BDH) and $0.5 \%$ BSA (Sigma). Blots were extensively washed with PBS containing $0.5 \%$ Triton X-100 (BDH) and peroxidase activity was detected by chemiluminescence (ECL-kit, Amersham, Buckinghamshire, UK). RX Fuji medical X ray films (Fuji, Tokyo, Japan) were used for the visualisation of the luminescent signals.

\section{Results}

Examination of lamin-GFP transfected $\mathrm{CHO}$ cells by confocal scanning laser microscopy showed that lamin A-GFP was localized in the nuclear lamina of transfected cells (fig. 1). Apparently, linkage of GFP to the amino-terminus of lamin A does not interfere with incorporation of the fusion protein into the lamina and does not disturb lamina formation in these cells. 


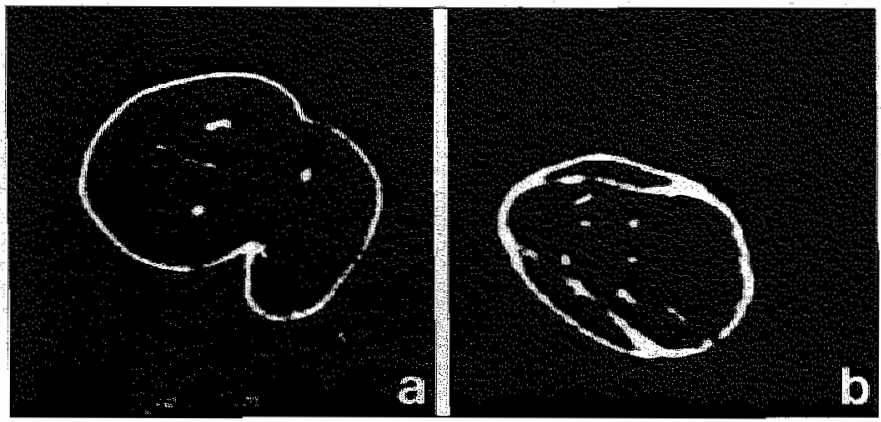

Figure 1. Confocal sowning laser microsoopy showing optical sections of tramsfected CHO cells expressing lamin $\mathrm{A}$ GFP (a) and lamin ASIOGFP (b):

To obtain further information on the expression levels of lamin A-GFP over endogenous lamin A, transfected CHO cultures were subcloned. Several clones were selected and used for gel electrophoresis and immunoblotting. The results show that the expression levels of lamin AGFP in the selected subclones were high as compared to the endogenous levels of lamin $A$, and that the fusion proteins had the expected molecular weight (fig 2). The results of lamin $A \Delta 10$ GFP transfected CHO cells were similar to those of lamin A-GFP transfected cells. Lamin A $\triangle 10-$ GFP was localized in the nuclear lamina of transfected CHO cells (fig. 1) and the expression levels of lamin A $\Delta 10$-GFP in subclones were comparable to those of lamin A-GFP (fig 2$)$.

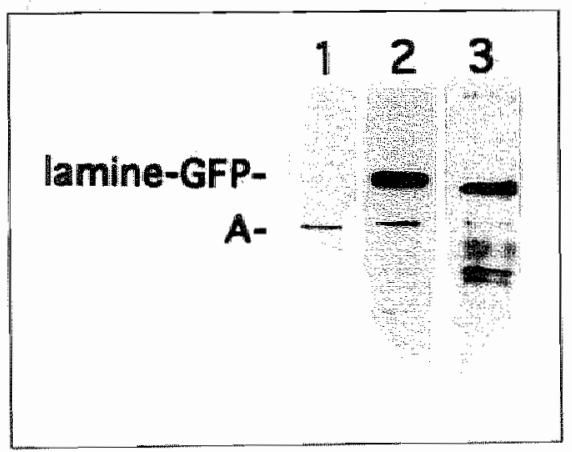

Figure 2. Trumunoblotting results of untransfected CHO cells (lane 1), CHO cells transfected with lamin A-GFP (lane 2), and CHO cells transfected with lamin $A \triangle 10$ GFP (lane 3 ), incubated with the lamin $A$ ancibody $133 A 2$.

It is likelly that the lamin-GFP proteins interact with the endogenous A-type lamins to associate with the nuclear membrane. In order to study the mutual dependence of the individual A-type lamins for this association we performed the same studies with a cell line known to have extremely low levels of endogenous lamin A, i.e. GLC-Al calls [27]. Lamin A was in general not detected at the nuclear membrane when these cells were examined with the lamin $A$ antibody $133 \mathrm{~A} 2$, but intranuclear aggregates were stained. We set out to examine the behaviour of transfected A-type lamins in these cells. For this purpose cDNA fusion constructs of lamin $A$, lamin $A \Delta 10$ and lamin $C$ with GFP were used for transfection of GLC-A1 cells. 

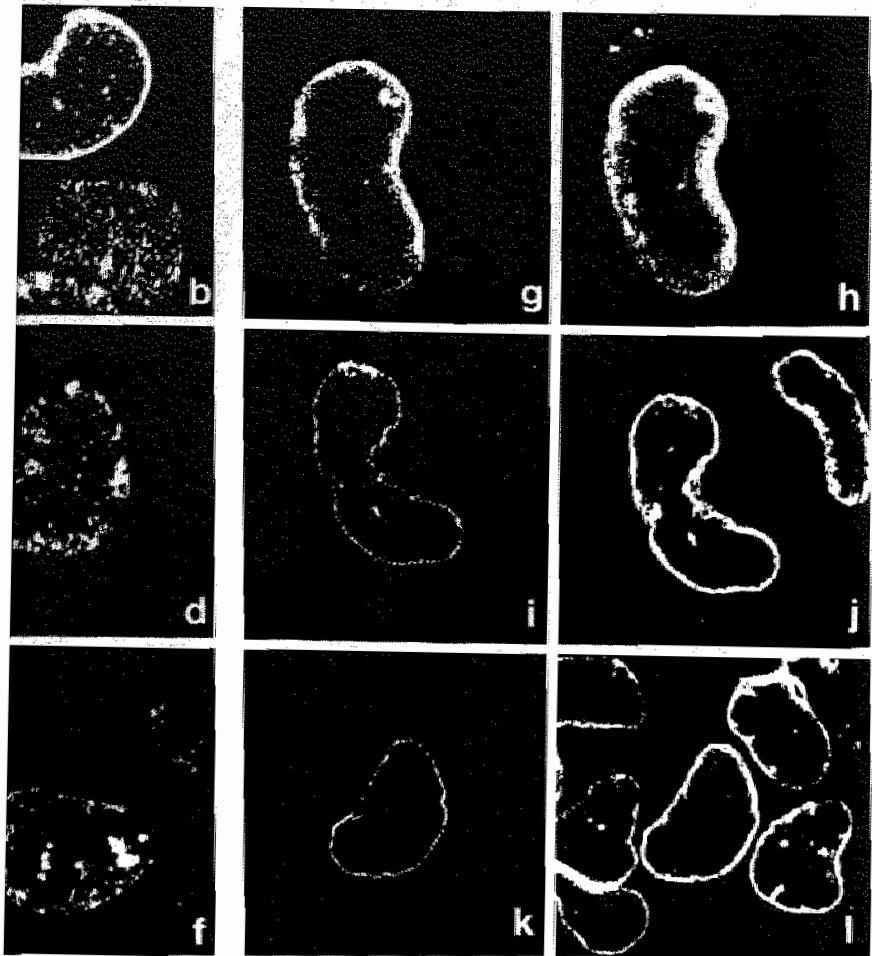

ected GLC-Al cells expressing lamin A-GFP $(a, b, g, h)$, lamin C-GFP $\left(c_{n}, d, j, j\right)$ tatned with lamin $A$ antibody $133 \mathrm{~A} 2(\mathrm{~b}, \mathrm{~d}, \mathrm{P})$ and lamin $\mathrm{A} / \mathrm{C}$ antibody $4 \| \mathrm{CC}$ 3 seen for lamin A-CFP (a,g), lamin C-GFP $\left(c_{,} i\right)$ and lamin $A \Delta 10-C F P(e, k)$, Btected with the lamin $A$ antibody $\left(b, d_{n}\right)$. In b and f the additional perinucleat is since the lamin $A$ antibody recognizes lamin A-GFP and lamin ADIO-GFP. ad cell whth only the intranuclenr aggregate like staining of the endogenous seen for the lamin $A / C$ antibody $\left(h_{4}, j, l\right)$ in transfected as well as untransfected ndogenous lamin $C$ in these cells.

i of transfected GLC-A1 cells, expressing either lamin A-GFP, GFP, showed that these fusion proteins localized to the nuclear 1). When transfected cells were stained with the lamin A antibody uggregates were detected (Fig $3 b, d, f$ ), which were not seem for In lamin AD10 GFP (Fig 3a,c,e). In case of lamin A 10 -GFP the f these aggregates is not due to the relatively high expression of lamin $\mathrm{A}$ and lamin $\mathrm{C}$, as suggested previously [29]. The lamin $\mathrm{A}$ :ted as well as endogenous lamin $A$ and does not discriminate IP and lamin A $\triangle 10-\mathrm{GFP}$, therefore the lamina of transfected cells 
was stained with the lamin $A$ antibody (Figure $3 b$ and $3 f$ ). The presence of ntranuclear aggregates in these cells was nevertheless obvious. The lamin $\mathrm{A}$ antibody does not react with lamin C-GFP allowing a separate detection of endogenous lamin $\mathrm{A}$ and lamin C-GFP Lamin CGFP localizes to the nuclear lamina, while endogenous lamin $\mathrm{A}$ is detected in the intranuclear aggregates (Figure $3 \mathrm{c}$ d). When GLC-A 1 cells were stained with the lamin AlC antibody $41 \mathrm{CC} 4$ (Figure $3 \mathrm{~h}, \mathrm{j}, \mathrm{l}$ ) a perinuclear fluorescence was seen in all cells, due to the endogenous lamin $\mathrm{C}$ present in the cells $[27,29]$. Intranuclear aggregates of endogenous lamin $A$ are not detected with this antibody because of the relatively low expression levels of lamin $A$ as compared to lamin $C$ in these cells. In transfected cells lamin A-GFP, lamin A 10 -GFP and lamin C-GFP were shown to colocalize with the endogenous lamin $C$ in the nuclear lamina (Figure $3 \mathrm{~g}, \mathrm{i}_{\mathrm{k}} \mathrm{K}$ ).

As demonstrated by staining of transfected cells with the lamin B2 antibody, a perfect colocalization of the endogenous lamin B2 and transfected lamin A-GFP (Fig. 4a,b), lamin A 1 0-GFP and lamin C-GFP (Fig.4c,d) was seen.
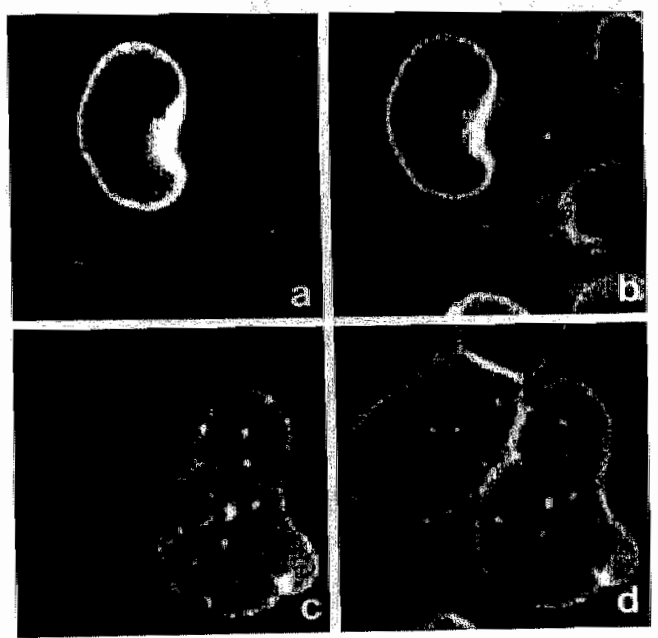

Figure 4. Conlocal sections of GLC-A1 cells ransfected with lamin A-GF or lamin C-GFP. The distribution of laming $A$. GPP (a) and lamin C-GFP (c) colocalizes with lamin $B 2$ immunofluoresicence $(b, d)$.

Furthermore, we showed that lamin-GFP proteins are part of the nuclear matrix fraction (Fig. 5), since they were resistant to extractions with detergents, nucleases and high salt. In situ preparations of the nuclear matrix revealed no apparent differences in the extractability of the individual lamin-GFP proteins. This confirmed that in GLC-A1 and CHO cells the GFP-fusion products are not only correctly lacalized to the nuclear lamina, but presumablly also properly incorporated into this structure. 

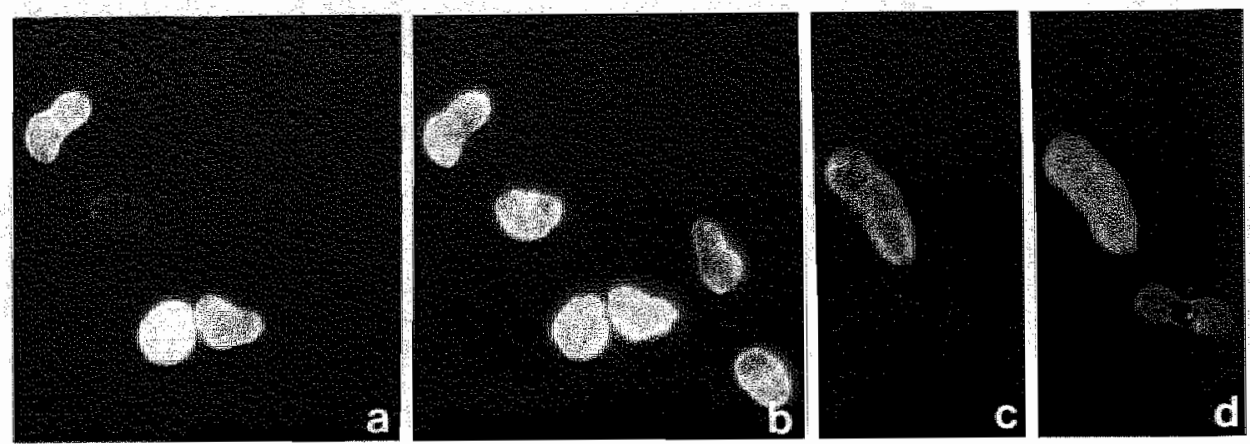

Figure 5. In situ nuclear matrix preparations of GLC-A1 cells transfected with lamin C-GFP (a) and lamin Ad10GFP (c) Lamins $A$ and $C$ were immunocytochemically counterstained with the lamin $A / C$ antibody $41 . C C 4$ (b) and the lamin B2 antibody LN43 (d).

\section{Discussion}

Several mechanisms have been described for the association of lamins with the nuclear membrane. B-type lamins and lamin A are isoprenylated, which provides them with a hydrophobic anchorage site for the nuclear membrane. Lamin $\mathrm{C}$ is not isoprenylated, and the mechanism for incorporation of lamin $\mathrm{C}$ into the lamina is not known, but there is evidence that lamin $\mathrm{C}$ requires progression through mitosis in order to be incorporated into the lamina [18]. It has also been suggested that for incorporation lamin $C$ needs association with isoprenylated lamin A [24]. With respect to the amino-ierminus of lamins, it has been demonstrated that the 28 amino-terminal amino acids of lamins are important for polymerization [15, 32]. Microinjected lamin mutants that lack these 28 amino acids showed impaired incorporation in the lamina. However, expression of amino-terminally deleted lamins in transfected cells resulted in proper lamina incorporation $[39,40]$. This was probably the result of association with endogenous lamins [21,39]. We chose to study lamin incorporation by transfecting GFP-tagged lamin constructs into cells. GFP was fused to the amino-terminal side of lamin $A$ and lamin AAl0, since the carboxy-terminus of lamin A, and presumably of lamin A $A 10$ as well, is processed. Fusion of GFP to the carboxy-terminus of the protein might interfere with farnesylation and subsequent cleavages. Besides, when the farnesylation and subsequent cleavages would not be disturbed and processing would take place, GFP would be cleaved off during the processing as a part of the carboxy-terminus [16].

The experiments presented in this paper show that lamin A with a considerable extension at the amino-terminus is properly incorporated into the nuclear lamina of transfected CHO cells. The results suggests that lamin A-GFP is properly processed and associates with the nuclear membrane. Furthermore, immunoblotting showed that proteins of the expected molecular mass were recognized by the lamin A antibody. Since the incorporation of GFP fusion proteins in 
CHO cells could be the result of interactions between endogenous lamin $A$ and lamin A-GFP the same experimental set-up was used to study A-type lamin incorporation in GLC-A1 cells, a cell line with extremely low levels of endogenous lamin A. Moreover, lamin A is not localized to the nuclear membrane in these cells [27]. Since the transfected GFP-lamins were properly incorporated into the lamina of these cells, it can be deduced that amino-terminally extended Atype lamins do not require interactions with endogenous lamin $A$ for proper incorporation into the lamina. However, heteropolymerization of the amino-terminally extended A-type lamins with B-type lamins cannot be excluded, since the GLC-Al cells form a normal lamina with endogenous B-type lamins. Transfection studies of GFP alone showed that this protein does not localize to the nuclear lamina, but is dispersed throughout the cytoplasm.

Expression of high levels of lamin C-GFP did not result in abnormal localization of these lamins, although lamin $\mathrm{C}$ is missing the anchorage site for the nuclear membrane [17]. Microinjection studies showed that incorporation of lamin $\mathrm{C}$ into the lamina is extremely delayed as compared to incorporation of lamin $A[13,18]$. The experiments presented here showed that expression of high levels of lamin C-GFP in transfected GLC-Al cells did not result in abnormal localization of lamin $C$. Thus, even in cells with very low levels of endogenous A-type lamins, lamin C can be incorporated into the lamina correctly. Therefore, it can be concluded that a balanced expression of lamin $A$ and $A \Delta 10$ compared to lamin $C$ is not obligatory for proper incorporation of lamin C into the lamina. Again, interactions with B-type lamins cannot be excluded.

Previously we have suggested $[27,29]$ that the alternative splicing product lamin A $\triangle 10$ might be responsible for the formation of intranuclear lamin A aggregates in GLC-A1 cells. The data presented in this report show that this is not the case. When lamin AD10-GFP was expressed in CHO or GLC-A1 cells, a normal perinuclear localization was seen. Furthermore, the intranuclear aggregates remained present in GLC-A1 cells next to the lamina that was formed with lamin A 110 -GFP. The nature of the intranuclear A-type lamin aggregates remains largely obscure. Since the staining intensity of the intranuclear aggregates in GLC-A1 with the lrmin A antibody is weak and the level of endogenous lamin $A$ is low, as detected in immunofluorescence, immunoblotting and northern blotting studies [27, 29], the formation of aggregates may be due to the inability of the cell to form a lamina at low concentrations of Atype lamins. In several other cases very low levels of A-type lamin expression also leads to intranuclear speckles of A-type lamins. For instance, several small cell lung cancer cell lines display very low levels of A-type lamins localized in intranuclear speckles. Furthermore, this phenomenon was seen in HL60 cells that do not contain A-type lamins, but upon induction of differentiation these cells start to express A-type lamins. During the early phase of expression intranuclear speckles were seen. As lamin A concentration rose the speckles disappeared and a normal lamina was formed (J.L.V. Broers, unpublished results). However, the aggregate like localization in GLC-Al is unlikely to result from a low concentration of lamin $A$, since in 
transfeeted GLC-AI cells with high expression levels of the A-type lamins the aggregate like pattern is still detectable next to the nornal lamina.

In conclusion, transfected A-type lamins, amino-terminally extended with a GFP-tag, are properly incorporated into the nuclear lamina. Lamin A $\Delta 10$ does not localize in intranuclear aggregates. Furthermore, relatively high levels of lamin C-GFP are incorporated into the lamina independent of balanced expression of lamin $A$.

\section{Acknowledgements}

The authors thank Dr. Y. Raymond, Dr. E.B. Lane, Dr. G. Krohne and Dr. G. Warren for providing the antibodies, Dr. F. McKeon for providing the lamin A cDNA and Dr. L. de Leij for providing the cell line GLC-A.I.

\section{References}

[1] Blamonti, G., M. Giacea, G. Permi, G. Contreas, L. Zentilin, F. Weighardt, M. Guerra, G. Della Valle, S. Sacone, S. Riva, A. Falaschi: The gene for a novel human tamin maps at a highly transeribed locus of chromosome 19 which replicates at the onset of S-phase. Mol. Cell. Biol. 12, 3499-3506 (1992).

[2] Bridger, J.M., I.R. Kill, M. OTarrel, C.J. Hutchison: Internal lamin structures within G1 nuclei of dermal fibroblasts. J. Cell Sci. 104, 297-306 (1993).

(3) Broers, J.L.V., B.M. Machiels, H.J.H. Kuijpers, F. Smedts, R, van den Kieboom, Y. Raymond, F.C.S. Ramaekers: A- and B-type lamins are differentially expressed in normal human tissues. Histochem. Cell Biol. 107, 505 m517 (1997).

[4] Burke, B., G. Tooze, G. Warten: A monoclonal antibody which recognises each of the nuclear lamin polypeptides in mammalian cells. EMBO J. 2, 361-367 (1983).

[5] Cance, W.G., N. Chaudhary, H.J. Worman, G. Blobell, C. Cordon Carda: Expression of the nuclear lamins in normal and neoplastic human tissues. J. Exp. Clin. Cancer Res. 11, 233-246 (1992).

[6] Chalfie, M., X. Tu, G. Euskirchen, W.W. Ward, D.C. Prasher: Green fluorescent protein as a marker for gene expression. Science $\mathbf{2 6 3}, 802-805$ (1994).

[7] Chong, L., J. Fu, A. Tsukamoto, R.G. Hawley: Use of green fluorescent protein variants to monitor gene transfier and expression in mammalian cells. Nature Biotechnology 14, 606-609 (1996).

[8] Chiu, W.- L., Y. Niwa, W. Zeng. T. Hirno, H. Kobayashi, J. Sheen: Engineered GFP as a vital reporter in plants. Current Biology 6, 325-330 (1996).

[9] Cubit, A.B., R. Hein, S.R.Adams, A.E. Boyd, L.A. Gross, R.Y. Tsien: Understanding, improving and using green fluorescent proteins. TIBS 20,448-455 (1995),

[10] De Giongi, F. M. Brini, C. Bastanutto, R. Marsault, M. Montero, P. Pizzo, R. Rossi, R. Rizzuto: Tangeting aequorin and green fluorescent protein to intracellular organelles. Gene 173, 113-11.17 (1996).

[11] Furakawa, K., H. Inagaka, Y. Hota: Identification and cloning of an mRNA coding for a germ cell-specific A-lype lanin in mice. Exp. Cell Res. 212,426-430 (1994).

[12] Gerace, L, B. Burke: Functional organization of the nuclear envelope. Annu. Rew. Cell Biol. 4, 335-374 $(1988)$

1131 Gerace, L., C. Comeau, M. Benson: Organization and modulation of nuclear structure. J. Cell Sci. Suppl. 1, $137.160(1984)$.

[1.4] Heim, R., A.B. Cubitt, R.Y. Tsien: Improved green lluorescence. Nature 373, 663-664 (1995).

[15] Heitlinger, E. M. Peter, A. Lustig, W. Villiger, E. A. Nigg, U. Aebi: The role of the head and tail domain in lamir structure and assembly: analysis of bacterially expressed chicken lamin $A$ and truncated Bi2 lamins. I. Struct. Biol. 108, 74-91(1992).

[16] Hennekes, H., E.A. Nigg: The role of isoprenylation in membrame attachment of nuclear lamins. J. Cell Sci. $107,1019-1029(1994)$.

[17] Höger, "T., G. Krohne, J.A. K]einschnidt: Interaction of Xenopus lamins LA and LII with chromatin in vitro mediated by a sequence element in the carboxylterminal domain. Exp. Cell Res. 197, 280-289 (1991). 
[18] Horton, H., I. McMorrow, B. Burke: Independent expression and assembly properties of heterologous lamin $A$ and $C$ in murine embryonal carcinoma. Eur. J. Cell Biol. 57, 172-183 (1992).

[19] Hozák, P., M.-J. Sasseville, Y. Raymond, P.R. Cook: Lamin proteins forn an internal nucleoskeleton as well as a peripheral lamina in human cells. J. Cell Sci. 108, (1995).

[20] Krohne, G., R. Benavente: The nuclear lamins. A multigene family of proteins in evolution and differentiation. Exp. Cell Res. 162, 1-10 (1986).

[21] Krohne, G., I. Waizenegger, T.H. Höger: The conserved carboxy-terminal cysteine of nuclear lamins is essential for lamin association with the nuclear envelope. J. Cell Biol. 109, 2003-2011 (1989).

[22] Laemmli, U.K.: Cleavage of structural proteins during the assembly of the head of bacteriophage T4. Nature $227,680-685(1970)$.

[23] Lin, F., H.J. Worman: Structural organization of the human gene encoding nuclear lamin A and nuclear lamin C. I. Biol. Chem. 268, 16321-16326 (1993).

[24] Loewinger, L., F. McKeon: Mutations in the nuclear lamin proteins resulting in their aberrant assembly in the cytoplasm. $\mathbb{E M B O}$ J. 7, 2301-2309 (1988).

[25] Ludin, B., T. Doll, R. Meili, S. Kaech, A. Matus: Application of novel vectors for GFP-tagging of proteins to study microtubule-associated proteins. Gene 173, 107-111 (1996).

[26] Lukz, R.J., M.A. Trujillo, K.S. Denham, L. Wenger, M. Sinensky: Nucleoplasmic localization of prelamin A: Implications for prenylation-dependent lamin A assembly into the nuclear lanina. Proc. Natl. Acad. Sci. USA 89, 300-3004 (1992).

[27] Machiels, B.M., J.L.V. Broers, Y. Raymond, L. de Ley, H.J.H. Kuijpers, N.E.H. Caberg, F.C.S. Ramaekers: Abnormal A-type lamin organization in a human lung carcinoma cell line. Eur. J. Cell Biol. 67, 328-335 (1995).

[28] Machiels, B.M., F.C.S. Ramaekers, H.J.H. Kuijpers, J.S. Groenewoud, J.W. Oosterhuis, L. H.J. Looijenga: Nuclear lamin expression in normal testis and testicujar germ cell tumors of adolecents and adults. I. Pathol. $182,197-204$ (1997).

[29] Machiels, B.M., A.H.G. Zorenc, J.M. Endert, H.J.H. Kuijpers, G.J.J.M. van Eys, F.C.S. Rameakers, J.L.V. Broers: An alternative splicing product of the lamin A/C gene lacks exon 10. J. Biol. Chem. 271, 9249-9253 (1996).

[30] Marshall, J., R. Molloy, G.W. Moss, J.R. Howe, T.E. Hughes: The jellyfish green fluorescent protein: a new tool for studying ion channell expression and function. Neuron 14, 211-215 (1995),

[31] McKeon, F.D., M.W. Kirschner, D. Caput: Homologies in both primary and secondary structure between muclear envelope and intermediate filament proteins. Nature 319, 463-468 (1986).

[32] Moir, R.D., A.D. Donaldson, M. Stewart: Expression in Escherichia coli of human lamins A and $\mathbb{C}^{\text {: }}$ influence of head and tail domains on assembly properties and paracrystal formation. J. Cell Sci. 99, 363372 (1991).

[33] Monosov, E.Z., T.J. Wenzel, G.H. Lüers, J.A. Heyman, S. Subrannani: Labeling of peroxisomes with green fluorescent protein in living P. pastoris cells. J. Histochem. Cytochem. 44, 58.1-589 (1996).

[34] Nigg, E. A.: Assembly - disassembly of the nuclear lamina. Curr. Opin. Cell Biol. 4, 105-109 (1992).

[35] Ogawa, H., S. Inouye, F.I. Tsuji, K. Yasuda, K. Umesono: Localization, trafficking, and temperaturedependence of the Aequorea green fluorescent protein in cultured vertebrate cells. Proc. Natl. Acad. Sci. USA 92, 11899-11903 (1995).

[36] Olson, K.R., J.R. McIntosh, J.B. Olmsted: Analysis of MAP4 function in liwing cells using green fluorescent protein (GFP) chimeras. J. Cell Biol. 130, 639-650 (1995).

[37] Pollard, K.M., E.K.L. Chan, B.J. Grant, K.F. Sulliwan, E.M. Tan, C.A. Glass: In vitro posttranslational modification of lamin B cloned from a human T-cell line. Mol. Cell. Biol 10, 2.164-2175 (1990).

[38] Rizzuto, R., M. Brini, P. Pizzo, M. Murgia, T. Pozzan: Chimeric green fluorescent protein als a tool fot visualizing subcellular organelles in living cells. Current Biology $5,636-642$ (1995).

[39] Schmidt, M., G. Krohne: In vivo assembly kinetics of fluorescently labeled Xenopus lamin A mutants. Eur. J. Cell Biol. 68, 345-354 (1995).

[40] Schmidt-Zachmann, M.S., C. Dargemont, L.C. Kuhn, E.A. Nigg: Nuclear export of proteins - The role of nuclear retention. Cell 74, 493-504 (1993).

[41] Towbin, H., T. Staehelin, J. Gordon: Electrophoretic transfer of proteins from polyacrylamide gels to nitrocellulose sheets: procedure and some applications. Proc. Natl. Acad. Sci. USA 76, 4350-4354 (1979).

[42] Verheijen, R., H.J.H. Kuijpers, R.O. Schlingernan, A.L.M. Boehmer, R van Driel, G.J. Brakenhoff, F.C.S. Ramackers: Kil-67 detects a nuclear matrix-associated proliferation-related antigen. Intracellular localization during interphase. J, Cell Sci. 92, 123-130 (1989).

[43] Yeh, E., K. Gustafson, G.L. Boullianne: Green fluorescent protein as. a vital marker and reporter of gene expression in Drosophila. Proc. Natl. Acad. Sci. USA 92, 7036-7040 (1995).

[44] Zatloukal, K., H. Denk, G. Spurej, H. Hutter: Modulation of protein composition of nuclear lamina reduction of Lamins-B1 and lamins-B2 in livers of griseofulvin-treated Mice. Lab. Invest. 66, 589-597 (1992). 


\section{Chapter 8}

Summary and General Discussion 


\section{Summary and General Discussion}

In the first part of this thesis lamin expression in normal and diseased human tissues has been described. A study in normal tissues, performed with a set of well characterized lamin antibodies, showed the differential expression of A-type lamins. The general hypothesis that Atype lamin expression is dependent on the degree of differentiation of cells was generally confirmed by immunostaining results of stratified squamous epithelia, but was not absolute in all tissues. Several highly differentiated cell types, including cells of white pulp of the spleen and cells of several neuroendocrine glands, show no expression of A-type lamins. This indicates that the degree of differentiation is not the only parameter that dictates A-type lamin expression. Furthermore, the general assumption that B-type lamins are constitutively expressed in all cells was found to be true for lamin B2, but not for lamin B1. Lamin B2 was extensively expressed in all examined tissues and cells except for hepatocytes and centrocytes and centroblasts of the reactive lymph nodes, which were partly negative or very weakly positive. Lamin B 1 expression was very heterogenous in all tissues. For instance, lamin Bl was absent from muscle cells, Sertoli and Leydig cells, fibroblasts and endothelial cells, basal cells of several epithelia, and epithelial cells with high levels of differentiation. Lamin B 1 expression is correlated with proliferation rather than differentiation, but the correlation was not valid for all examined tissues.

Distinct tumour types were investigated for their lamin expression, in order to get more insight into their development. Specimens of testicular germ cell tumours of adolescents and adults showed that carcinoma in situ, either adjacent to seminomas or non-seminomas, is positive for lamin $B 1$ and $B 2$ but negative for lamins $A$ and $C$. This expression pattern resembled that of normal spermatogonia, which together with their morphological similarities suggests a close relationship between these two cell types. Also seminomas express only lamin $\mathrm{B} 1$ and $\mathrm{B} 2$, and resemble the lamin expression patterns of spermatogonia, suggesting that this tumour type is differentiated along the spermatogenic pathway. Since in several species germ cells specific lamins have been detected it can be anticipated that also in man such subtype may exist. The presence of such lamin subtype in spermatogonia as well as seminomas would confirm the differentiation pathway of these tumours along the spermatogenic lineage. Furthermore, a $R a s$ dependent A-type lamin expression was found in seminomas, in that only tumours with a Ras mutation showed expression of A-type lamins next to lamin B1 and B2 expression. Similar Ras depedent changes in A-type lamin expression have been described in vitro in the small cell lung cancer cell line NCI-H249 (Kaufmann et all. (1991), Cancer Res. 51: 581-586), and could also be induced in the colon carcinoma cell line $\mathrm{CaCo} 2$ by transfection with c-Ha-Ras.

Differentiated non-seminomas, including yolk sac tumours, choriocarcinomas and teratomas, which are differentiated along a somatic pathway, consequently express both A- and B-type lamins. Embryonal carcinomas, which are the least differentiated non-seminomas, were found to 
express lamin B1, B2 and C, but not lamin A. This implies that lamin $C$ expression preceeds lamin $A$ expression during the process of somatic differentiation. Such an intermediate differentiation stage has not been detected in normal human tissues, but differentiating cells displaying only lamin $\mathrm{C}$ expression may have been overlooked in normal tissues, because this transient phase of differentiation lasts only for a short time, resulting in only few cells expressing this lamin pattern.

Another tumour type that was studied for lamin expression was Hodgkin"s disease. In lymph nodes characterized with Hodgkin's disease all cells were positive for lamin B1 and B2. This was remarkable since in the reactive lymph nodes a specific population of cells, namely the centrocytes and centroblasts, were negative for lamin B2. Such a population was not detected in Hodgkin's disease. Furthermore, only a small fraction of cells in Hodgkin's disease is positive for A-type lamin expression. Many of these cells are CD30 positive, fairly mature B- and T. lymphocytes, whereas a fraction of these A-type lamin positive cells remained unidentified by the used lymphocyte markers. The CD30 positive Reed-Sternberg and Hodgkin cells were also positive for A-type lamin expression, confirming a relatively mature and differentiated phenotype for these cells. In the small lymphocytes surrounding the Reed-Sternberg and Hodgkin cells A-type lamin expression and Ki-67 staining segregate, indicating that A-type lamin expressing lymphocytes do not proliferate. In the malignant Reed-Sternberg and Hogkin cells A-type lamin expression and Ki-67 positivity may co-occur in one cell. This proves that in malignant tissues mature A-type lamin expressing cells may retain the ability to proliferate.

Earlier studies on in lung cancer showed that the lamin expression patterns are dependent on the degree of differentiation and on the subtype of lung cancer. Furthermore, aberrant localizations of the A-type lamins were seen in adenocarcinomas of the lung. The second part of the thesis focusses therefore on the molecular background of this aberrant lamin expression in lung cancer cells by in vitro studies. In the adenocarcinoma cell line of the lung GLC-A1 an abnormal aggregate-like intranuclear staining is seen when stained with an antibody to lamin $A$. Furthermore, immunoblotting of these cells showed that very little lamin $\mathrm{A}$ was detectable in these cells, which was confirmed by Nothern blotting showing extremely low levels of lamin $A$ mRNA. For lamin C slightly higher levels of protein and mRNA were detected, but they were still low compared to other cell lines. Lamin $\mathrm{C}$, however seemed to be incorporated into the lamina in a normal way, since no abnormal localization was detected in immunofluorescence when the cells were stained with antibodies recognizing both $\|$ amins $A$ and $C$. GLC-A1 is a cell line that is known to display neuroendocrine characteristics in a subpopulation of the cells and may therefore not be regarded as a fully differentiated adenocarcinoma. This cell line may be another example of cells that are interrupted in their differentiation process and therefore show a transient expression pattern of the A-type lamins, by analogy of the embryonal carcinoma cells described above.

Molecular biological analysis showed that GLC-A1 cells expressed an as yet unknown alternative splicing product of the lamin $\mathrm{A} / \mathrm{C}$ gene. This alternative splicing product was 
Identical to lamin A except for exon 10, which was completely missing in the newly found splicing product, and therefore it was designated as lamin $A \Delta 10$. Further analysis learned that this product was a common product in many cell lines and tissues. A major difference between GLC-Al and many of the other cells that were tested for lamin A $\Delta 10$ expression, was the ratio of lamin A $\triangle 10$ over lamin A. Most cells express high levels of lamin $A$ when compared to the levels of lamin $A \Delta 10_{*}$, whereas in GLC-A1 the expression of lamin $A \Delta 10$ is relatively high due to the very low expression of lamin A. In order to study the influence of high levels of lamin $A \Delta 10$ and to investigate the localization of lamin $A \Delta 10$, transfections with $C D N A$ encoding lamin $A \triangle 10$ were performed. Since none of the antibodies to A-type lamins could discriminate between lamin $A \Delta 10$ and lamin $A$, the transfected lamins were tagged with green fluorescent protein (GFP). In this way transfected lamin $A \Delta 10$ could be recognized by its green fluorescence. An additional advantage was that now endogenous A-type lamins could be distinguished from transfected lamins. The study of lamin A 10 -GFP showed that this fusion protein localized to the nuclear membrane, and is $\rrbracket$ ikely to incorporate properly into the lamina, since it was shown to be part of the nuclear matrix.

Fusion of GFP to the aminoterminus of lamin $A$, lamin $C$ or lamin $A \Delta 10$ did not prevent or disturb the incorporation into the nuclear lamina. Also high expression levels of lamin-GFP fusion proteins in GLC-A1 cells did not result in abnormal localization or disturbed incorporation. This was expecially remarkable for lamin $\mathrm{C}$, since lamin $\mathrm{C}$ has no isoprenylation site at the carboxyterminus, and was expected to be unable to incorporate into the nuclear lamina without interaction with lamin A. In GLC-Al cells incorporation of lamin C-GFP cannot be aided by interactions with lamin $A$, since lamin $A$ is almost absent from these cells. Therefore we conclude that lamin $\mathrm{C}$ is capable of incorporating into the lamina without help of lamin $\mathrm{A}$. This was also confirmed by the normal laminar localization of lamin $\mathrm{C}$ in embryonal carcinomas, which also lack Jamin $A$ and in which no abnormal localization of lamin $C$ was seen. Furthermore, varying ratios of lamin $A$ over lamin $C$ do not influence the incorporation of lamin $C$ into the lamina. However, it has to be noted that the cells that form a lamina with lamin C in absence of lamin A contain lamin B1 and B2. Since it has been shown that heterodimer formation of lamins can occur, it is possible that lamin $C$ is incorporated into the lamina via interaction with the B-type lamins. 


\section{Samenvatting}


weing lamine $A$ aanwezig is in deze cellen. Dit werd bevestigd in Northern blotting studies die aamgaven dat extreem lage niveaus van lamine $\mathrm{A}$ mRNA anwezig waren. Lamine $\mathrm{C}$ werd door deze cellinin iets meer tot expressie gebracht, maat vergeleken met andere cellinnen was dit niveau ook nog erg laag. Lamine $C$ werd echter wel ingebouwd in de kemlamina, want als de GLC-AI cellen werden gekleurd met antilichamen die lamme $A$ en $C$ herkennen, dan werd een zwakke, maat normale lamina-kleuring gezien. Omdat GLC-AI een adenocarcinoom-cellijn is die weinig klierbuis differentiatie vertoont en warvan bekend is dat een subpopulatie van de cellen ook neuro-endocriene eigenschappen bezit, kan deze cellijn worden betiteld als een slecht gedifferenteerde adenocarcinoor cellijz. Deze cellijn kan een voorbeeld zijn van cellen die niet volledig zijn gedifferentieerd of cellen die hun differentiatie-route niet hebben voltooid en mogelijk in en overgangsfase van ongedifferentheerd naar gedifferentieerd verkeren. Daarom is het mogelijk dat deze cellen ook een overgangsvom van lamine-expressie laten zien, geen c.q. weing lamine A mar wel lamine $\mathrm{C}$, zoals bij de herboven beschreven embryonaalcel carcinomen.

Moleculair biologische analyse bracht aan het licht dat GLC-A1 cellen een tot nu toe onbekend alternatief splicingsprodukt van het lamine $\mathrm{A} / \mathrm{C}$ gen tot expressie brengen. Dit altematief splicingsproduct is identick an lamine $A$, mel uitzondering van exon 10 , dat afwezig is. Daarom werd dit nieuwe produkt lamine $A \Delta 10$ genoemd. Analyse van andere cellijmen en weetsels leerde dat lamine $A \Delta I 0$ een splicingsprodukt is dat in alle geteste cellen en weefsels voorkomt. Het grote verschil tussen GLC-AL en de andere cellinen was de verhouding tussen de expressie niveaus van lamine $\mathrm{A}$ en lamine $\mathrm{A} \Delta \mathrm{I0}$. In de meeste andere celtypen was de lamine A expressie hoog in wergelijking tot het expressie niveau wan lamine $A \Delta 10$. In GLC-Al is just hel expressie niveau van lamine $A \Delta 10$ relatief hoog in vergelijking tot het expressiemiveau van lamine A. Om de invloed van hoge lamine A $\Delta 10$ niveaus te bestuderen en on de lokalisatie van

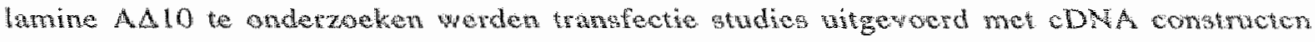
coderend voor lamine A $\triangle 10$. Ondat geen van de voomanden zijnde antilichamen kon discrimineren tussen lamine $A$ en lamine $A \Delta 10$, werden de gerransfecteerde lamines gelabeld met 'green fluorescent protein' (GFP). Op deze manier konden de getransfecteerde lamine $A$ of lamine $\mathrm{A} \Delta 10$ herkend worden aan hun groene fluorescentie. Tevens konden mu getramsfecteerde lamines onderscheiden worden van endogene lamines. Uit het transfectie onderzoek met lamine AM10-GFP bleek dat het husieprodukt van lamine AD10 en GFP nomaal in de lamina gelocaliseerd was. Verder kon worden aangetoond dat het lamine AD10-GFP fusiepodukt goed ingebouwd was in de lamina, omdat het niet te extraheren was met detergentia of hoog zout. Aminoterminale koppeling van GFP an lamine $A$, lamine $C$ of lamine $A \Delta l O$ heeft kennelijk geen invloed op de lokalisatie en incorponatie van deze lamines in de kemlamina. Dit was opmerkelijk voor lamine $C$, omdat deze lamine in tegenstelling tot lamine A niet geisoprenyleerd word en verwacht werd dat deze lamine niet goed naar de kernmembraan gebracht en ingebouwd wordt zonder de hulp van lamine A. Omdat in GLC-Al cellen bijna geen lamine $A$ anwezig is kan de inbouw van lamine $C$ in de lamina dus niet lamine $A$. 
gemedieerd zijn in deze cellen. Daaruit kon worden gecondiudeerd dat inboww van lamine C onahankelijk is van aanwezigheid van lamine $\mathrm{A}$. Dit was ergenlyk ook al duidelijk uit de nomale localisatie van lamine $C$ in embryonaalcel carcinomen, die eveneens geen lamine $A$ lot expressie brengen. Blijkbaar hebben de verhoudingen tussen lamine $\mathrm{A}$ en lamine $\mathrm{C}$ geen effect op de incorporatie van lamine $\mathrm{C}$ in de lamina. Men dient echter wel in gedachten te houden dat alle cellen die een lamina vormen met lamine $C$ in afwezigheid van lamine $A$, endogen lamine $^{2}$ $B 1$ en $B 2$ tot expressie brengen. Omdat vorming van heterodimeren tussen $A$-type en $B$-type lamines mogelijk is, kan niet worden witgesloten dat inbouw van lamine $C$ in afwezigheid van lamine $\mathrm{A}$ gebeurt via interactie met én of beide B-type lamines. 


\section{Curriculum Vitae}

Barbie Machiels werd geboren op 2 december 1965 te Maastricht. In 1985 behaalde zij haar atheneum $B$ diploma aan het Henric van Veldeke College te Maastricht. In datzelfde jaar begon ze met haar studie Moleculaire Wetenschappen aan de Landbouw Universiteit te Wageningen. Tijdens haar studie liep ze drie maanden stage bij het Department of Chemical Engineering, Division Bioseparations wan de University of Washington te Seattle, USA, onder leiding van Prof. Dr. R.R. Fisher. Daarna deed ze in 1989 een afstudeeronderzoek van zes maanden bij de vakgroep Moleculaire Biologie van de Landbouw Universiteit Wageningen, onder leiding van R. Verkerk en Dr. P. Zabel. Een tweede afstudeeronderzoek van zes maanden heeft ze uitgevoerd binnen de sectie CP-Intermediates van DSM Research B.V., onder leiding van Dr. R.J. Vijn (DSM Research) en Prof. Dr.A. de Groot (Organische Chemie, Landbouw Universiteit Wageningen). In juni 1990 behaalde ze het doctoraal diploma Moleculaire Wetenschappen binnen de biologisch-chemische oriëntatie. Vanaf november 1990 heeft ze een half jaar als vrijwilliger gewerkt bij de vakgroep Biochemie van de Universiteit Matastricht. In juni 1991 is ze als OIO gestart bij de vakgroep Moleculaire Celbiologie van de Universiteit Maastricht binnen het door STW gefinancierd 'proteasomen-project'. Dit project, onder leiding van Prof. Dr. F.C.S. Ramaekers, heeft geresulteerd in enkele wetenschappelijke publicaties. Sinds september 1993 is ze ook bij het lamine-onderzoek van de vakgroep Moleculaire Celbiologie betrokken, onder leiding van Dr. J.L.V. Broers en Prof. Dr. F.C.S. Ramaekers, wat geleid heeft tot het proefschrift: Differential expression of nuclear lamins in normal and diseased human cells. 


\section{List of publications}

R.R. Fisher, B.M. Machiels, K.C. Kyriacou and I.E. Morris. Affinity ultafitration and affinity precipitation using a water-soluble complex of poly(winyl)alcohol and cibacron blue F3GA. In Protein-dye interactions, development and applications, M.A. Vijayalakshrmi and $\mathrm{O}$. Bertrand, Eds, Elsevier applied science Amsterdam: 190-196 (1988).

R. Klein-Lankhorst, P. Rietweld, B. Machiels, R. Verkerk, R. Weide, C. Gebhardt, M. Koomneef and P. Zabel. RFLP markers linked to the root knot nematode resitance gene $\mathrm{Mi}$ in tomato. Theoretical and Applied Genetics 81: 661-667 (1991).

Georgine M. Sanders, Marinus van Dijk, Barbara M. Machiels and Albertus van Veldhuizen. Identification of a pair of atropisomeric porphyrins by $I H$ NMR investigations on their zinc derivatives. The Journat of Organic Chemistry 56: 1301-1305 (1991).

Barbie M. Machiels, Mieke E.R. Henfling, Jos L.V. Broers, Klavs B. Hendil, Firans C.S. Ramaekers. Changes in immuno-cytochemical detectability of proteasome epitopes depending on cell growth and fixation conditions of lung cancer cell lines. European Joumal of Cell Biology 66: 282-292 (1995).

Barbie M. Machiels, Jos L.V. Broers, Yves Raymond, Lou de Ley, Helma J.H. Kuijpers, Nicole E.H. Caberg, Frans C.S. Ramaekers. Abnormal A-type lamin organization in a human lung carcinoma cell line. European Journal of Cell Biology 67: 328-335 (1995).

Barbie M. Machiels, Micke E.R. Henfling, Bert Schutte, Manon van Engeland, Frans C.S. Ramaekers. Subcellulat localization of proteasomes in apoptotic Jung tumor cells and their persistence as compared to intermediate fillaments. European Journal of Cell Biology $70: 250$. 259 (1996).

Barbie M. Machiels, Antoine H.G. Zorenc, Jorike M. Endert, Helma J.H. Kuijpers, Guillaume J.J.M. van Eys, Frans C.S. Ramaekers, Jos L.V. Broers. An alternative splicing product of the lamin $\mathrm{A} / \mathrm{C}$ gene in lung carcinomas lacks exon 10. Journal of Biological Chemistry 16: 9249 9253 (1996).

Barbie M. Machiels, Frans C.S. Ramaekers, Helma, J.H. Kuijpers, Jacqueline S. Groenewoud, J. Wolter Oosterhuis, Leendert H.J. Looijenga. Nuclear Iamin expression in normal testis and testicular germ cell tumors of adolescents and adults. Joumal of Pathology 182: 197-204 (1997). 
Barbie M. Machiels, Mieke E.R. Henfling, Will L.H. Gerards, Jos L.V. Broers, Hans Bloemendal, Frans C.S. Ramaekers, Bert Schutte. Proteasome inhibition blocks the cell cycle at G1/S transition and metaphase. Cytometry 28: 243-252 (1997).

Jos. L.V. Broers, Barbie M. Machiels, Helma J.H. Kuijpers, Frank Smedts, Ronald van den Kieboom, Yves Raymond, Frans C.S. Ramaekers. A- and B-type lamins are differentially expressed in normal human tissues. Histochemistry and Cell Biology 107: 505-517 (1997).

Maurice P.H.M. Jansen, Barbie M. Machiels, Anton H.N. Hopman, Jos L.V. Broers, Frans C.S Ramaekers, Jan Willem Arends, Harry C. Schouten. Differential expression of A- and B-type lamins in reactive lymph nodes and Hodgkin's disease. Histopathology (1997), in press 


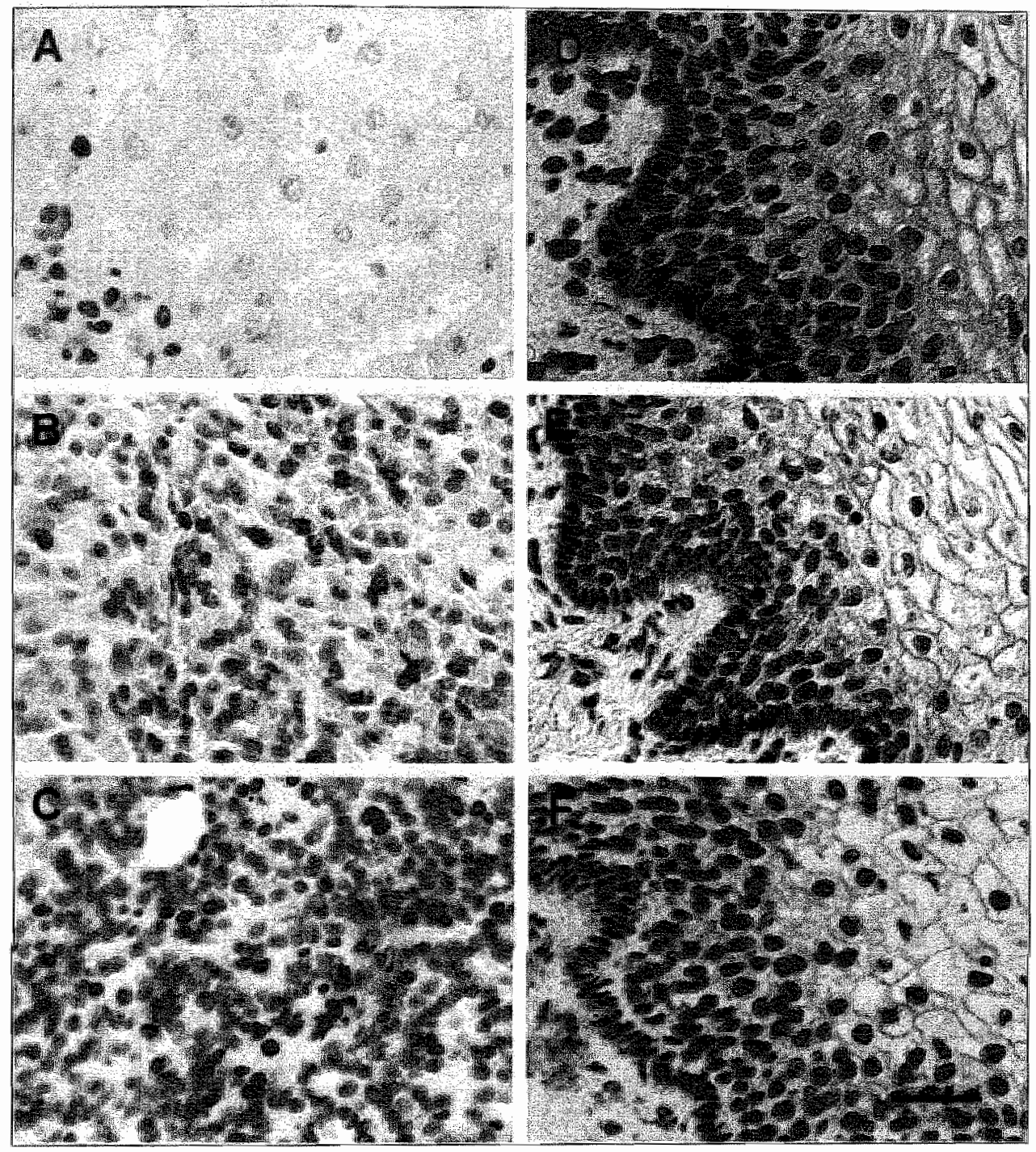

Chapter 2, figure 4. Immunoperoxidase staining of liver $(A)$, pancreas $(B)$, parathyroid $(C)$ and vagina epithelium (D-F), using the lamin B2 antibody $L N 43$ (A, D), the lamin B1 antibody (B,E) the lamin $A$ antibody (C) and the lamin $A / C$ antibody $4 / C C 4$ (F). Note the very weak staining of hepatocyles as compared to bile duct cells using the lamin B2 antibody (A). In pancreas lamin B1 staining shows large variation in intensities between different acinar cells (B). Parathyroid cells are only very weakly stained with the lamin $A$ antibody, while sturounding stromal and wascular cells are strongly positive (C). In vagina (D-F), all epithelial and stromal nuclei are stained with the lamin B2 antibody (D). In contrast, the lamin B1 anibody stains few basal cells and all parabasal cells. Staining intensity is clearly decreased in the upper intermediate layer and superficial layer of epithelium (E). Lamins $\mathrm{A} / \mathrm{C}$ are (very) weakly expressed in basal cells and staining intensity increases with level of differentiation (F). Bar represents $50 \mu \mathrm{m}$. 

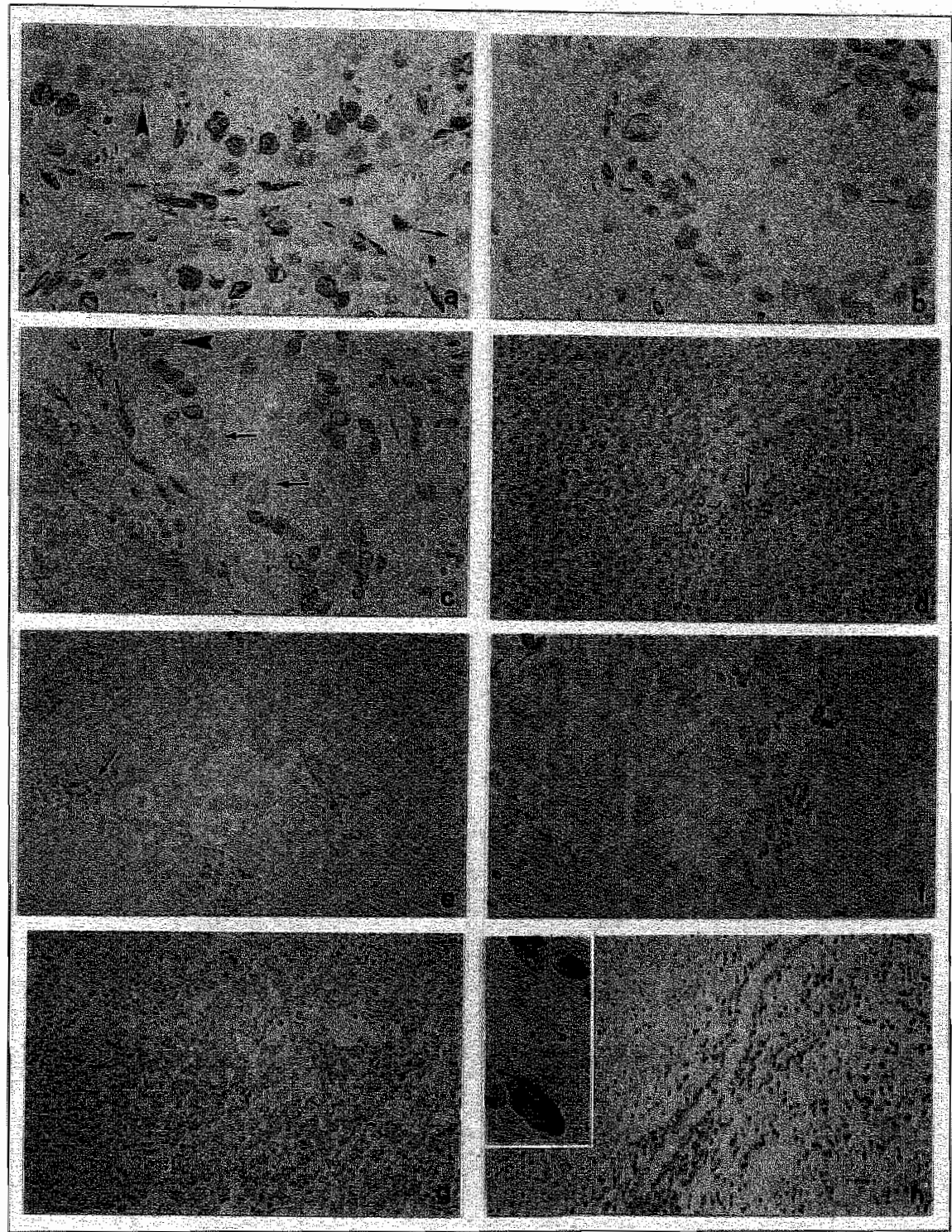

Chapter 3, figure 2. Representative iflustrations of immunostainings of parenchyma adjacent to testicular germ cell tumours (a-c) and testicular germ cell tumours (d-h). (a) Testicular parenchyma adjacent to testicular germ cell tumours containing carcinoma in situ, stained with lamin B 1 anlibody 119D5; Sertoli (arrowhead) and Leydig (arrow) cells are negative for Jamin B1. (b) Testicular parenchyma adjacent to enbryonal carcinoma containing carcinoma in situ, stained with lamin B2 antibody X223; Sertoli cells (arrows) are positive for lamin B2. (c) Testicular parenchyma adjacent to a testicular germ cell tumour containing carcinoma in situ, stained with lamin A/C antibody R.27; spematogonia (arrowhead) and carcinona in situ (arrows) are negative for A-type lamins. (d) Ras- seminoma stained with lamin B2 antibodly X223; both normal (lymphocytes, arrow) and tumour cells are positive for lamin B2. (e) Ras- seminoma stained with lamin A/C antibody R27; tumour cells are negative for lamin $A$ and $C$, while focal spots of normal tissue (lymphocytes, arrow) are positive for lamin $A$ and $C$. (f) Embryonal carcinoma stained with lamin A antibody 133A2; tumour cells are negative for lamin A. (g) Embryonal. carcinoma stained with lamin $\mathrm{A} / \mathrm{C}$ antibody $\mathrm{R} 27$; both tumour cells and normal tissues are positive. (h) Teratona stained with lamin $\mathrm{A} / \mathrm{C}$ antibody R.27; the inset shows a higher magnification of the teratoma illustrating the lamina staining. 


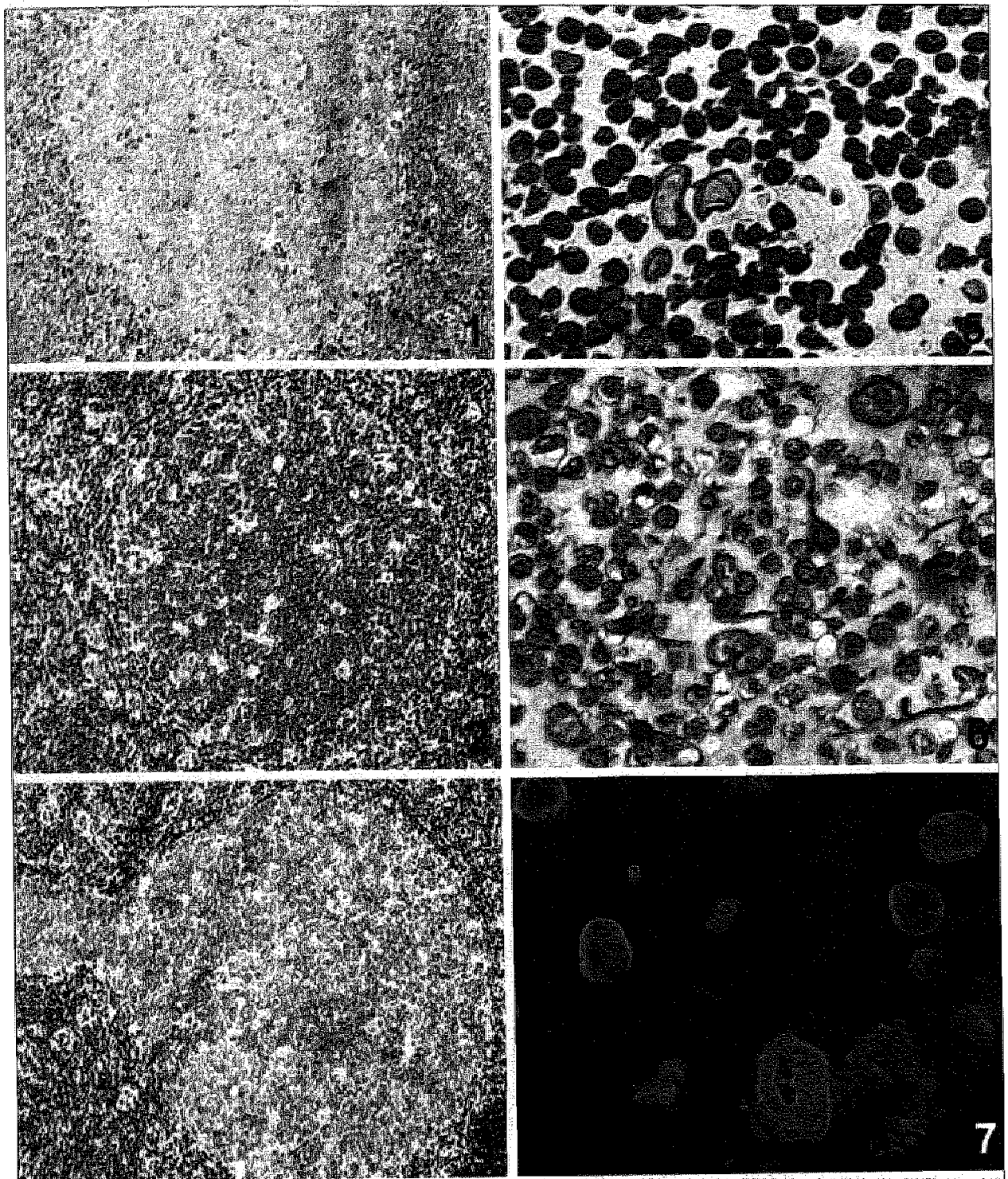

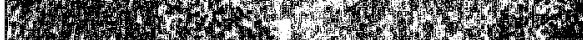

\section{cb}

$\mathrm{CO}$ 
Chapter 4, figure 1. Reactive lymph node stained with antibody $R 27$, showing that A-fype lamins are present in a few cells of the follicle centre and a population of cells in the paracortex.

Chapter 4, figure 2. Staning of the reactive lymph node with antbody 11905 showing that cells of the follicle centre and the surrounding areas exhibit lamin B1.

Chapter 4 , figure 3. The reactive lymph node after antibody LN43 3aining, showing that lamin $B 2$ is not on very weakly expressed in the cells of the follicle centre.

FChapter 4, figure 4. Double-label fluorescence microscopy of a reactive lymph node showing that centroblasts of the follicle centre express the proliferation marker Ki-67 (in green) but not lamin B2 (in red), while the majority of the surrounding cells in the mantle zone, paracortex and medulla show the reverse staining pattern. Centrocytes were negative for boh $\mathrm{Ki}-67$ and lamin B2. cc: centrocyte region; cb: centroblast region.

Chapter 4, figure 5. Reed-Sternberg/Hodgkin cells do express lamin $B 2$, as shown after staining wilh LN43. Note that surrounding cells stain more strongly.

Chapter 4, figure 6. Hodgkin lymphoma stained with antibody R27 shows that Reed-Sternberg and Hodgkin cells express A-type lamins.

Chapter 4, figure 7. Double-label fluorescence microscopy of Hodgkin lymphoma with the proliferation marker Ki-67 (in green) and antibody R27 for A-type lamins (in red), showing that in general Ki-67 and A-type lamin staining are mutually exclusive. DNA was counterstained with DAPI (blue).

Chapter 4, figure 8. Triple-label fuorescence microscopy of a CD30-positive Reed-Sternberg cell (in blue) expressing A-type lamins as detected with antibody $\mathrm{R} 27$ (in red) and the proliferation marker Ki-67 (in green). 


\section{Dankwoord}

Nu het proefschrift af is wil ik graag iedereen bedanken die daaran meegeholpen heeft. Wen aantal mensen wil ik daarbij graag even bij nam noemen. Als eerste mijn promotor Frans Ramaekers, die me de mogelijkheid heeft gegeven te promoveren. Beste Frans, zoals je weet liepen de eerste jaren van mijn promotie-onderzoek miet op rolletjes, maar mu ligt er toch een boekje waar ik trots op ben. Ik waardeer de mogelijkheden die je me geboden hebt om kennis te maken met nieuwe onderzoeksvelden en de vrijheid die ik de laatste jaren in mijn werk heb gehad.

Verder hebben mijn paranimfen Mieke en Helma een belangrijke bijdrage geleverd aan dit proefschrift. Lieve Mieke, je zult nu wel denken: "Wat is dan mijn bijdrage geweest, er staat niets over proteasomen in dit boekje". Ik wil je zeggen dat ik veel steun heb gehad an jouw inzet en daadkracht. Ook de proeven die we als laatste strohalm beschouwden voerde je altijd met veel toewijding uit, zelfs als dat in het weekend of 's nachts moest gebeuren. Ik wil je bedanken voor al het werk dat je gedaan hebt; ook voor de proeven die niet in publikaties terecht zijn gekomen en wellicht nooit in een proefschrift beschreven zullen worden. Ik had me voor het begin van mijn wetenschappelijke carrière geen betere collega kunnen wensen, en ik moet dan ook bekennen dat ik zonder jou waarschijnlijk al lang het "slagveld" had verlaten. Marr niet alleen op het praktisch vlak heb je veel ervaring, ook op het persoonlijk vlak ben je een kei. Je had mijn gebruiksaanwijzing snel door en dit heeft ertoe geleid dat ik met veel plezier op onze samenwerking terug kan kijken.

Beste Helma, ik bewonder de handigheid en precisie waarmee je je experimenten plant en uitvoert. Vaak verzamelden de resultaten zich in jouw klappers, zonder dat ik dat door had. Indien nodig kon je de gewenste gels en blots feilloos tevoorschijn halen tijdens de werkbesprekingen, zodat ze konden worden gebruikt voor dit proefschrift. Je nuchtere kijk op het verloop van experimenten, gecombineerd met een goeie dosis humor spreken ne wel an. Kortom, bedankt voor de prettige samenwerking.

Natuurlijk heb ik ook éen en ander te danken aan de loyaliteit van mijn co-promotor Jos Broers. Beste Jos , je heb ervoor gezorgd dat ik een vliegende start kon maken met het lamine werk. lk ben je daarvoor zeer erkentelijk, temeer omdat ik me realiseer dat het voor jouw ook niet gemakkelijk moet zijn geweest om plotseling een eigenwijze oio op je dak te krijgen. Geiukkig heeft de samenwerking kunnen leiden tot dit proefschrift.

Alle (ex)labgenoten van lab 5.225 wil ik bedanken voor de prettige werksfeer. Tussen het serieuze werk door was er altijd tijd om te kletsen en lachen, hetgeen onontbeerlijk is als proeven niet willen verlopen zoals gedacht of gehoopt.

Verder wil ik Guillaume van Eys en Bert Schutte bedanken voor liun waardevolle suggesties en vernieuwende inzichten en invalshoeken met betrekking tot de moleculair biologische experimenten en het proteasomen werk. 
Ik wil Leendert Loojenga bedanken voor de korte maar prettige samenwerking. Leendert, ik heb jo ongetwiffeld aan de telefoon wel eens bestookt met onbenullige vragen, maar ik heb zelf veel geleerd van en veel plezier beleefd an het uitstapje naar de wereld wan de testiculaire tumoren. Verder in Matice Janssern en Harry Schouten bedanken voor het kijkje dat ik samen met hen mocht memen in de "Hodgkin-wereld".

Alle (ex)medewerkers van MCB: bedankt woor alle hulp, medewerking en gezelligheid. Jullie "koffiekamel-praat" zal ik wel gaan missen.

Niet te vergeten wil ik ook mijn trouwe trein-maatjes Josien en Manon bedanken, die mij op het traject Sittard-Maastricht altijd vergezelden.

Lieve Zef, jij zag niet altijd het nut in van promoveren, maar als het moeilijk was heb je me altijd gestennd. 